\title{
MODELING AND TEST OF THE EFFICIENCY OF ELECTRONIC SPEED CONTROLLERS FOR BRUSHLESS DC MOTORS
}

\author{
A Thesis \\ presented to \\ the Faculty of California Polytechnic State University, \\ San Luis Obispo
}

\author{
In Partial Fulfillment \\ of the Requirements for the Degree \\ Master of Science in Aerospace Engineering
}

by

Clayton R. Green

September 2015 
(c) 2015

Clayton R. Green

ALL RIGHTS RESERVED 
COMMITTEE MEMBERSHIP

TITLE:

Modeling and Test of the Efficiency of Electronic

Speed Controllers for Brushless DC Motors

AUTHOR:

Clayton R. Green

DATE SUBMITTED: September 2015

COMMITTEE CHAIR: $\quad$ Robert McDonald, Ph.D.

Professor of Aerospace Engineering

COMMITTEE MEMBER: Aaron Drake, Ph.D.

Associate Professor of Aerospace Engineering

COMMITTEE MEMBER: Kurt Colvin, Ph.D.

Professor of Industrial and Manufacturing

Engineering

COMMITTEE MEMBER: Russell Westphal, Ph.D.

Professor of Mechanical Engineering 


\begin{abstract}
Modeling and Test of the Efficiency of Electronic Speed Controllers for Brushless DC Motors
\end{abstract}

Clayton R. Green

Small electric uninhabited aerial vehicles (UAV) represent a rapidly expanding market requiring optimization in both efficiency and weight; efficiency is critical during cruise or loiter where the vehicle operates at part power for up to $99 \%$ of the mission time. Of the four components (battery, motor, propeller, and electronic speed controller (ESC)) of the electric propulsion system used in small UAVs, the ESC has no accepted performance model and almost no published performance data. To collect performance data, instrumentation was developed to measure electrical power in and out of the ESC using the two wattmeter method and current sense resistors; data was collected with a differential simultaneous data acquisition system. Performance of the ESC was measured under different load, commanded throttle, bus voltage, and switching frequency, and it was found that ESC efficiency decreases with increasing torque and decreasing bus voltage and does not vary much with speed and switching frequency. The final instrumentation was limited to low-voltage systems and error propagation calculations indicate a great deal of error at low power measurements; despite these limitations, an understanding of ESC performance appropriate for conceptual design of these systems was obtained. 


\section{ACKNOWLEDGMENTS}

The road to graduation is never an easy one and cannot be done with out the help and support of professors, colleagues, friends, and family. I was no exception. I was blessed with a great network that supported me and gave me strength not only to finish but to do so with my best work. I would like to start by thanking my adviser, Dr. Robert McDonald. You have journeyed with me into a whole different majors. We have built heat engines, explored the electric power system, designed three phase wattmeters, built printed circuit boards, presented at conferences, and enjoyed tri-tip. All along the way you supported me, gave me life advise, supplied great stories, and even tried to find me a job. Thank you for being my adviser.

I would like to thank the faculty and staff at Cal Poly. The faculty here has always been bright and uplifting making it a wonderful adventure. Bruce Wright, I loved taking your class and being your TA. Thank you for the experience of working with you through one of the biggest learning experiences of my undergraduate career. Thank you Kendra for always happily helping with the constant paperwork and reimbursements. You were always

a joy. I especially would like to thank my thesis committee: Dr. Aaron Drake, Dr. Russell Westphal, and Dr. Kurt Colvin. Thank you for the constant advise and interest throughout my thesis.

Thank you classmates and comrades for the endless collaboration and support. I could never do this journey without the support of my peers. You have not only made it possible to complete this odyssey but have managed to make it enjoyable.

The biggest thank you goes out to my family. My parents have not only helped financially support me, but gave me all of the right ethics and morals to succeed. I am the man I am today because of them. Thank you mom and dad. Thank you to all of the family who 
have made sacrifices to help me reach my goals. Lastly I would like to thank my grandfather, Larry Green. You have inspired me in every way. All throughout my childhood, you have shown me the fun and mysteries of science and the value of knowledge. It was because of you I sought Aerospace Engineering. I am proud to follow in your footsteps. 
TABLE OF CONTENTS

Page

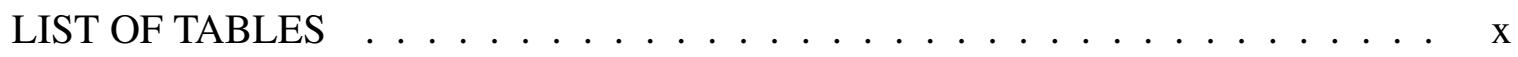

LIST OF FIGURES . . . . . . . . . . . . . . . . . . . . xi

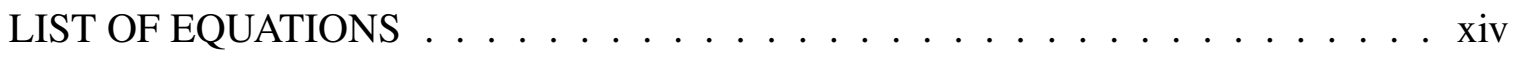

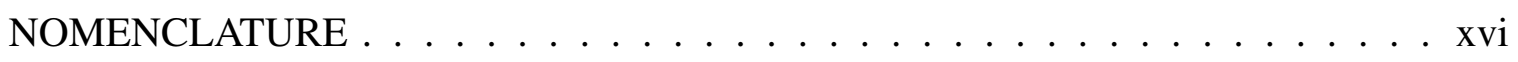

CHAPTER

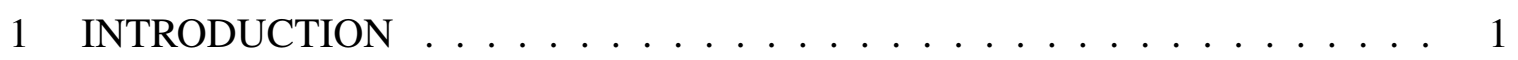

1.1 MODELING ELECTRICAL POWER SYSTEM . . . . . . . . . . . . . 1

1.1.1 BRUSHLESS SPEED CONTROL . . . . . . . . . . . 5

1.2 MODELING OF ELECTRONIC SPEED CONTROLLERS . . . . . . . . 6

1.3 AVAILABLE DATA . . . . . . . . . . . . . . 9

2 MEASURING POWER . . . . . . . . . . . . . . . . . 14

2.1 MEASUREMENT TECHNIQUES . . . . . . . . . . . . . . . . 14

2.1.1 THREE WATTMETER METHOD . . . . . . . . . . . 16

2.1.2 ONE WATTMETER METHOD . . . . . . . . . . . . . . 17

2.1.3 TWO WATTMETER METHOD . . . . . . . . . . . . . . 17

2.1 .4 READING TYPES . . . . . . . . . . . . . . . 18

2.1.5 AVERAGING TECHNIQUES . . . . . . . . . . . . . . . 19

2.1.6 MEASUREMENT REQUIREMENTS . . . . . . . . . . . 20

2.1.7 PROPELLER POWER . . . . . . . . . . . . . . . 22 
2.2 DATA ACQUISITION . . . . . . . . . . . . . . . . . . . . 24

$2.2 .1 \quad$ SIMULTANEOUS DAQ $\ldots \ldots \ldots \ldots \ldots$

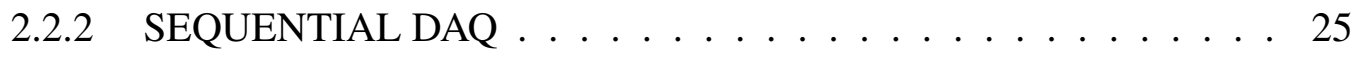

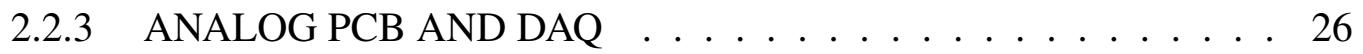

2.2 .4 TEST SETUP MATRIX _ . . . . . . . . . . . . . . . 26

3 ATTEMPTED CONFIGURATIONS . . . . . . . . . . . . . . . . . . 27

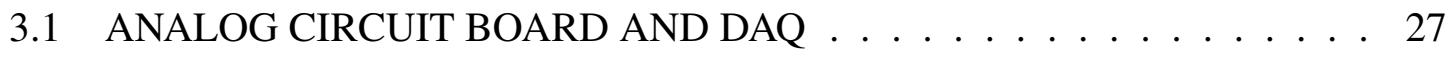

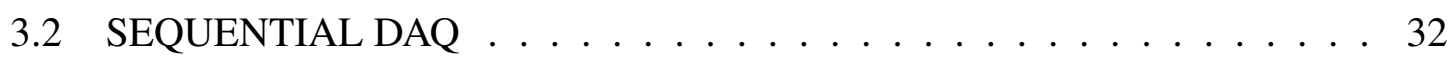

3.3 SINGLE ENDED SIMULTANEOUS DAQ $\ldots \ldots \ldots \ldots$

4 FINAL INSTRUMENTATION . . . . . . . . . . . . . . . . . . . 36

5 UNCERTAINTIES AND SENSITIVITIES . . . . . . . . . . . . . . 41

5.1 UNCERTAINTIES . . . . . . . . . . . . . . . . 41

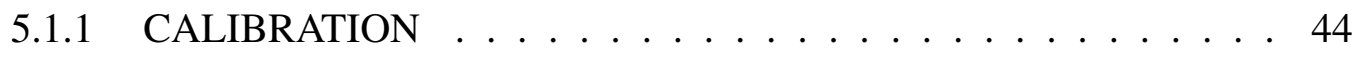

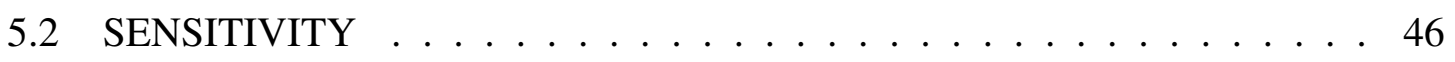

5.2 .1 HARDWARE SENSITIVITIES . . . . . . . . . . . 47

5.2.2 CONTROL INPUT SENSITIVITIES . . . . . . . . . . . . 49

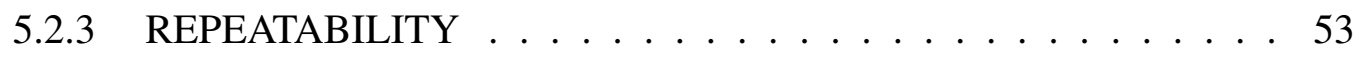

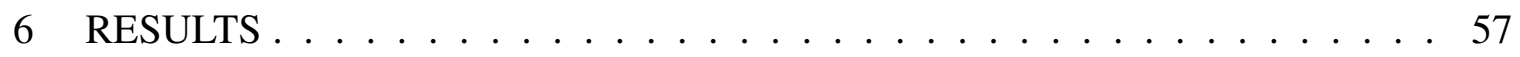

6.1 LOAD MAP . . . . . . . . . . . . . . . . . 57

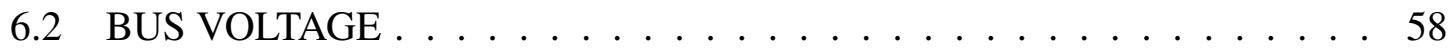

6.3 SWITCHING FREQUENCY $\ldots \ldots \ldots \ldots \ldots \ldots$

6.4 ESC SIZE AND BRAND . . . . . . . . . . . . . . . . . . . . . 59

6.5 QUIESCENT POWER . . . . . . . . . . . . . . . . . . . . 59

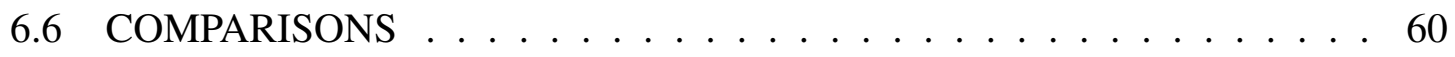

7 TEST SYSTEM IMPROVEMENTS . . . . . . . . . . . . . . . . . . . 67 


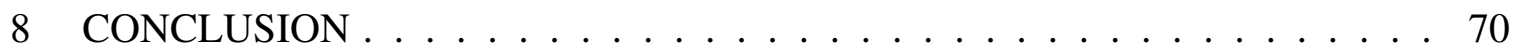

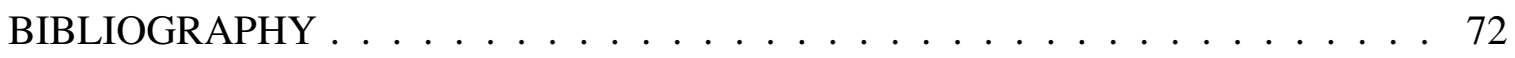

\section{APPENDICES}

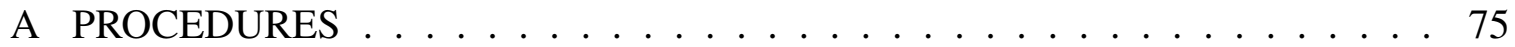

A.1 TEST BED SETUP $\ldots \ldots \ldots \ldots \ldots \ldots$

A.2 TEST RUN PROCEDURES . . . . . . . . . . . . . . . 76

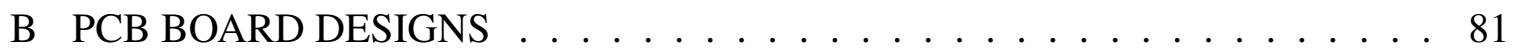




\section{LIST OF TABLES}

Table

Page

1.1 Phase rotation schedule. Refer to Figure $1.2 \mathrm{I}$-closed $\mathrm{O}-$ open . . . . . . . . . . 6

2.1 Measurements required and their magnitudes . . . . . . . . . . . . 22

2.2 Simultaneous DAQ requirements . . . . . . . . . . . . . 25

2.3 Sequential DAQ requirements . . . . . . . . . . . . . 26

2.4 Test setup matrix. X -not attempted A-attempted. $\sqrt{ }$-final $\ldots \ldots \ldots$

3.1 Differential evolution specifications . . . . . . . . . . . 32

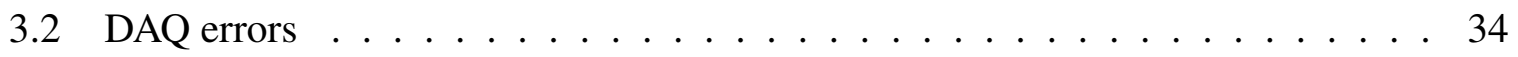

4.1 Test system specifications . . . . . . . . . . . . . . . . 37

5.1 Comparison of sense resistor accuracy error propagation for $96 \mathrm{~W}$. . . . . . 41

5.2 DAQ errors from Chapter 3 Table $3.2 \ldots \ldots . \ldots$. . . . . . . . . 42 


\section{LIST OF FIGURES}

Figure $\quad$ Page

1.1 Three constant motor model DC representation of a three phase motor . . . . 3

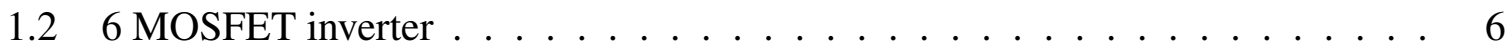

1.3 Voltage (yellow) and current (purple) on one of the phases . . . . . . . 6

1.4 Tritium power loss model $[8] \ldots \ldots \ldots \ldots$

1.5 VFD efficiencies for induction motors . . . . . . . . . . . . . 11

1.6 Efficiencies measured by the Army Research Laboratory [17]. Although not stated in their graphs, Torque is in $m N-m$ and efficiency is in \% . . . . . . 12

1.7 Combined efficiencies (a) 100\% throttle and varying voltage and (b) constant voltage and varying throttle $[17] \ldots \ldots \ldots \ldots$

2.1 Three wattmeter method setup . . . . . . . . . . . . . . 17

2.2 One wattmeter method setup . . . . . . . . . . . . . 18

2.3 Two wattmeter method setup . . . . . . . . . . . . . . . 18

2.4 Comparisons of different stop times . . . . . . . . . . . . . . 20

2.5 Current sense resistor . . . . . . . . . . . . . . . 21

2.6 Fast Fourier Transform of a phase voltage signal . . . . . . . . . . . . . . 22

2.7 Coefficient of power for the $11 \times 8.5$ propeller [20] . . . . . . . . . . . . 24

3.1 One wattmeter wiring diagram . . . . . . . . . . . . . 28

3.2 PCB iterations . . . . . . . . . . . . . . . . . . . 29

3.3 Final PCB disassembled . . . . . . . . . . . . . . . 30

3.4 Current sense resistors . . . . . . . . . . . . . . . 30

3.5 Comparisons of different large-signal step responses . . . . . . . . . . . . 32

3.6 FFT approximation of the voltage signal out of the ESC . . . . . . . . . . 33 
3.7 Discrete steps caused by digitization $\ldots \ldots \ldots \ldots$

4.1 Simultaneous DAQ used $\ldots \ldots \ldots \ldots$

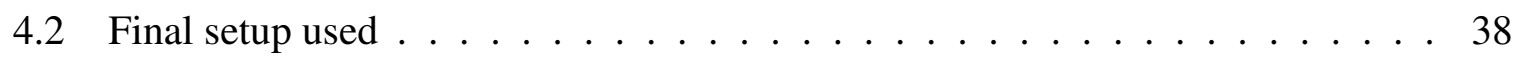

4.3 Labview control panel . . . . . . . . . . . . . . . . . 40

5.1 Estimated current and voltage out of the ESC $\ldots \ldots \ldots \ldots$

5.2 Propagated error through $I_{1}$ and $I_{2} \ldots \ldots \ldots \ldots \ldots$

5.3 Propagated error through $I_{2}$ and $I_{3} \ldots \ldots \ldots \ldots \ldots$

5.4 Comparison of propagated error between the high and low current systems . . . 45

5.5 Gain error sensitivities of the DAQ . . . . . . . . . . . . . 47

5.6 Sensitivity of non-linearity error of the DAQ $\ldots \ldots \ldots$

5.7 Sensitivity of the resolution in the DAQ . . . . . . . . . . . . . 49

5.8 Current sense resistor sensitivities $\ldots \ldots \ldots \ldots \ldots \ldots$

5.9 Variance of data recorded while DAQ sampling rate is varied holding the total number of samples constant. . . . . . . . . . . . . . . . 51

5.10 Variance of data recorded while varying number of sets per division $\ldots \ldots 52$

5.11 Variance of data recorded while varying number of divisions $\ldots \ldots \ldots 3$

5.12 A test with no delay per division showing transients. Green is data taken after

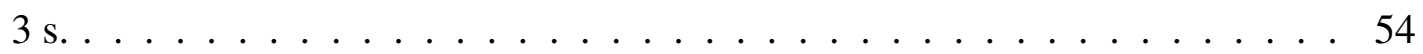

5.13 Variance of data recorded for repeated efficiency tests. Magenta shaded area is the error bounds for the $\min$ to $\max$ July 14 th run $\ldots \ldots \ldots 55$

6.1 Efficiency load map and load lines for the Hobbywing Platinum 50 A $\ldots 62$

6.2 The effects on the ESC performance from changing bus voltage $\ldots \ldots$. . . 63

6.3 Comparison of the effects on the ESC performance from changing switching frequency for the $13 \times 6.5$ and the $18 \times 12$ propellers $\ldots \ldots \ldots 63$

6.4 Comparison of different ESCs for the $13 \times 6.5$ and the $18 \times 12$ propellers . . . . 64

6.5 Power loss of the ESC versus speed for Hobbywing 50 A ESC using the 18x12

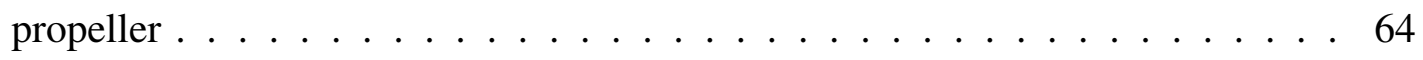


6.6 Comparison of the experimental ESC performance data of the Hobbywing 50 A ESC using the $18 \times 12$ propeller with the Tritium model . . . . . . . . . . 65

6.7 Comparison of ESC performance with the VFD data . . . . . . . . . . 66

6.8 Comparison of ESC performance with the Army Research Laboratory . . . . . 66

A.1 Mounting of the motor . . . . . . . . . . . . . 75

A.2 Alignment of the propeller within the cage . . . . . . . . . 76

A.3 Wiring diagram of the test bed . . . . . . . . . . . . 77

A.4 Copy of Figure 4.3 of the Labview front panel . . . . . . . . . . . . 78

A.5 First Labview command dialog to operator . . . . . . . . . . . . . . 79

A.6 DC offset calibration connectors . . . . . . . . . . . . . . . . 79

A.7 Second Labview command dialog to operator . . . . . . . . . . . . . . . 80

B.1 OrCAD wiring design of the main $\mathrm{PCB} \ldots \ldots \ldots \ldots$

B.2 Manufacturing design of the main $\mathrm{PCB} \ldots \ldots \ldots$. . . . . . . . 82

B.3 OrCAD wiring design of the gain and voltage divider resistor PCB . . . . . . 83

B.4 Manufacturing design of the gain and voltage divider resistor PCB . . . . . . 83 


\section{LIST OF EQUATIONS}

Equation

Page

1.1 Power into the ESC . . . . . . . . . . . . . . 3

1.2 Power out of the motor for the three constant motor model . . . . . . . . . 3

1.3 Efficiency of the motor for the three constant motor model . . . . . . . . 3

1.4 Current for the maximum efficiency for the three constant motor model . . . . 3

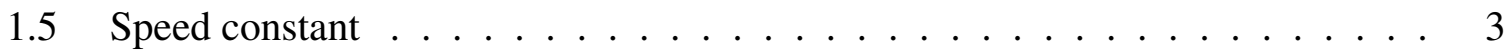

1.6 Torque constant . . . . . . . . . . . . . . . . 4

1.7 Power in terms of speed and torque . . . . . . . . . . . . 4

1.8 Conversion from rotations per minute to radians per second $\ldots \ldots \ldots$

$1.9 K_{v}$ relationship with $K_{Q} \ldots \ldots \ldots \ldots \ldots \ldots \ldots \ldots$

1.10 Tritium's power loss model . . . . . . . . . . . . . . . . . 7

1.11 Conduction loss for the Infineon model $\ldots \ldots \ldots$. . . . . . . . 8

1.12 Switching loss for the Infineon model $\ldots \ldots \ldots$. . . . . . . . . 8

1.13 On state energy of the MOSFET for the Infineon model . . . . . . . . . . 8

1.14 Off state energy of the MOSFET for the Infineon model $\ldots \ldots \ldots$

1.15 On state energy of the reverse recovery diode for the Infineon model . . . . . 8

1.16 Off state energy of the reverse recovery diode for the Infineon model . . . . . 8

1.17 Total power loss of the MOSFETs for the Infineon model . . . . . . . . . . 8

1.18 Dale Lawrence's motor/ controller interaction model . . . . . . . . . . . . . . 9

1.19 Equation for $V_{i}$ in Dale' Lawrence's model . . . . . . . . . . . . . . . . . . 9

2.1 Resultant apparent power from active and reactive power . . . . . . . . . 15

2.2 Apparent power from voltage and current . . . . . . . . . . . . 15

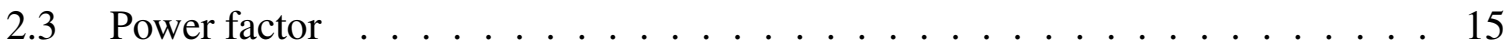


2.4 Active power from apparent power . . . . . . . . . . . . . . . 15

2.5 Reactive power from apparent power $\ldots \ldots \ldots \ldots$

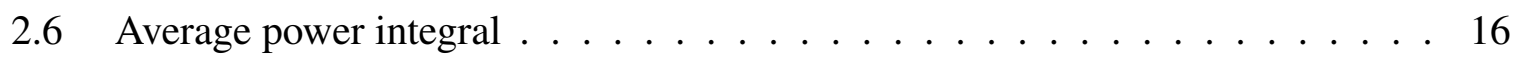

2.7 Three phase apparent power $\ldots \ldots \ldots \ldots$

2.8 Three phase active power $\ldots \ldots \ldots \ldots \ldots \ldots$

2.9 Reactive power calculated using each phase active and apparent power . . . . 16

2.10 Reactive power calculated using total active and apparent power $\ldots \ldots$. . 16

2.11 Instantaneous power for a three phase system $\ldots \ldots \ldots \ldots$

2.12 One wattmeter method $\ldots \ldots \ldots \ldots \ldots \ldots$

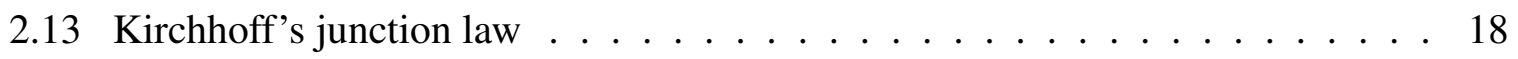

2.14 Two wattmeter method . . . . . . . . . . . . . . . . . . 18

2.15 Current sense implementation $\ldots \ldots \ldots \ldots$

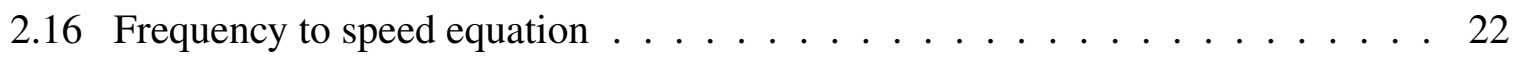

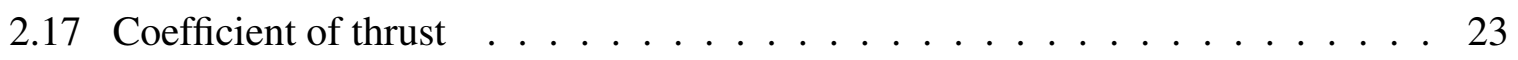

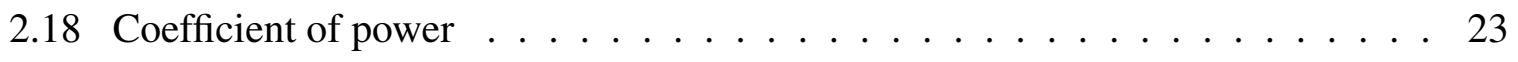

2.19 Advance ratio . . . . . . . . . . . . . . . . . 23

2.20 Static propeller power . . . . . . . . . . . . . . . . 23

3.1 Applying a phase shift to a FFT $\ldots \ldots \ldots 33$

5.1 Standard error propagation $\ldots \ldots \ldots \ldots \ldots \ldots$

5.2 Estimated current assuming constant voltage $\ldots \ldots \ldots$. . . . . . . 43

5.3 Estimated voltage out for an equivalent DC system assuming DC current is equal to $\mathrm{AC}$ current $\ldots \ldots \ldots \ldots \ldots \ldots \ldots \ldots$

5.4 Derivative used for sensitivity analysis . . . . . . . . . . . . 46 


\section{NOMENCLATURE}

$C_{P} \quad$ Coefficient of power

$C_{T} \quad$ Coefficient of thrust

$C f_{e q} \quad$ Equivalent capacitance*frequency product of the entire controller

$D \quad$ Propeller diameter $(f t)$

$d t \quad$ Time between readings ( $\mathrm{s}$ )

E $\quad$ Energy (J)

$f \quad$ Frequency $(\mathrm{Hz})$

I Current (A)

$i \quad$ Instantaneous current (A)

$I_{D} \quad$ Drain source current (A)

$I_{f} \quad$ Current through diode (A)

$I_{O} \quad$ Motor no load current (A)

$J \quad$ Advance ratio

$K_{Q} \quad$ Motor torque constant (ft-lb/A)

$K_{v} \quad$ Motor speed constant $(\mathrm{rpm} / \mathrm{V})$

$L \quad$ Inductance $(H)$

$n \quad$ Motor speed in rotations per second (rpm) 
$N_{p} \quad$ Number of motor poles

$P \quad$ Active power (W)

$Q \quad$ Reactive power (var)

$Q_{r r} \quad$ Reverse recovery charge (nC)

$R_{d} \quad$ Diode on-state resistance $(\Omega)$

$R_{i} \quad$ Motor line to line resistance $(\Omega)$

$R_{D S o n}$ Drain source on-state resistance $(\Omega)$

$R_{e q} \quad$ Equivalent resistance of the entire controller $(\Omega)$

$R P M$ Rotations per minute

$S \quad$ Apparent power (VA)

$T \quad$ Period of the waveform $(s)$

$t \quad$ Time $(s)$

$V \quad$ Fluid velocity $(\mathrm{ft} / \mathrm{s})$

V Voltage (V)

$v \quad$ Instantaneous voltage (V)

$V_{\text {bus }} \quad$ Bus voltage (battery voltage) of the controller (V)

BLDCM Brushless direct current motor

DAQ Data acquisition device

EMF Electromotive force

ESC Electronic speed controller 
FFT Fast Fourier transform

FSR Full scale range

GND Ground

IC Integrated circuit

MOSFET Metal-oxide-semiconductor field-effect transistors

NP Neutral Point

PCB Printed circuit board

PMSM Permanent magnet synchronous motor

PWM Pulse width modulation

rms Root mean square

UAV Uninhabited aerial vehicles

Z Complex load

Subscript and Superscripts

$1 \quad$ Line 1

2 Line 2

$3 \quad$ Line 3

ave Average

CL Conduction loss

$D \quad$ Diode

est Estimated

xviii 


$\begin{array}{ll}f & \text { Fall } \\ i & \text { Current } \\ \text { inst } & \text { Instantaneous } \\ M & \text { MOSFET } \\ m & \text { Motor } \\ n & \\ n & \text { Neutral }\end{array}$

PWM Pulse width modulation

$r \quad$ Rise

rms Root mean square

sw Switching

$u \quad$ Voltage

H High

L Low

Greek

$\alpha \quad$ Linear component of the switching loss (per unit of bus voltage)

$\beta \quad$ Constant component of the switching loss (per unit of bus voltage)

$\chi \quad$ Sensitivity derivative

$\delta \quad$ Duty cycle $(\%)$

$\omega \quad$ radians per second (rps)

$\phi \quad$ Phase angle (rad) 
$\rho \quad$ Density (slugs $\left./ f t^{3}\right)$

$\tau \quad$ Torque of the motor (ft-lb)

$\varepsilon \quad$ Error or uncertainty 


\section{INTRODUCTION}

Electric motors have been around for over a hundred years and are thought to be well researched. Permanent magnet synchronous motors (PMSM), also known as Brushless DC (BLDC) motors, were invented in 1962 by T. G. Wilson and P. H. Trickey [1] increasing lifespan, efficiency, and power-to-weight while decreasing maintenance as compared to brushed DC motors. This opened many new applications for electric motors. BLDC motors are used in a variety of applications today from a pumps to ceiling fans. A growing field of BLDC motors is in small uninhabited aerial vehicles (UAVs). In most applications used today, the motor is either optimized for weight or efficiency. However in electric vehicles such as UAVs, optimization of both weight and efficiency is essential to closing design. Also electric vehicles often require full throttle for takeoff and climb, but greatly reduced part power upon reaching cruise. In an electric power system it has been said that full throttle can be an almost perfect efficiency, but at part throttle, efficiency can drop off considerably. Considering cruise could be up to $99 \%$ or more of the mission time, an improvement of cruise efficiency would significantly increase the range of the UAV. This growing application has reopened and pressed for new research in electric power systems in order to increase efficiency for brushless DC motors.

\subsection{MODELING ELECTRICAL POWER SYSTEM}

In order to design electric propulsion system such as a UAV, a simple performance model of the propulsion system is required. It is preferred for design that these models easily incorporate parameters given by the manufacturer. No comprehensive model of the complete electric propulsion system is available because there are too many variables. Therefore in order to model the system, a model of each component must be made and combined. Elec- 
tric power systems have four basic components: battery, electronic speed controller (ESC), motor, and propeller.

Batteries are the typical form of energy used in UAVs today. Batteries come in a variety of chemistries from nickel-cadmium to lithium-ion. Batteries have been heavily researched in the past few years. In Advanced Lithium-ion Batteries [2], Lithium-ion batteries were tested and compared to a linear model [3]. The linear model is the most common model of batteries. It is simply a voltage across an internal resistance which can be easily extracted from manufacturer's supplied data. The author measured open circuit voltage and internal resistance as a function of state of charge. The results verified the model's accuracy.

The electronic speed control controls the voltage passed to motor. ESCs are also called motor drivers or pulse width modulation (PWM) drivers. It receives a throttle signal and changes the duty cycle and frequency of the output 3-phase voltage waveform to adjust the motor's speed and torque. ESCs come in different max amperage sizes, and are usually accompanied by their specifications of switching frequency and internal resistance. Only a few models exists for ESC, and there is very little public data available. In a correspondence with Castle Creations, a large hobbyist ESC manufacturer, they replied,"The overall efficiency of our ESCs is between $98.5 \%$ and $99.5 \%$ efficient. Lower throttle gives the lower efficiencies, high throttle is as close to $100 \%$ as you can get." [4]

BLDC motors are used in UAVs because of their high specific power, reliability, and efficiency. Many models exists for BLDC motors, but the most common is the three constant motor model [5]. The three constants are the speed constant, $K_{v}$, motor line to line resistance, $R_{i}$, and motor no load current, $I_{o}$. The three motor parameters are usually supplied by the manufacturer. The three constant motor model simplifies the system by making a DC equivalent as shown in Figure 1.1. Its description is helpful in understanding the system. Power in for the three constant motor model is a DC equivalence of product of voltage and current out of the ESC as shown in Equation 1.1.

$$
P_{\text {in }}=V_{\text {in }} I_{\text {in }}
$$




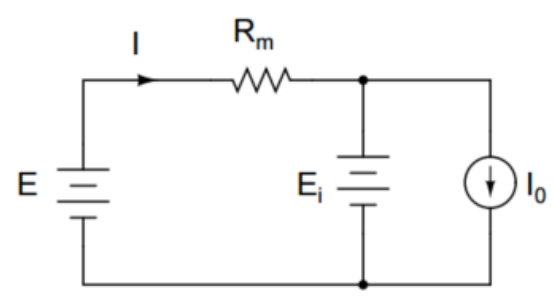

\section{Figure 1.1: Three constant motor model DC representation of a three phase motor}

$I_{O}$ is subtracted off of the input current to get useful current used by the motor. Also the voltage drops by $I_{o} R_{i}$ representing the voltage drop due to the resistance of the motor. This results in Equation 1.2 for power out of the motor.

$$
P_{\text {out }}=\left(V_{\text {in }}-I_{\text {in }} R_{i}\right)\left(I_{\text {in }}-I_{o}\right)
$$

And the motor efficiency is given by Equation 1.3.

$$
\eta_{\text {motor }}=\left(1-\frac{I_{\text {in }} R_{i}}{V_{\text {in }}}\right)\left(1-\frac{I_{o}}{I_{\text {in }}}\right)
$$

Driver efficiency, most of the time, is assumed constant or ignored altogether. Solving Equation 1.3 for maximum motor efficiency, ignoring driver efficiency, results in the maximum efficiency at the current described in Equation 1.4.

$$
I_{\eta \max }=\sqrt{I_{o} \frac{V_{i n}}{R_{i}}}
$$

Peak efficiency of Equation 1.3 will also increase with $V_{\text {in }}$ [6]. However $V_{\text {in }}$ is only a DC representation of the three phase voltage out of the ESC. $V_{i n}$ is a result of bus voltage and duty cycle. The last coefficient is given to get speed and torque of the motor. The speed constant $K_{v}$ is given by Equation 1.5.

$$
K_{v}=\frac{n}{V_{\text {in }}-I_{\text {in }} R_{i}}
$$

In this equation " $n$ " in the speed of the motor in rotations per minute. Some publications also give a torque constant, $K_{Q}$, relating torque $(\tau)$ and input current, Equation 1.6.

$$
K_{Q}=\frac{\tau}{I_{\text {in }}-I_{o}}
$$


Rearranging power out, as seen in Equations 1.7-1.9, demonstrates that $K_{Q}$ is the inverse of $K_{v}$ with appropriate conversion factors.

$$
P_{\text {out }}=\omega \tau * 1.356
$$

where $\omega$ is radians per second as shown in Equation 1.8

$$
\omega=n \frac{2 \pi}{60}
$$

Substituting into Equation 1.2

$$
\begin{gathered}
\omega \tau * 1.356=\left(V_{\text {in }}-I_{\text {in }} R_{i}\right)\left(I_{\text {in }}-I_{o}\right) \\
\frac{n}{\left(V_{\text {in }}-I_{\text {in }} R_{i}\right)}=\frac{60}{2.713 \pi} \frac{\left(I_{\text {in }}-I_{o}\right)}{\tau} \\
K_{v}=\frac{60}{2.713 \pi} \frac{1}{K_{Q}}
\end{gathered}
$$

The three constant motor model gives two big conclusions about the system: torque is proportional to current and speed is proportional to motor voltage.

A wide variety of propellers are available to designers of small UAVs. Most small propulsion systems use a fixed pitch propeller. Small propellers are defined by their diameter and pitch. A variety of tools may be used to model propeller performance. Many of these tools use one of three techniques: CFD, blade element analysis, or empirical data [7].

The electronic speed controller has only a few performance models and even fewer experimental data sets to verify model accuracy. Most of the tests today combine ESC and motor efficiency for ease of power reading. Understanding of the ESC's independent performance could provide insight on the causes for the power losses and help develop solutions to minimize these losses. For these reasons, the author decided to pursue modeling and testing of ESCs. 


\subsubsection{BRUSHLESS SPEED CONTROL}

An ESC controls the three phase waveform applied to the motor. It uses a series of at least six metal-oxide-semiconductor field-effect transistors (MOSFETs) and diodes to modulate the three phase signal shown in Figure 1.2. The transistors apply voltage to one phase and ground another; the third is disconnected. The current generated through the motor coils creates a magnetic field that attract the permanent magnets. The current is alternated around the motor in six steps pulling the rotor with it. The rotating schedule is illustrated in Table 1.1, and the resulting current and voltage signal is demonstrated in Figure 1.3. The third disconnected phase still experiences the magnetic field from the rotating rotor. This is called the back electromotive force or back EMF. In sensorless ESC, the controller uses this back EMF as position sensing for commutating. The combination of the applied voltage and the back EMF creates a trapezoidal wave. AN ESC can be programed to output a PWM sine wave instead and are becoming more popular because of their lower noise and supposed higher efficiency at part power. Sine wave speed controllers tend to be more expensive due to the increase in software complexity. The controller's output waveform is therefore a three-phase, unipolar, trapezoidal wave, voltage signal. The signal has a switching frequency of 8 to $32 \mathrm{kHz}$ with an output frequency typically between 100 to $1000 \mathrm{~Hz}$ depending on the motor and its speed. A demonstration of this signal is shown in Figure 1.3. Figure 1.3 captures voltage (top in yellow) and current (bottom in purple) signal at part throttle. It shows the $8 \mathrm{kHz}$ switching frequency creating the $590 \mathrm{~Hz}$ signal. The three line signals are phase shifted by 120 degrees apart from each other.

The number of switches per cycle and frequency are determined by the $K_{v}$ of the motor and the speed. The frequency is matched to the speed through a relationship described later in Subsection 2.1.6. The number of switches per cycle is then adjusted to handle the torque required. 


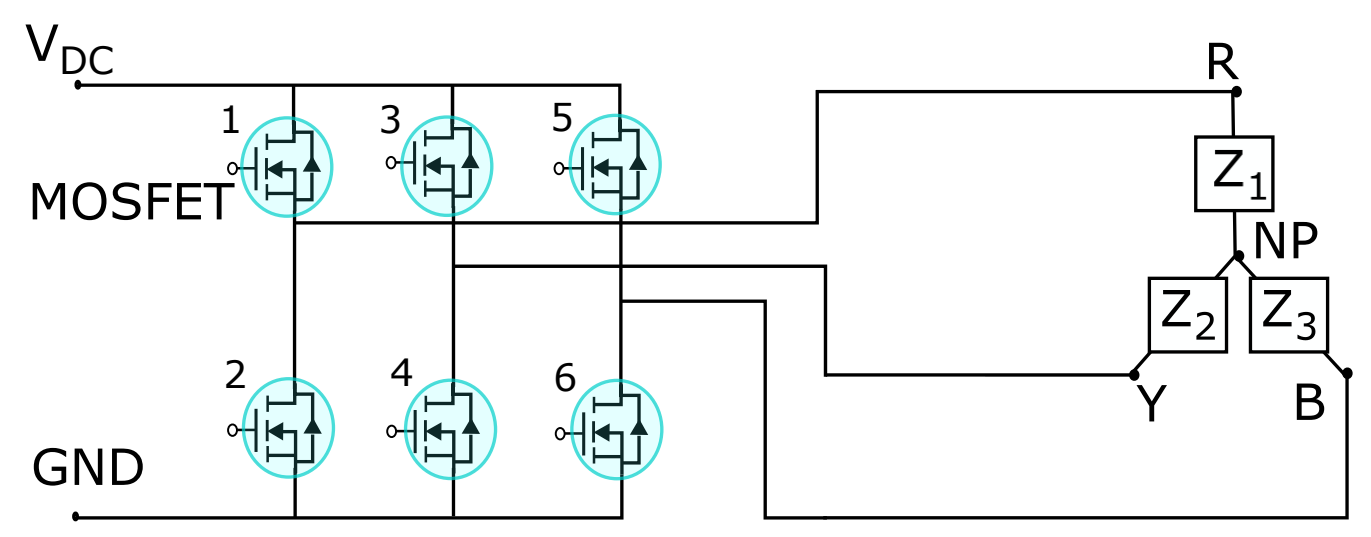

Figure 1.2: 6 MOSFET inverter

\begin{tabular}{|l|c|c|c|c|c|c|}
\hline MOSFET & Step 1 & Step 2 & Step 3 & Step 4 & Step 5 & Step 6 \\
\hline 1 & I & O & O & O & O & I \\
\hline 2 & O & O & I & I & O & O \\
\hline 3 & O & O & O & I & I & O \\
\hline 4 & I & I & O & O & O & O \\
\hline 5 & O & I & I & O & O & O \\
\hline 6 & O & O & O & O & I & I \\
\hline
\end{tabular}

Table 1.1: Phase rotation schedule. Refer to Figure 1.2 I-closed O-open

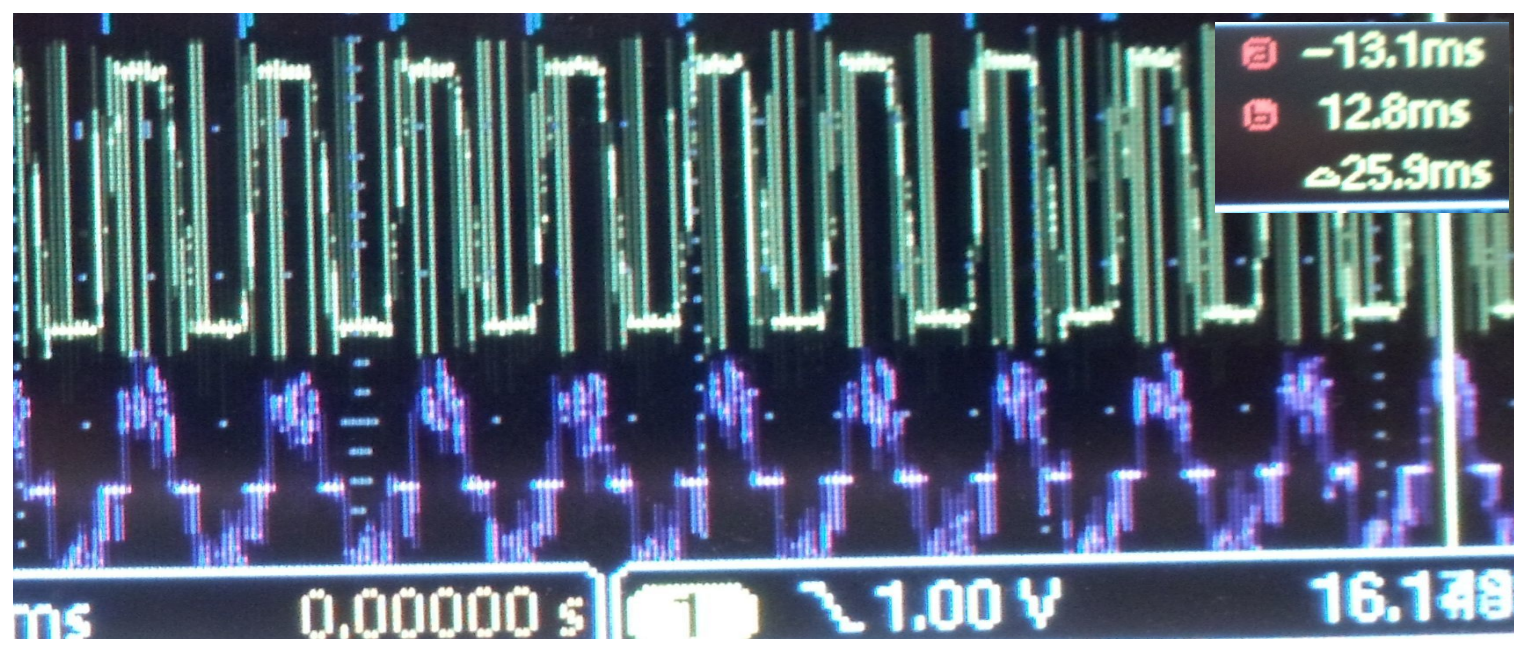

Figure 1.3: Voltage (yellow) and current (purple) on one of the phases

\subsection{MODELING OF ELECTRONIC SPEED CONTROLLERS}

Tritium, Texas Instruments, Infineon, and International Rectifier have published predictive models of ESC power loss $[8,9,10,11]$. Tritium's model was used on their large motor 
drivers (ESC) for solar car racing. Equation 1.10 shows their simple power loss equation used for heatsink calculations and race strategy algorithms [8].

$$
P_{l o s s}=R_{e q} I_{E S C}^{2}+\left(\alpha I_{E S C}+\beta\right) V_{b u s}+C f_{e q} V_{b u s}^{2}
$$

There are four components in their power loss equation. $R_{e q} I_{E S C}^{2}$ is the conduction loss of the driver. The $R_{e q}$ is sometimes supplied by the manufacturer. The next two are related to switching losses in the MOSFETs. $\alpha$ is the linear component and $\beta$ is the constant component of switching loss. The last component is the equivalent capacitive switching loss. $R_{e q}, \alpha, \beta$, and $C f_{e q}$ are constants. Figure 1.4 demonstrates the power loss equation for their driver.

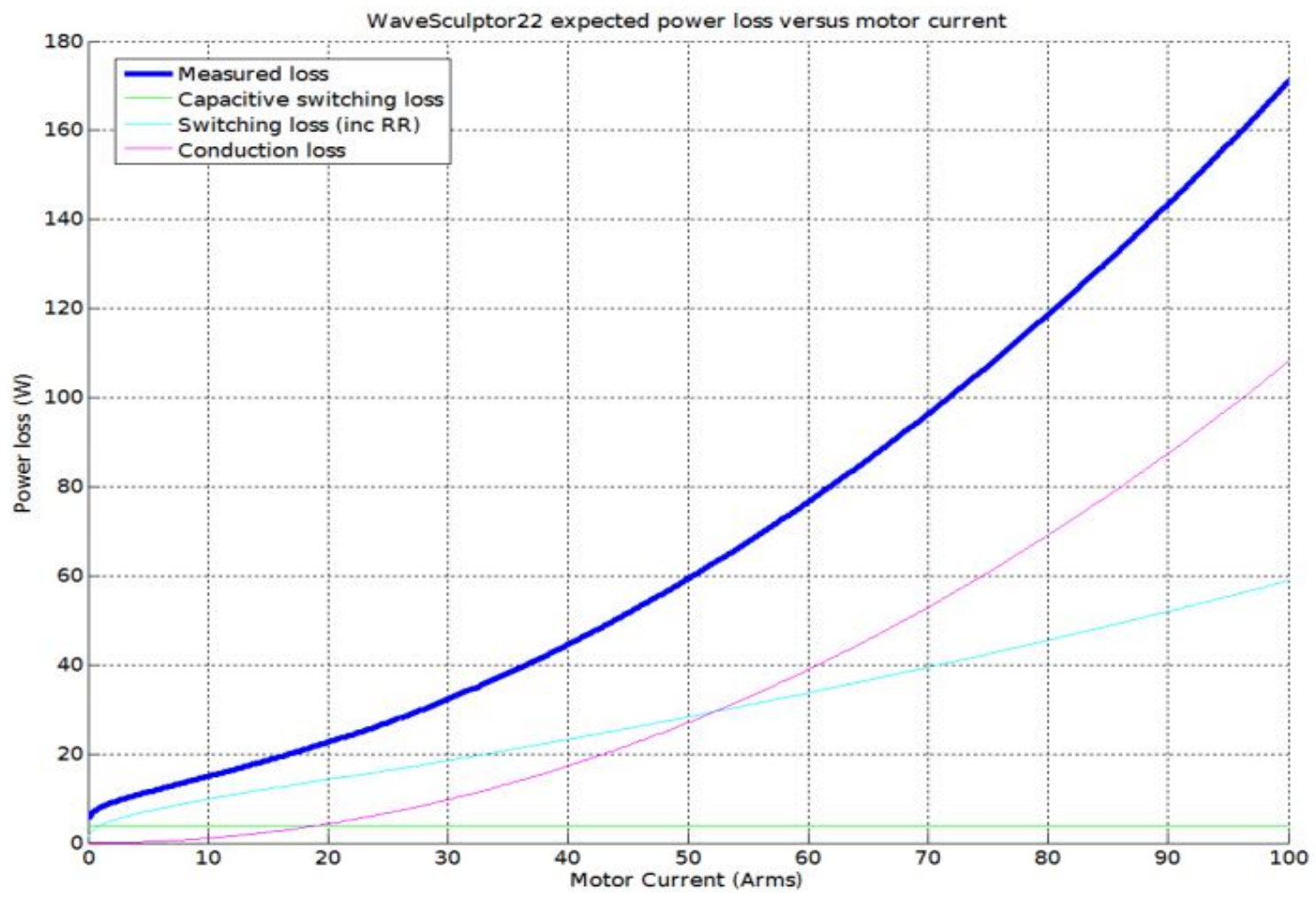

Figure 1.4: Tritium power loss model [8]

Texas Instruments, International Rectifier, and Infineon had similar models that did not model the system as a whole but instead broke it down into components $[9,10,11]$. These models considered conduction loss, switching loss, and operating quiescent power loss. MOSFETs have two components. One is the switch, and the other is the reverse recovery 
diode. The reverse recover diode releases current returned by the inductance. Infineon's MOSFET power loss calculations [11] considered two sources of conduction losses: onstate resistance of the switch and the reverse current diode. These losses sum to the total conduction loss shown in Equation 1.11.

$$
P_{C L}=R_{D S o n} I_{\text {Drms }}+V_{\text {bus }} I_{\text {fave }}+R_{d} I_{\text {frms }}^{2}
$$

In Equation 1.11, $R_{D S o n} I_{D r m s}$ is the loss through the switch, and $V_{\text {bus }} I_{\text {fave }}+R_{d} I_{\text {frms }}^{2}$ is the loss through the diode. Switching losses were calculated as the sum of switch-on energy $\left(E_{\text {onM }}\right)$ of the switch and the switch-on energy of the reverse-recovery of the diode $\left(E_{o n D}\right)$ as well as their corresponding switch off energy loss displayed in Equation 1.12. Switch-off losses in the diode have been found to be negligible.

$$
P_{s w}=\left(E_{o n M}+E_{o f f M}+E_{o n D}+E_{o f f D}\right) f_{s w}
$$

Where $E_{o n M}, E_{o f f M}, E_{o n D}$, and $E_{o f f D}$ are defined in Equation 1.13-1.16.

$$
\begin{gathered}
E_{\text {onM }}=V_{\text {bus }} I_{\text {Don }}\left(\frac{t_{r i}+t_{f u}}{2}\right)+Q_{r r} V_{b u s}^{2} \\
E_{\text {off }}=V_{\text {bus }} I_{\text {Doff }}\left(\frac{t_{r u}+t_{f i}}{2}\right) \\
E_{\text {onD }}=\frac{1}{4} Q_{r r} V_{b u s} \\
E_{\text {offD }} \approx 0
\end{gathered}
$$

Accounting for both the high and low voltage MOSFETs of all 3 phases and summing switching losses and conduction loss for total MOSFET losses results in Equation 1.17.

$$
P_{M}=6\left(P_{s w}+P_{C L}\right)
$$

For further explanation of this model refer to MOSFET Power Losses Calculation Using the Data-Sheet Parameters by Infineon [11]. Also quiescent power loss was added to this 
model. Quiescent power is simply the power required in order to run the ESC's hardware without the motor drawing current. This model requires a manufacturer's data sheet of the MOSFETs used and a quiescent power test.

Dale Lawrence derived a motor/ controller interaction model [12]. The model accounted for AC power loss from insufficient filtering of PWM harmonics by the motor inductance. The loss calculations are summarized in Equation 1.18.

$$
P_{P W M}=2 \sum_{i=1}^{n}\left|V_{i}\right|^{2}\left(\frac{R_{i}}{R_{i}^{2}+\left(2 \pi i L_{m} / T\right)^{2}}\right)
$$

Where $V_{i}$ is defined in Equation 1.19.

$$
V_{i}=V_{b u s} \frac{\sin \delta \pi i}{\pi i}
$$

This model required the MOSFETs' period $(T)$ and wave type, the motor line to line resistance $\left(R_{i}\right)$, and the inductance of the motor $\left(L_{m}\right)$. However validating this model is difficult. It is not defined what component experiences this power loss.

Some of these models presented in this section may be able to be slightly altered to only use ESC manufacturers' given data. However comparison of these models to experimental data is needed to validate their accuracy.

\subsection{AVAILABLE DATA}

Validation of an analytical model of an ESC requires experimental data, but there is little published data on ESC efficiency. The data that is available has significant limitations. For example, in Validation of Small Scale Electric Propulsion System Models by D. Lundström [13] two overall efficiency tests were taken by measuring DC power into the ESC using a standard wattmeter and measuring the power out of the motor using a dynamometer. One of his test varied duty cycle and held a constant input voltage, and the other held $100 \%$ duty cycle and varied input voltage. The ESC efficiency was extracted from the two curves as the cause of the difference in efficiency. This relies on two major 
assumptions: the only power loss from an ESC is caused from a reduction of duty cycle and at $100 \%$ duty cycle the ESC is always $100 \%$ efficient. By the law of conservation of energy, the ESC can never be $100 \%$ or greater efficient at any state. The efficiency loss they derived could be caused from several factors such as torque ripple or switching loss. Torque ripple is a periodic change in output torque caused by slight asymmetries in magnetic field by the motor windings. Torque rippling is more prevalent is brushless DC motors due to a combination of the finite number of poles and trapezoidal computation. The method they used does not isolate the ESC.

Three other data set were found for variable frequency drive (VFD) efficiency by the Department of Energy, Oregon State University, and Cal Poly San Luis Obispo [14, 15, 16]. The Department of Energy data is presented in Figure 1.5. The other two sources had similar results. VFDs are a speed controllers for induction motors. Although induction motors have a different architecture from BLDC motors, some of their speed controllers have many similarities. Many VFDs and ESCs have the same three MOSFET pairs that produce the PWM signal. Also both controllers maintain close to constant Volts-per-Hertz $(\mathrm{V} / \mathrm{Hz})$ or Volts-per-rpm $(\mathrm{V} / \mathrm{rpm}), \frac{1}{K_{v}}$, ratio per motor. Understanding of VFD losses might bring insight on ESC losses.

All of these data sets on VFDs presented had similar systems. The VFDs used were PWM sine wave controllers that were for motors greater than $1 \mathrm{hp}$. The commodity controllers tested in this thesis were less than $1 / 2 \mathrm{hp}$ and used PWM trapezoidal wave. Also all four data sets had vary sparse data making it poorly defined for interpolation.

The Army Research Laboratory researched the electrical power system in 2013 and has some of the only data available for ESC efficiency [17]. In their report motor and ESC efficiency was measured. Shaft power was measured using a dynamometer and torque cell. Three phase power and DC power was measured using a Yokogawa WT-3000 precision three-phase power analyzer. This power analyzer costing roughly $\$ 21,000$ was out of the budget for this thesis. However there appears to be differences between their equations and 


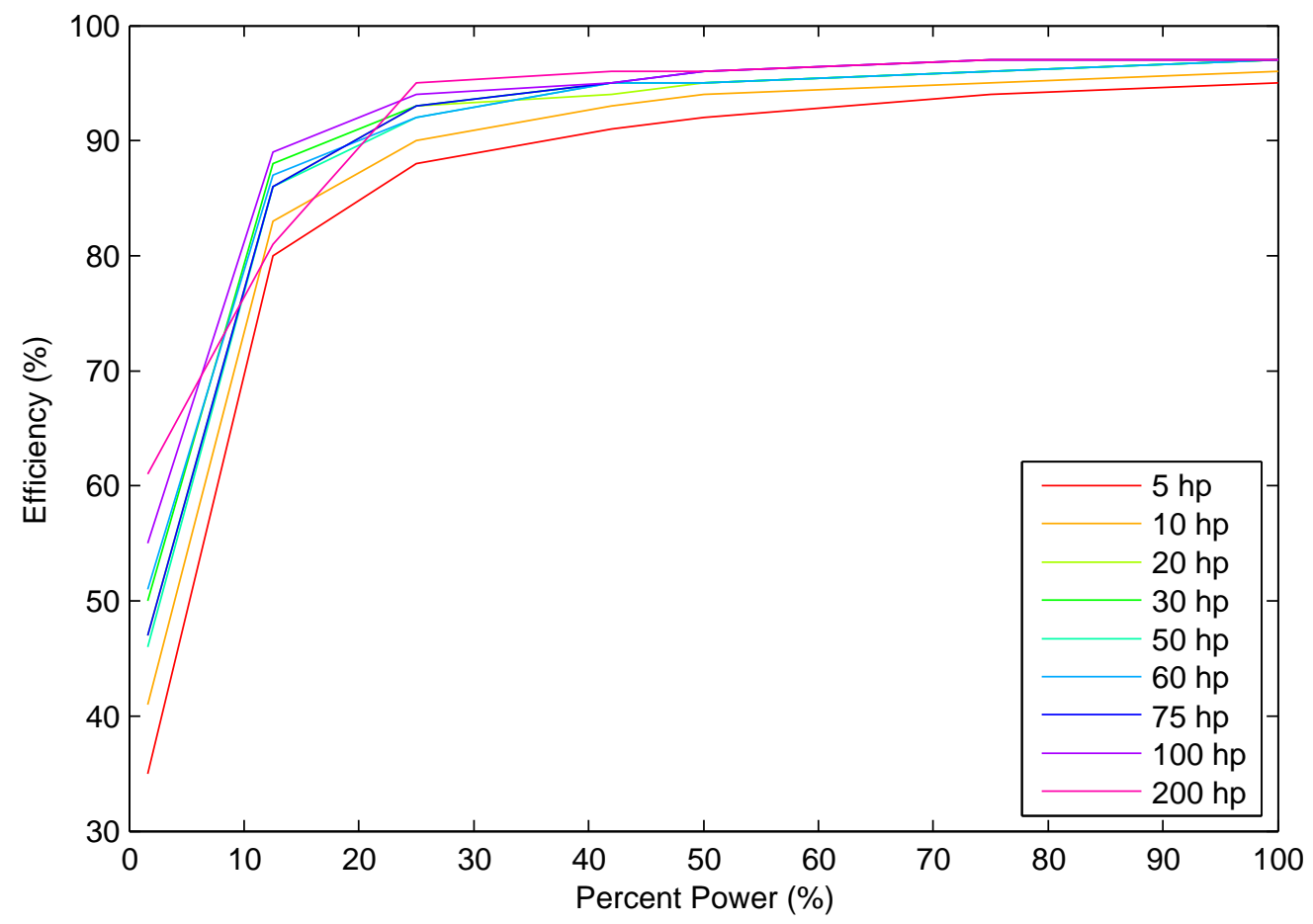

Figure 1.5: VFD efficiencies for induction motors

what the power analyzer does. It is likely they used the power analyzer's method avoiding incorrect calculations. Also the power analyzer can calculate active power, reactive power, and apparent power in three different ways. No mention is made in the report as to what method they used. Research and correspondence with the manufacturer is needed in order to assure which method to use and if it is correct for this application. The Yokogawa analyzer does not measure inverter efficiency directly. It only displays motor efficiency and combined motor and ESC efficiency. Therefore in order to get ESC efficiency, the Army Research Laboratory divided combined efficiency by the motor's efficiency. Figure 1.6 shows the two efficiency curves and the derived ESC curve.

They repeated this test for several motors and got similar data. They also tested the effect of different input DC voltages. One test they held voltage constant and changed throttle and on the second test they held throttle constant and varied voltage. For these test they looked at combined efficiency. This was similar to D. Lundström's test, but they did 


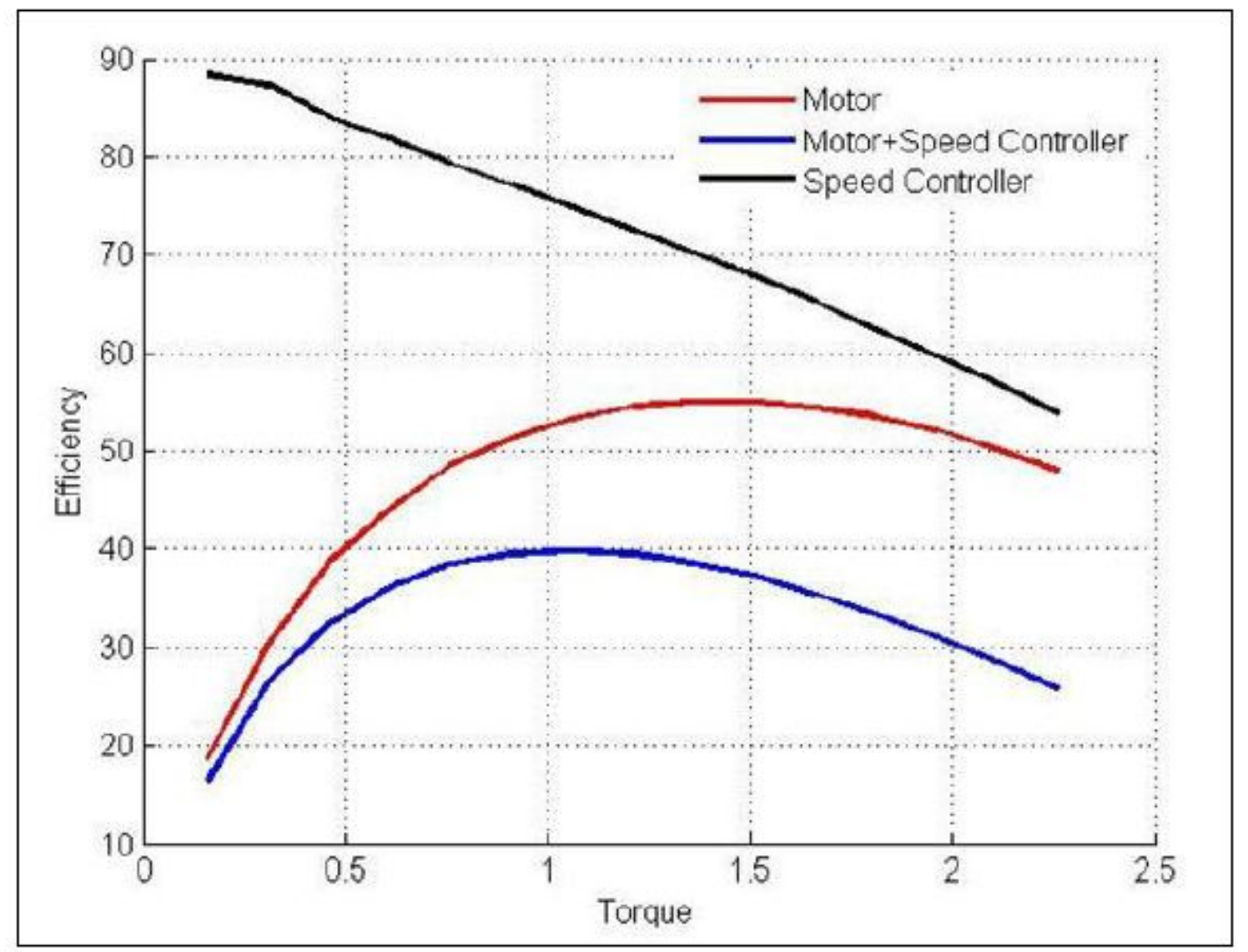

Figure 1.6: Efficiencies measured by the Army Research Laboratory [17]. Although not stated in their graphs, Torque is in $m N-m$ and efficiency is in \% 


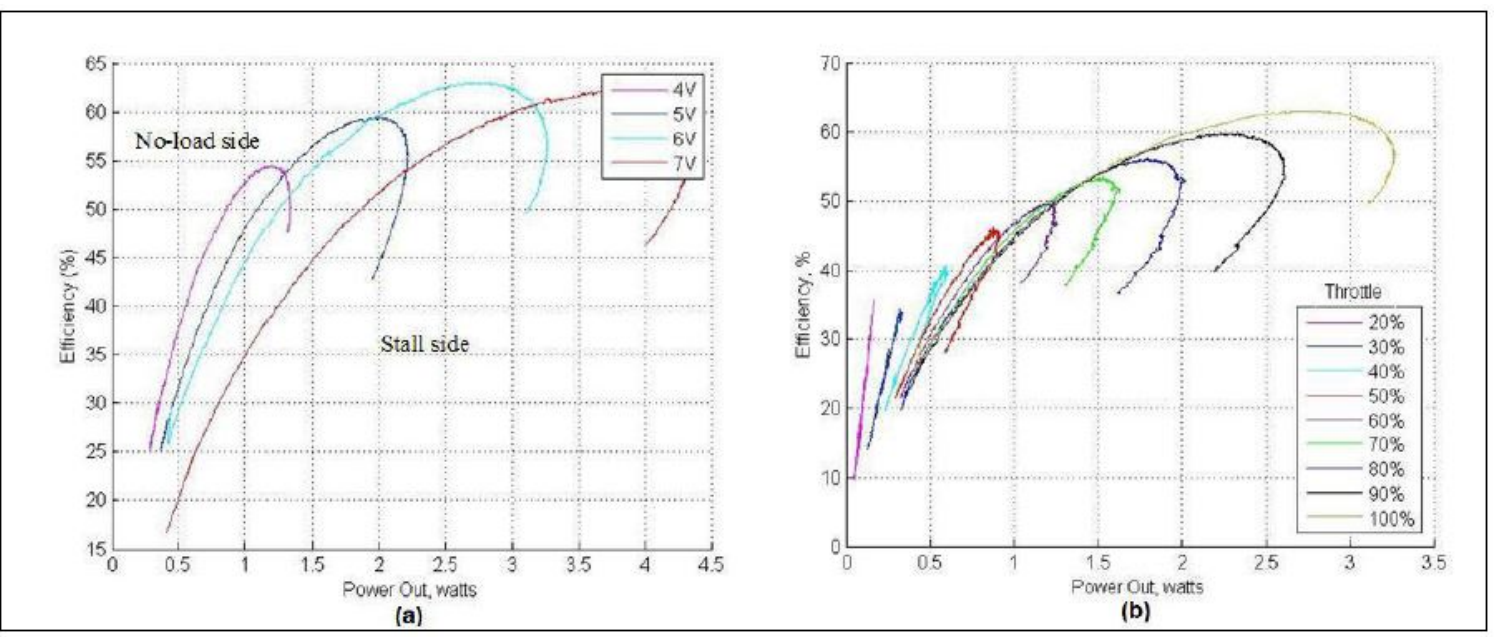

Figure 1.7: Combined efficiencies (a) $100 \%$ throttle and varying voltage and (b) constant voltage and varying throttle [17]

not claim the difference to be the ESC efficiency. Figure 1.7 displays the results for this test.

These graphs are hard to compare due to their different axis scales. Regardless it appears to be some advantage to changing the voltage and keeping high throttle. For example a battery pack could change series parallel combinations in order to get different output voltages. They recommended that it can be a method for improving efficiency. This thesis will perform the same test looking only at the ESC efficiency to see its contribution.

Overall there is little data for ESC efficiency. The data that is available has a good deal of ambiguity on its accuracy of its methodology. The lack of data for ESC for BLDC motors lead the author into developing instrumentation that was capable of measuring the DC power into and the three-phase AC power out of the ESC. 


\section{MEASURING POWER}

Measurement of power for a three phase system is significantly more complex than a DC system. The trapezoidal shape of the signal with the near instantaneous pulses that come from a PWM controller make it even harder. Many three phase power analyzers exist, but most are built around standard three phase power which is $60 \mathrm{~Hz}$ sine wave. Some power analyzers exist that do true rms, root mean square, but they either are for high power $(>1 \mathrm{hp})$ or cannot handle high frequency $(<1000 \mathrm{~Hz})$. True rms actually perform the root mean square calculation rather than assume the waveform is a sine wave. The ones that do exist, like the Yokogawa, are difficult to find and are difficult to tell from the specification sheet if they are appropriate for this thesis. This lead to the author to develop a test bed capable of handling the complex system.

\subsection{MEASUREMENT TECHNIQUES}

Two power readings are required to measure the efficiency of an ESC: DC power into the ESC and AC three phase power out of the ESC. DC power is a simple reading of bus voltage and current.

Three different types of power exist for electrical power into an electric motor. Alternating current systems that have inductance or capacitance can have some power reversal resulting in stored power be returned to source. This "reverse power" is known as reactive power, $Q$. An electric motor is designed around inductance contributing to reactive power. The net power that flows into the motor is defined as active power, $P$. Active power can also be called average power or real power. The resultant of these two powers is apparent power, $S$ as shown in Equation 2.1.

$$
S^{2}=Q^{2}+P^{2}
$$


For one-wire power transfer, apparent power is the product of rms voltage and rms current displayed in Equation 2.2.

$$
S=V_{r m s} I_{r m s}
$$

There are two ways to measure active power. The first method takes advantage of the triangular relationship that these powers share. Using Equation 2.1, active power would be the adjacent leg and reactive power would be the opposite leg. The angle between active power and apparent power, $\phi$, which is the phase shift between current and voltage in a sine wave output. The cosine of this angle is the power factor. Power factor is also by definition the ratio of active power over apparent power as presented in Equation 2.3. $\phi$ looses meaning when referring to non-sinusoidal waveforms. However power factor as a ratio of active power over apparent power retains its meaning.

$$
\begin{gathered}
p f=\cos (\phi) \\
p f=\frac{P}{S}
\end{gathered}
$$

Therefore active power would be Equation 2.4 and reactive power would be Equation 2.5 .

$$
\begin{aligned}
& P=V_{r m s} I_{r m s} \cos (\phi) \\
& Q=V_{r m s} I_{r m s} \sin (\phi)
\end{aligned}
$$

The second method of measuring active power is where it gets it second name of average power. Active power can be directly measured as the time average of the product of instantaneous voltage, $v$, and current, $i$, presented in Equation 2.6. " $T$ " is the period of the waveform.

$$
P=\frac{1}{T} \int_{0}^{T} v i d t
$$


In a three phase system reactive power's definition is less clear. Apparent power and active power are simply the sum of each phase's power demonstrated in Equation 2.7-2.8.

$$
\begin{gathered}
S=V_{1 r m s} I_{1 r m s}+V_{2 r m s} I_{2 r m s}+V_{3 r m s} I_{3 r m s} \\
P=\frac{1}{T} \int_{0}^{T} v_{1} i_{1}+v_{2} i_{2}+v_{3} i_{3} d t
\end{gathered}
$$

Reactive power, since it is hard to measure, is still calculated through the power factor relationship. However it could be calculated using each phase apparent and active power and summed up as in Equation 2.9 or it can use total apparent and active power as presented in Equation 2.10.

$$
\begin{gathered}
Q=\sqrt{S_{1}^{2}-P_{1}^{2}}+\sqrt{S_{2}^{2}-P_{2}^{2}}+\sqrt{S_{3}^{2}-P_{3}^{2}} \\
Q=\sqrt{S_{\text {total }}^{2}-P_{\text {total }}^{2}}
\end{gathered}
$$

Active power is the true power used in the system. This is the power to use for efficiency calculation. Instantaneous power is easy to record and calculate. All ambiguity of reactive power and power factor are avoided. There are three different methods for measuring threephase, three-wire active power into a electric motor. The three methods are defined by the number of wattmeters required.

\subsubsection{THREE WATTMETER METHOD}

The three wattmeter method is the most intuitive method. In Equation 2.11 instantaneous power is measured by multiplying the current and voltage per phase and summing the products.

$$
P_{\text {inst }}=v_{1 n} i_{1}+v_{2 n} i_{2}+v_{3 n} i_{3}
$$


The average of this instantaneous power is active power. The voltage in this method is measured to neutral wire, or neutral point (NP), as demonstrated in Figure 2.1. This wire is not available in the three wire motors used in this thesis.

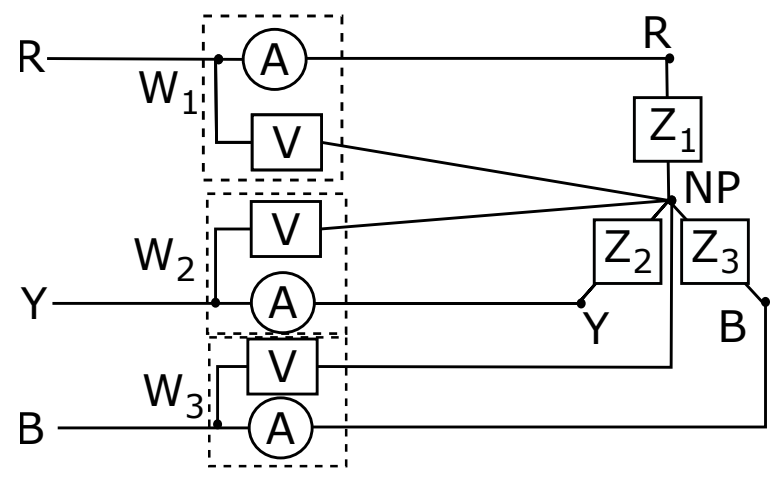

Figure 2.1: Three wattmeter method setup

\subsubsection{ONE WATTMETER METHOD}

The one wattmeter method is derivative of the three wattmeter method. This method assumes all three phases on the motor are balanced, equal resistance. Therefore the power in one phase is equal to the power in the other two as shown in Equation 2.12

$$
\begin{aligned}
& P_{1}=P_{2}=P_{3} \\
& P_{\text {inst }}=3 v_{1 n} i_{1}
\end{aligned}
$$

Figure 2.2 exhibits the setup for the one wattmeter method. The one wattmeter method still has the same problem that the three wattmeter method had. It has to measure voltage with comparison to the neutral wire which does not exist for our system.

\subsubsection{TWO WATTMETER METHOD}

The two wattmeter method takes advantage of the common node inside the motor. Applying Kirchhoff's junction law to this node, Equation 2.13, the two wattmeter method for measuring three-phase power, Equation 2.14, is obtained. 


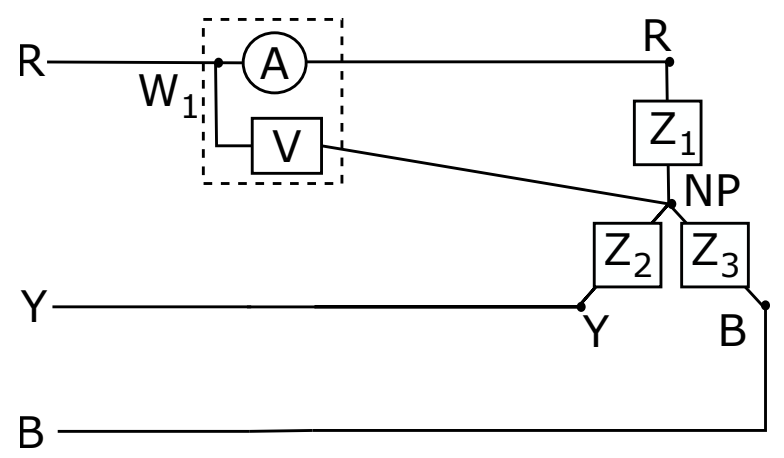

Figure 2.2: One wattmeter method setup

$$
\begin{gathered}
i_{1}+i_{2}+i_{3}=0 \\
P_{\text {inst }}=i_{2}\left(v_{2}-v_{1}\right)+i_{3}\left(v_{3}-v_{1}\right)
\end{gathered}
$$

The setup, Figure 2.3, only requires two amp-meters and two voltmeters to measure three-phase power. It also has the added value of not having to reference the neutral point, and it does not assume a balance load. This method was implemented on all tests performed in this thesis.

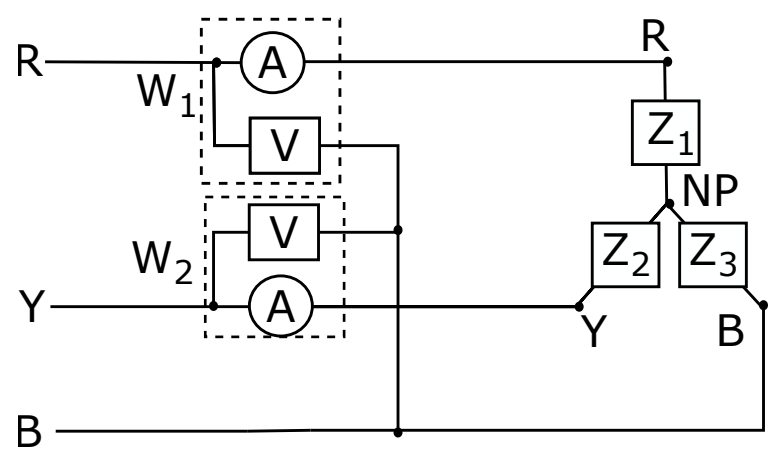

Figure 2.3: Two wattmeter method setup

\subsubsection{READING TYPES}

There are two different reading types when measuring voltage. All potential readings are relative to some other reference point. Voltages are no exception. For example, say there are three voltages and a ground: Voltage $1\left(V_{1}\right)$ is $10 \mathrm{~V}$, voltage $2\left(V_{2}\right)$ is $5 \mathrm{~V}$, voltage $3\left(V_{3}\right)$ 
is $4 \mathrm{~V}$, and ground is zero. Differential inputs are readings where the signal's HI and LOW are floating with respect to the DAQ's ground. Given the example, if $V_{1}$ is the HI and $V_{2}$ was the LOW, the reading would be $5 \mathrm{~V}$ regardless of what is connected to the DAQ's ground. Therefore a HI and LOW must be supplied. Single ended reading are those that share a given common, reference ground amongst all other single ended measurements. Using the example, if all three voltages had their own single ended channel and the common reference ground was connected to the signal ground, the readings would be $10 \mathrm{~V}, 5 \mathrm{~V}$, and $4 \mathrm{~V}$. Single ended measurements require less wires and appear to be the same reading if the voltages are subtracted in the software. However each input channel has its own error. So two reading will have twice the error just from the data acquisition device, DAQ, as a differential reading would have. This causes poor accuracy on measurements with high common-mode voltages. However single ended DAQs are usually cheaper. Differential measurements have the benefit of eliminating common-mode voltage and noise. It also would have only one set of DAQ reading errors instead of two. This makes differential reading ideal for readings that are small and have high common-mode voltage.

\subsubsection{AVERAGING TECHNIQUES}

There are several ways to take an average of a periodic signal. The difficulty with averaging is when to start and stop the signal. Figure 2.4 demonstrates the errors for a zero average sine wave. If the average is not ended on a complete cycle the average is biased towards the incomplete wave. In the case of Figure $2.4 \mathrm{~b}$ the average is $3.38 * 10^{-2}$. This has less of an affect as the sample size increases like Figure $2.4 \mathrm{c}$ with a average of $2.12 * 10^{-3}$. Therefore extremely large sample sizes dilutes this problem.

In this thesis, the mean was taken over 300 kilo-samples taken at $250 \mathrm{kHz}$. This was done ten times per speed, and then the ten averages were averaged together since they are equally weighted. The lowest motor frequency seen was $100 \mathrm{~Hz}$. This means that there 


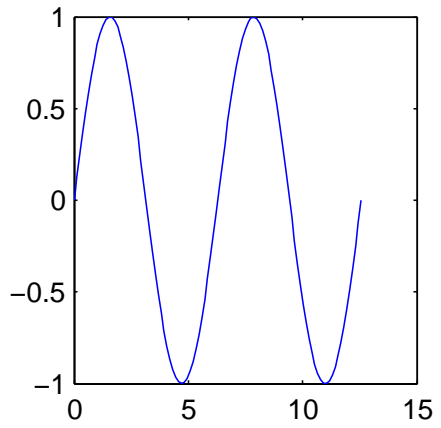

(a) Two period sine wave. Average is 0 .

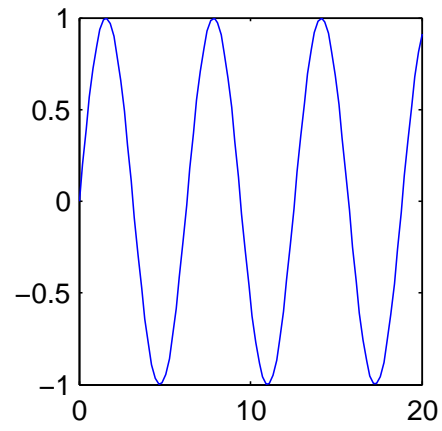

(b) 20 radians of a sine wave. Average is $3.38 * 10^{-2}$.

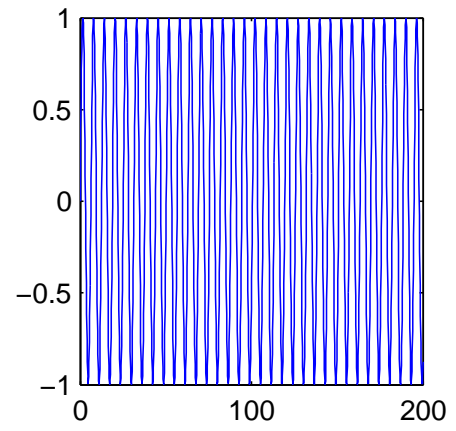

(c) 200 radians of a sine wave. Average is $2.12 * 10^{-3}$.

Figure 2.4: Comparisons of different stop times

were about 1,200 wavelengths recorded at this low frequency. Enough wavelengths were recorded and averaged to assume that the error of the start and stop time was negligible.

\subsubsection{MEASUREMENT REQUIREMENTS}

The two wattmeter method requires four differential readings plus two more for the DC side. Three of the readings are voltage readings, and the other three are current readings. Current is recorded by inserting a current sense resistor in-line with the desired measurement. A current sense resistor, shown in Figure 2.5, is a highly calibrated low resistance resistor used to supply a small change in voltage proportional to the current. This method only requires two current sense resistors for $\mathrm{AC}$, but resistors were put in line with all three phases to balance the motor. This thesis used two sizes of current sense resistors to match the wide range of current being delivered. The $20 \mathrm{~A}$ resistor and $50 \mathrm{~A}$ resistor were $0.005 \Omega$ and $0.002 \Omega$ respectively. Both resistors were $0.25 \%$ accurate and were designed to give a $100 \mathrm{mV}$ output at their max amperage. Therefore all current readings were less than $100 \mathrm{mV}$ with a common-mode voltage ranging from ground to bus voltage. Equation 2.15 shows the change in the Equation 2.14 by implementing a current sense resistor.

$$
i=\frac{\left(v_{H}-v_{L}\right)}{R_{\text {sense }}}
$$




$$
P_{\text {inst }}=\frac{\left(v_{H}-v_{L}\right)_{2}}{R_{\text {sense }}}\left(v_{2}-v_{1}\right)+\frac{\left(v_{H}-v_{L}\right)_{3}}{R_{\text {sense }}}\left(v_{3}-v_{1}\right)
$$

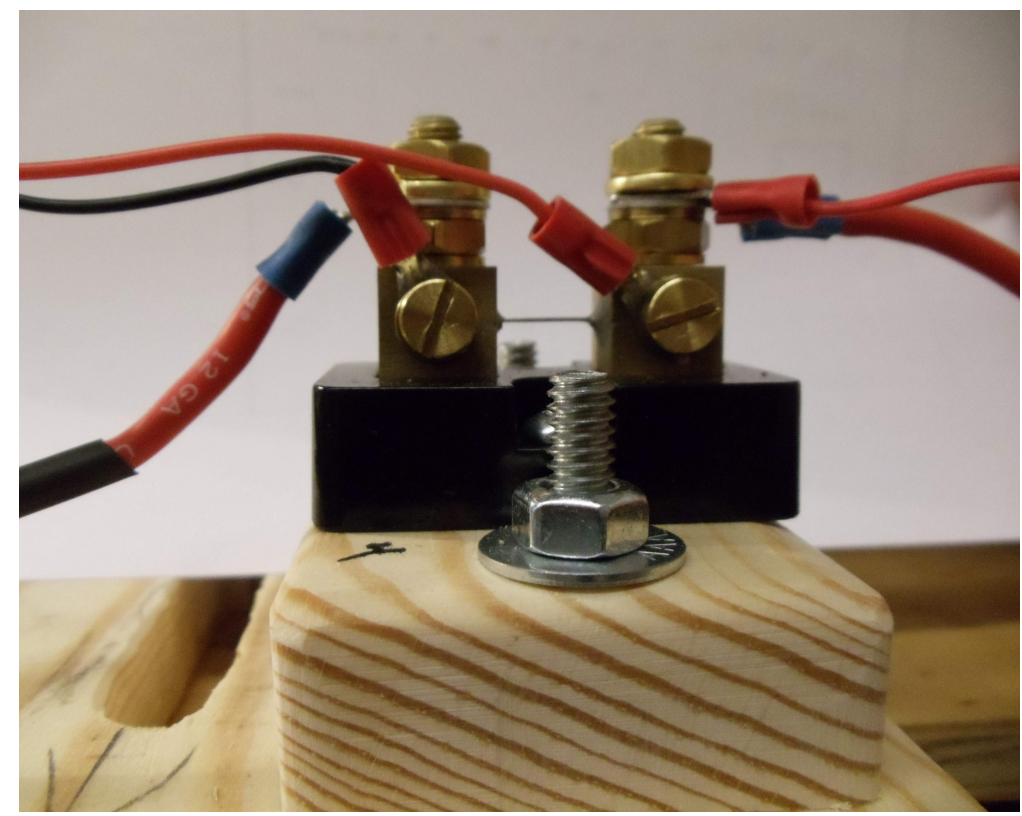

Figure 2.5: Current sense resistor

The voltage readings on the AC will only be slightly greater than the bus voltage. This is due to the back EMF increasing the voltage slightly.

Speed was measured using the back EMF. Since BLDC motors are synchronous motors, the inputted frequency is proportional to rotational speed because there is almost no slip. The benefit of this method is that no additional readings are required. The software takes one of the voltage readings and applies a FFT to the signal. Figure 2.6 is an example of a FFT applied to the phase voltage signal. There are two frequency spikes plus their harmonics shown by the FFT. The first spike in red is the frequency that controls speed. The second spike in black is the switching frequency. The third spike in cyan is the first harmonic of the switching frequency. The switching frequency is at least ten times greater than the rotational frequency. This makes it easy to use a tone extractor to pull out the lower frequency. The speed relationship to rotational frequency is described in Equation $2.16[18]$. 


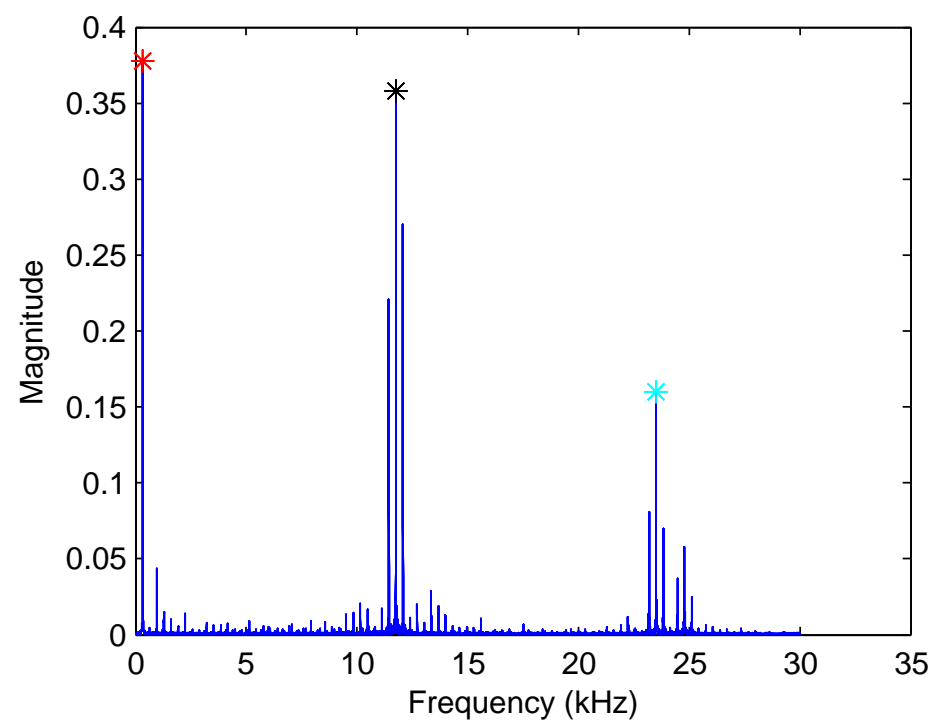

Figure 2.6: Fast Fourier Transform of a phase voltage signal

\begin{tabular}{|l|c|c|}
\hline Measurement & Number & Magnitude \\
\hline$v_{\text {current }}$ & 3 & $\Delta v_{\text {sense }} \leq 100 \mathrm{mV}$ \\
\hline Voltage & 3 & $\left(v_{2}-v_{1}\right) \approx v_{\text {bus }}$ \\
\hline Power & 2 & $1 W \leq P \leq 300 \mathrm{~W}$ \\
\hline Efficiency & 1 & $\eta \approx 99 \%$ \\
\hline RPM & 1 & $250 \leq R P M \leq 10,000$ \\
\hline
\end{tabular}

Table 2.1: Measurements required and their magnitudes

$$
R P M=\frac{120 f_{\text {rotational }}}{N_{p}}
$$

Although this relationship is for a VFD, it is the same for an ESC. This speed calculation was verified with an ESC's internal RPM sensor. For example, this method measured speed at $7616 \mathrm{rpm}$, and the ESC measured a speed of $7635 \mathrm{rpm}$. Table 2.1 is a list of the measurements required and their magnitude.

\subsubsection{PROPELLER POWER}

All test systems used in this thesis used propellers as the loads to simulate loads seen on a small UAVs. If the efficiency of the motor was constant, the power into the motor would be proportional to the power required by the propeller. The motor efficiency is not constant 
but the power into the motor should at least resemble the power required by the propeller. Thrust and power of a propeller are usually nondimensionalized into coefficients [19]. The coefficients of thrust, $C_{T}$, and power, $C_{P}$ are shown in Equations 2.17 and 2.18.

$$
\begin{aligned}
& C_{T}=\frac{T}{\rho n^{2} D^{4}} \\
& C_{P}=\frac{P}{\rho n^{3} D^{5}}
\end{aligned}
$$

In Equation 2.17-2.18, $T$ is thrust, $P$ is the input power, $\rho$ is the density, $n$ is the rotation rate in rotations per second, and $D$ is the propeller diameter. The coefficients are a function of advance ratio, $J$, which is the ratio of the distance the propeller moves forward through the air in one revolution and the diameter of the propeller. Advance ratio is defined by Equation 2.19.

$$
J=\frac{V}{n D}
$$

In Equation 2.19, $V$ is the fluid velocity. Measured values of coefficient of thrust, coefficient of power, and advance ratio can be seen in the University of Illinois at UrbanaChampaign (UIUC) propeller database [20]. UIUC has recorded these coefficients for a number of small hobbyist propellers similar to the ones used in this thesis. Figure 2.7 shows the coefficient of power for a static test system on the $11 \times 8.5$ propeller used in Section 6.1.

The coefficient for power in the static test is near constant. Therefore on a static test Equation 2.18 can be solved for power getting Equation 2.20.

$$
P=C_{P} \rho n^{3} D^{5}
$$

Propeller power in a static test is proportional to $n^{3}$. The power into the motor should reflect this cubic power demand. 


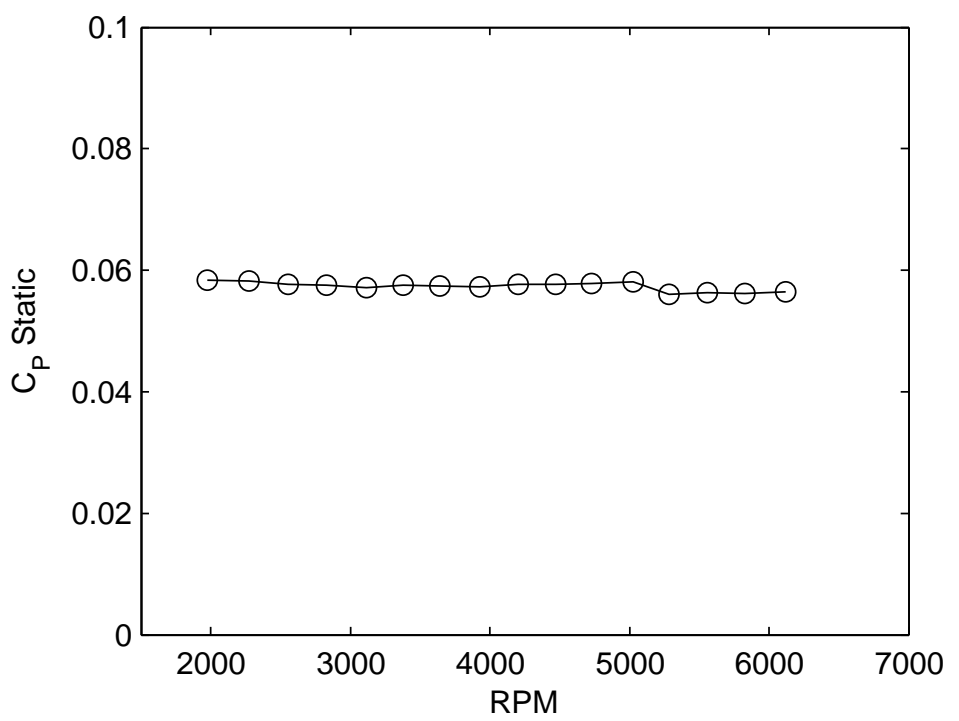

Figure 2.7: Coefficient of power for the $11 \times 8.5$ propeller [20]

\subsection{DATA ACQUISITION}

There are three main approaches to acquiring the measurements required. In all approaches an analog to digital (AD) converter, part of a data acquisition device (DAQ), is required at some point to change analog voltage signals to data a computer can intake. Each method has their own requirements on the DAQ ranging from accuracy, sampling rate, reading type, and number of inputs. All methods also require a digital control signal output. Most ESCs' throttle are controlled by a $50 \mathrm{~Hz}$ pulse train with a high time ranging from $1 \mathrm{~ms}$ to $2 \mathrm{~ms}$. $1 \mathrm{~ms}$ is off and $2 \mathrm{~ms}$ is full throttle. The DAQs used have a digital counter output that is able to simulate this control. This allows for evenly spaced throttles and repeatable test. All DAQs used in this thesis were also 16 bit resolution.

\subsubsection{SIMULTANEOUS DAQ}

A simultaneous DAQ is a DAQ that can take all measurements at the same time. Each channel has its own dedicated AD converter. This DAQ would require six analog differential measurements. It also allows each channel to be taken at its max sampling rate. However 


\begin{tabular}{|l|c|}
\hline Variable & Requirement \\
\hline Input ranges & $\pm 15 \mathrm{~V}$ and $\pm 1 \mathrm{~V}$ \\
\hline Sampling rate & $>60 \mathrm{kHz}$ \\
\hline Channels & $\geq 6$ \\
\hline
\end{tabular}

\section{Table 2.2: Simultaneous DAQ requirements}

these DAQs are usually a great deal more expensive then the next two methods. In order for this DAQ to handle the power readings it must be able to satisfy the requirements in Table 2.2.

Input range is the range that it divides the 16 bits over. For example, for a range of $\pm 10 \mathrm{~V}$ the step size would be $305 \mu \mathrm{V}$ whereas for a $\pm 1 \mathrm{~V}$ the step size would be $30.5 \mu \mathrm{V}$. The first input range in the example was for voltages and the second range was for current readings. Power readings taken are averaged over many waveform periods. If the sampling rate is not a harmonic of the switching frequency or speed frequency, it should gather a near random collection of data. Therefore the mean of this random sample should be equal to the true average.

\subsubsection{SEQUENTIAL DAQ}

Sequential DAQ is a DAQ that takes all measurements with the same AD converter sequentially. Therefore the more channels you add the slower your sampling rate. For example, if the sampling rate of the DAQ is $250 \mathrm{kHz}$ but there are five inputs, it will read each input at $50 \mathrm{kHz}$. If a sequential DAQ is the only instrumentation used to measure power, then voltage and current would be taken at different times. Current measurements would then have to be phase shifted by the difference in time to approximate its value at the same time as the voltage. The requirements for a sequential DAQ are similar to the simultaneous DAQ, but the sampling rate has to be much higher to account for the channels sharing this speed, Table 2.3. 


\begin{tabular}{|l|c|}
\hline Variable & Requirement \\
\hline Input ranges & $\pm 15 \mathrm{~V}$ and $\pm 1 \mathrm{~V}$ \\
\hline Sampling rate & $>360 \mathrm{kHz}$ \\
\hline Channels & $\geq 6$ \\
\hline
\end{tabular}

Table 2.3: Sequential DAQ requirements

\subsubsection{ANALOG PCB AND DAQ}

Before the age of digital circuits most functions were done in analog on a printed circuit board (PCB). Today, integrated circuits (IC) can perform almost any mathematical function using electrical physics. ICs can multiply, divide, integrate, differentiate, subtract, add, and so on. IC that are in parallel can operate simultaneously avoiding the problems that come with the sequential DAQ. Analog circuits that can handle the necessary constraints are easy to find. For implementation ease, this system still requires a DAQ to transfer the analog voltage signal representing power to the computer. However since the DAQ is measuring power which is averaged, it does not affect the results whether it is simultaneous or sequential. Circuitry and requirements for such a system are explained further in Chapter 3.

\subsubsection{TEST SETUP MATRIX}

Table 2.4 is all of the possible test setups. All of the "A" setups were attempted and deemed unpractical. The one checked setup is the final setup. "X" setups were not pursued. All setups used the two wattmeter method. The "A" setups' attempts and trials are described in Chapter 3, and the final configuration is detailed in Chapter 4. If only interested in the system used to record the presented data then skip to Chapter 4.

\begin{tabular}{|l|c|c|c|}
\hline Type & Analog + DAQ & Sequential DAQ & Simultaneous DAQ \\
\hline Single Ended & $\mathrm{X}$ & $\mathrm{X}$ & $\mathrm{A}$ \\
\hline Differential & $\mathrm{A}$ & $\mathrm{A}$ & $\sqrt{ }$ \\
\hline
\end{tabular}

Table 2.4: Test setup matrix. $X$-not attempted A-attempted. $\sqrt{ }$-final 


\section{ATTEMPTED CONFIGURATIONS}

This chapter describes in detail the three test system setups that were attempted but were not used for data collection. The three configurations attempted are (1) an analog board and a sequential DAQ, (2) a differential sequential DAQ, and (3) a single ended simultaneous DAQ. Again if only interested in the system used to record the presented data than skip to Chapter 4, which describes the final instrumentation.

\subsection{ANALOG CIRCUIT BOARD AND DAQ}

An analog circuit board was designed and attempted to avoid phase shifting or buying an expensive DAQ. The analog system also allows flexibility in testable systems without greatly increasing cost. Figure 3.1 is a simplified wiring diagram of the circuitry used to measure the power in and out of the ESC. It does not include the sense resistors and other circuitry required to support the main integrated circuits, and it is only for one wattmeter. The full PCB design is in Appendix B. The two $10 M \Omega$ resistors per phase were used as a voltage divider to meet the hardware limits. The current sense op amps measured the change in voltage across the current sense resistors and produced an output voltage proportional to that change in voltage. The multipliers output a voltage proportional to the change in voltage across the lines times the voltage output of the current sense op amps divided by 10. The output voltage is than multiplied by a conversion factor in Labview to relate it to power in and out of the ESC. In Labview, a mean of the signal was taken, and a Fast Fourier Transform was applied to a line signal to extract the speed.

The circuit board was designed and built using standard electrical engineering principles. First hardware requirements were collected from the required measurements and was broken down into IC requirements. The first design was built to handle a possible $300 \mathrm{~V}$ 


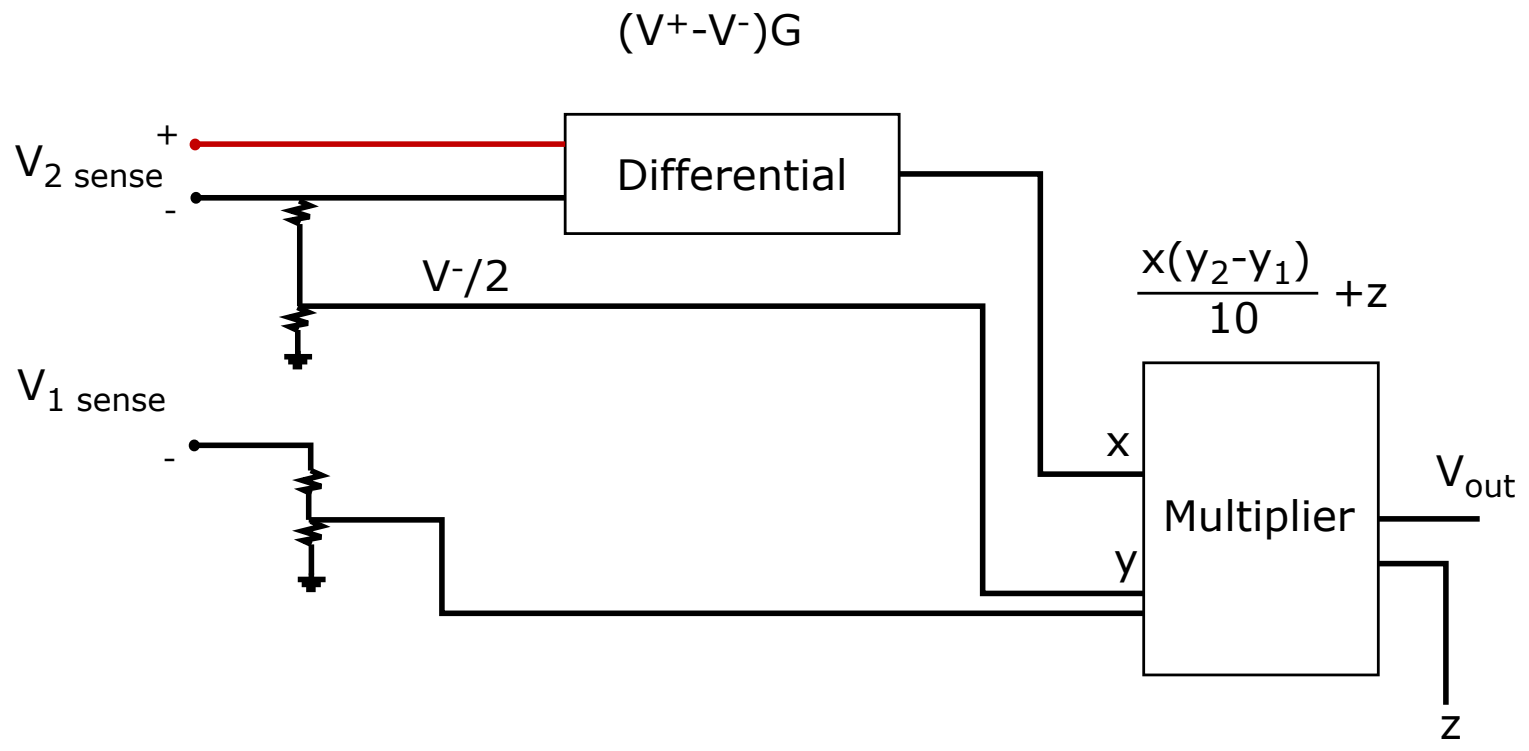

Figure 3.1: One wattmeter wiring diagram

system that was in the process of procurement. Therefore there are additional options on the board to handle high voltage. The $300 \mathrm{~V}$ system was never acquired, but the additional flexibility did not hurt design. Next, parts were selected that could handle the requirements. Error propagation calculations were built around the components to check sensitivities of IC options. Most had to have a high degree of accuracy to meet minimum overall accuracies. The components were bought and assembled in a breadboard. The breadboard system, shown in Figure 3.2a, was tested using a signal generator for verification of outputs. This exposed misunderstandings in part specifications and additional limitations on parts. Once a properly verified system was working on the breadboard, it was designed in OrCAD [21] and was made into a PCB. Verification was repeated on the PCB to prove it matched the breadboard. This uncovered some incorrect wiring which was corrected with a jumper wire and retested. After retesting, the board was tested on the full system to gauge its output and to test adjustable parameters. Some of the first tests showed efficiencies over $100 \%$, so the tolerances were tightened and new parts were selected using error propagation to find the biggest contributions. Feeling confident in the PCB design a new modified version was made, Figure 3.2b and was verified again. The new PCB visually remained the same. This 
was again modified by scratching traces and using jumper wires in order to isolate power ground from test ground to restrict ground loop current flow.

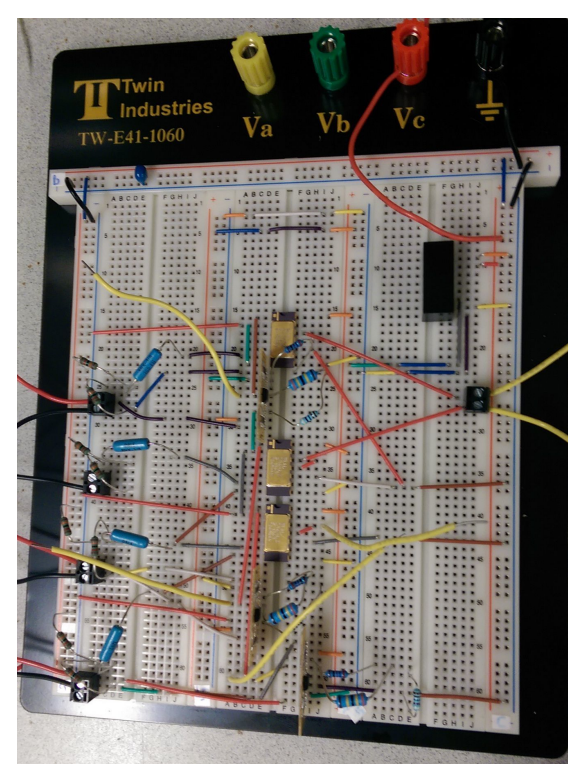

(a) Breadboard design

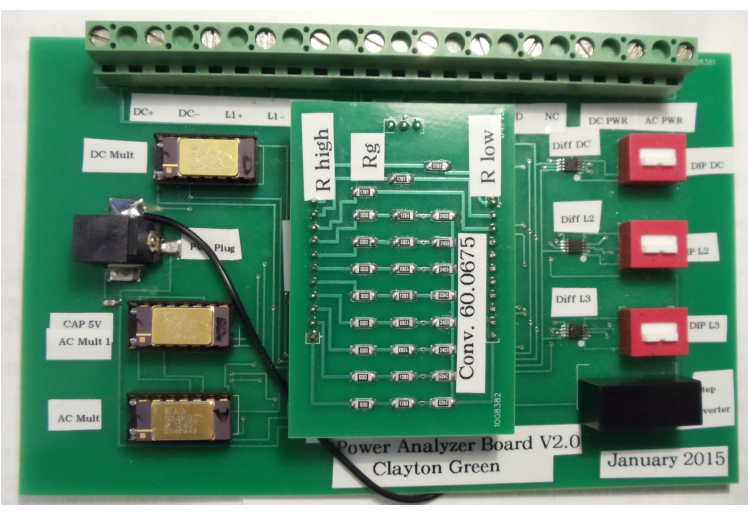

(b) Final PCB design with jumper wire

Figure 3.2: PCB iterations

The three little black boxes on the right of Figure $3.2 \mathrm{~b}$ are the differentials. The three gold IC on the left are the multipliers which are the two wattmeters plus the DC wattmeter. The red boxes are switches to change reading locations for a $300 \mathrm{~V}$ system. Since the 300 V system was never acquired, the switches remain in the down position. The black box on the bottom right is the power supply, and the last one on the left is the power plug. The top green bar is the connectors. The board in the center is removable as seen in Figure 3.3. This is to allow for easy exchange of different voltage reducing resistors and gains. It has a built in dummy plug to avoid incorrect input.

Even after all of the regression testing and improvements the testbed still struggled to measure the system's efficiency accurately enough. The significant contributing error sources were current sense resistors, phase shift, slew rate, and fall time. The current sense resistors are proportional to current by 1:200 or more. Error in their resistance can cause the greatest change error propagation. Thus higher accuracy resistors were acquired. Figure 


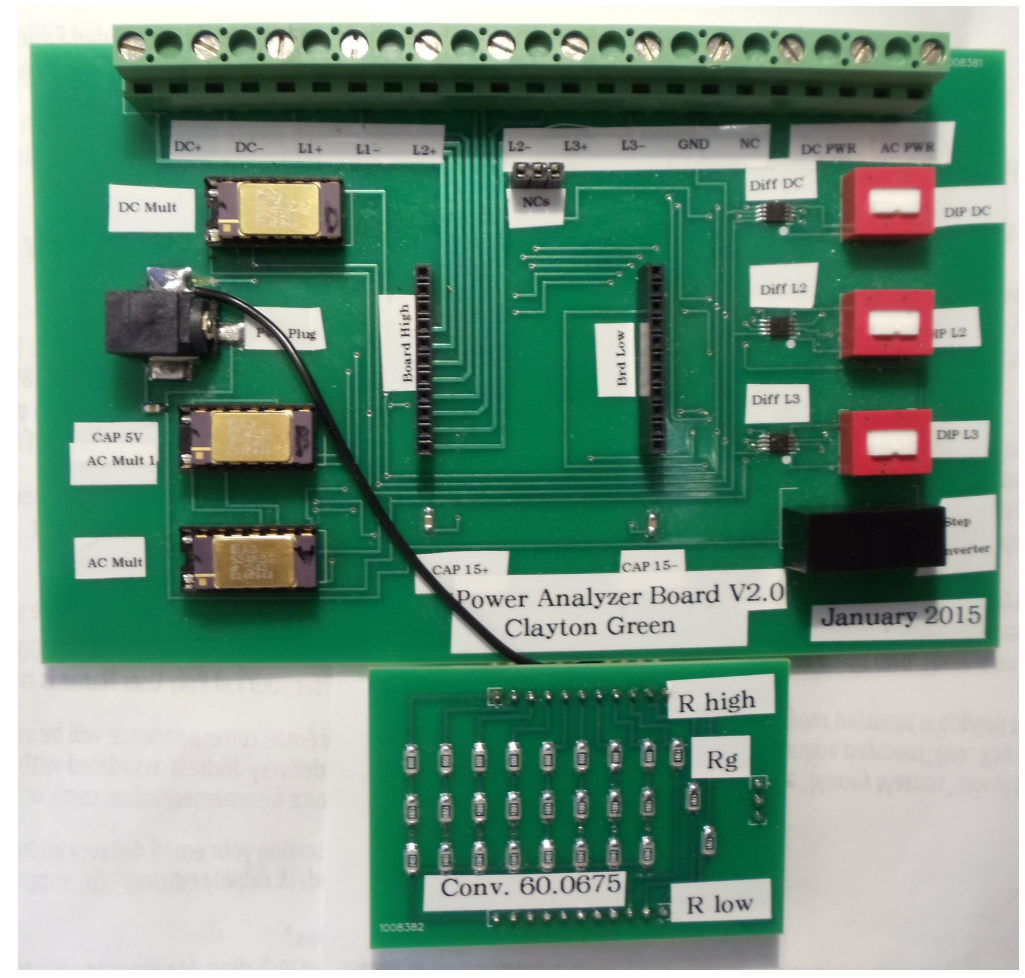

Figure 3.3: Final PCB disassembled

3.4 shows the old $1 \%$ tolerance current sense resistors to the new $0.25 \%$ resistors. These resistors were used on all setups.

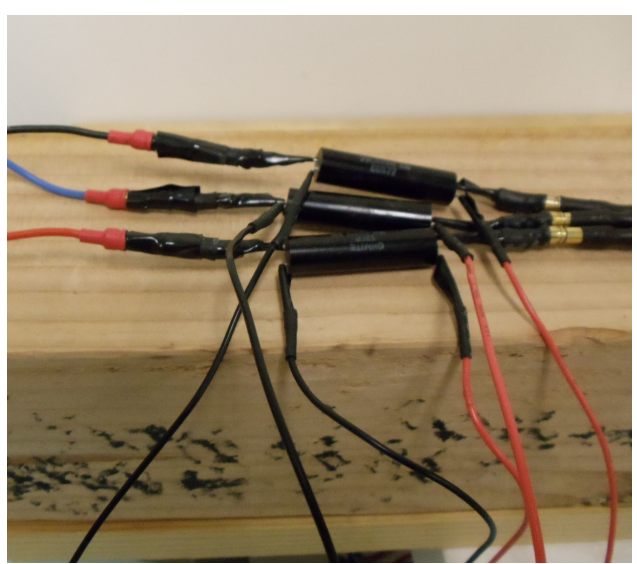

(a) Old $1 \%$ resistors

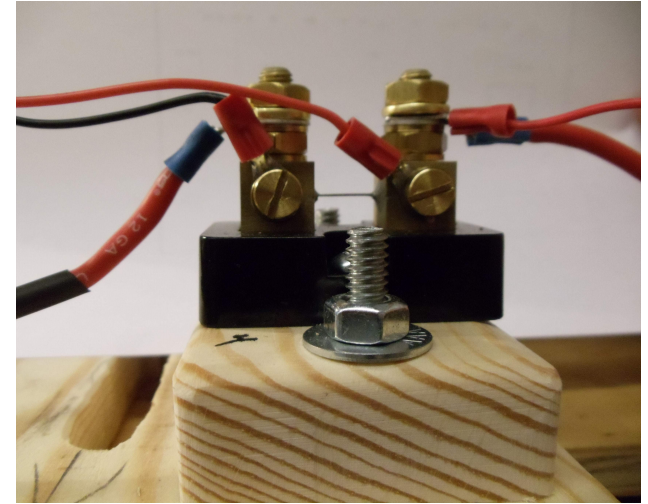

(b) New $0.25 \%$ resistors

Figure 3.4: Current sense resistors

Phase shift, slew rate, overshoot, and settling time are similar problems which were all contributions from the differential and multipliers. The underlying problem that these all contribute to is that the testbed was trying to model a discontinuous signal with a continuous 
output. A PWM signal has lots of near instantaneous switches on and off. This is difficult for a continuous model. Phase shift is the time difference between the output from the input usually given in degrees. Slew rate is the rising and falling speed of the IC from a step response given in $V / \mu s$, and settling time is the time it takes settle to a constant value after a step response given in $\mu s$. Overshoot is the percentage the signal goes over the given step response. The faster settling time and slew rate the more overshoot there will be. Phase shift in the IC is a problem only when not all of the signals receive the same procession of ICs. An example of a problem is that the voltages into the multiplier only go through passive components, no phase shift, and the current sense voltage goes through the differential IC adding some phase shift. Now they come in at slightly different times. If all voltages go through the same differentials the phase shift would have no effect. Slew rate and settling rate have a huge affect. Table 3.1 shows the progression of differentials used for the circuit board. Phase shift was not always supplied. The first IC was a misunderstanding in the specifications. The next three all handled the voltage range. The AD 628 did not have a large enough bandwidth so it attenuated the signal, Figure 3.5a. Bandwidth is a direct function of slew rate and output voltage range. INA 827 passed the signal generator test but the slew rate and settling time were still not good enough. Although it has the bandwidth for the switching frequency, it still slightly attenuated and extended the signal, Figure $3.5 \mathrm{~b}$. This has the greatest affect on low throttles where there was a high degree of switching. LT 1995 was the next candidate for the system but was not tested because other methods were pursued. It is extremely fast but it has a good deal of overshoot as shown in Figure 3.5c. Notice the change in scale of the $\mathrm{x}$-axis on Figure 3.5. The $\mathrm{x}$-axis scales are $40 \mu s, 50 \mathrm{~ms}$, and $100 \mathrm{~ns}$ respectively.

AD 734 is a drop in replacement for AD 534 multiplier with higher slew rates and smaller settling time. However this part was also untested. A swap to the LT 1995 and the $\mathrm{AD} 734$ might have made this circuitry a viable technique to measure power, but the method was set aside for other methods with less untestable uncertainties. 


\begin{tabular}{|l|c|c|c|c|}
\hline Measurement & LT 6100 [22] & AD 628 [23] & INA 827 [24] & LT 1995 [25] \\
\hline Type & One sided & Rail to rail & Rail to rail & Rail to rail \\
\hline$V_{\text {common }}$ & 5 & \pm 120 & \pm 14.1 & \pm 15.5 \\
\hline Gain $(\mathrm{V} / \mathrm{V})$ & $10-50$ & $0.1-100$ & $5-1000$ & $1-7$ \\
\hline Slew rate $(\mathrm{V} / \mu s)$ & 0.05 & 0.3 & 1.5 & 1000 \\
\hline $\begin{array}{l}\text { Large signal band- } \\
\text { width }(\mathrm{kHz})\end{array}$ & 20 & 2 & 25 & 1500 \\
\hline Settling time $(\mu s)$ & 15 & 40 & 11 & 0.1 \\
\hline Phase shift $(\mathrm{deg})$ & NA & NA & NA & 0.15 \\
\hline Problems & One sided, & $\begin{array}{c}\text { Attenuated } \\
\text { signal at } 15 \\
\mathrm{kHz}\end{array}$ & $\begin{array}{c}\text { Slew rate } \\
\text { caused time } \\
\text { lowift }\end{array}$ & untested \\
\hline
\end{tabular}

Table 3.1: Differential evolution specifications

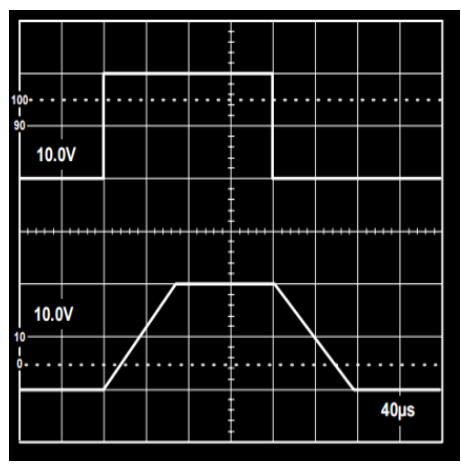

(a) $\mathrm{AD} 62810 \mathrm{~V}$ step response. $\mathrm{x}$ scale is $40 \mu \mathrm{s}$. Gain $=1$ [23]

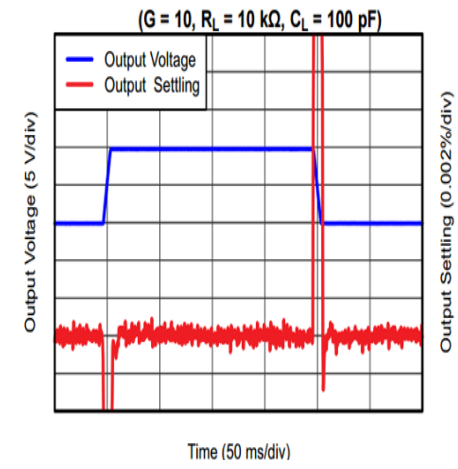

(b) INA $82710 \mathrm{~V}$ step response. $\mathrm{x}$ scale is $50 \mathrm{~ms}$. Gain=10 [24]

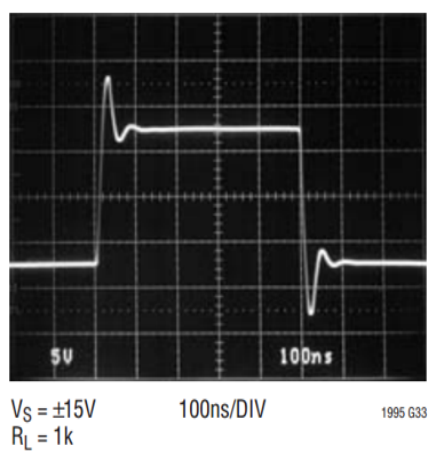

(c) INA $8277 \mathrm{~V}$ step response. $\mathrm{x}$ scale is $100 \mathrm{~ns}$. Gain=1 [25]

Figure 3.5: Comparisons of different large-signal step responses

\subsection{SEQUENTIAL DAQ}

Another method that was tried was to use a sequential DAQ and shift the signal back onto each other. This method required the program to account for a time shift. Therefore the current signal was converted into the frequency domain using fast Fourier transform, and a phase shift was applied to its phase component in Equation 3.1. Fast Fourier transform (FFT) is a method to apply Fourier transform to a finite sampling set resulting in an summation that approximates the signal [26].

$$
\phi_{\text {new }}(f)=\phi(f)+2 * \pi * d t * f
$$




$$
d t=\frac{1}{\text { samplingrate }}
$$

In the equation, "f" is the frequency component, " $\phi$ " is the phase at that frequency component, and "dt" is the time shift. After the phase shift, it was converted back into the time domain where instantaneous current and voltage were multiplied together giving instantaneous power. The average of the periodic signal and the speed were taken just like the previous method.

This method has severe limitations. First is that in order to do the phase shift using a Fourier Transform, sampling rate needs to be high enough to capture Nyquist frequency. However trapezoidal waves have infinite frequency components, so Nyquist is based on acceptable error. Figure 3.6 shows the error imposed after the voltage is sampled at $60 \mathrm{kHz}$ and is approximated with a FFT.

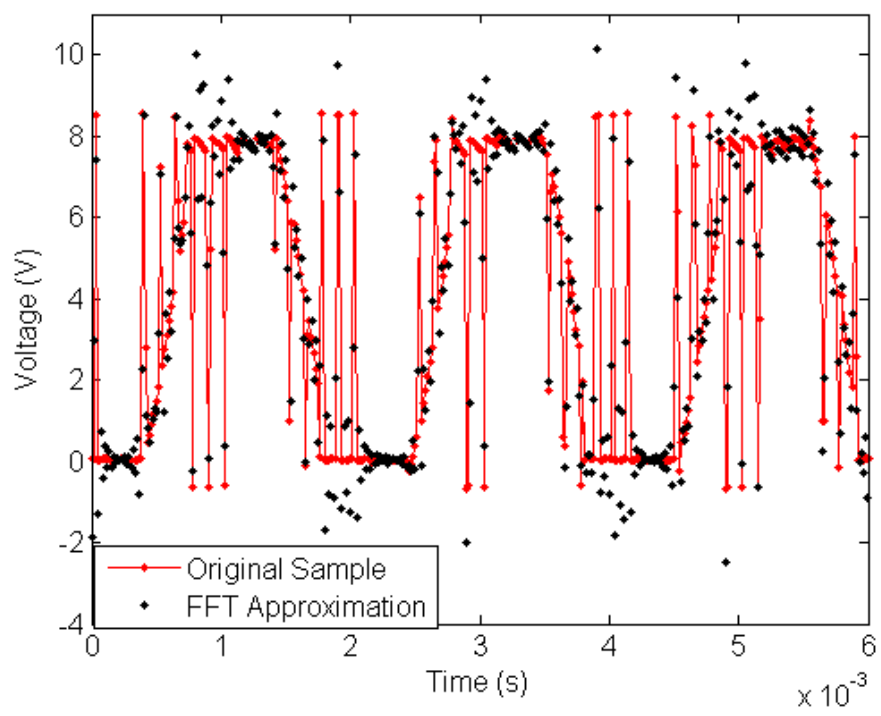

Figure 3.6: FFT approximation of the voltage signal out of the ESC

The FFT has high overshoots and undershoots. FFT cannot model discontinuous rises and falls. This gives a nonzero value where there should be no power transfer. This error is too great for the accuracy required to measure close to $100 \%$ efficiency. Each channel reduces the speed, so to improve the sequential DAQ sampling rate needs to be many times greater. The data acquisition system was only able to measure $\pm 10 \mathrm{~V}$. This imposed an 


\begin{tabular}{|l|c|c|c|}
\hline Error Source & $\begin{array}{c}\text { Magnitude } \\
(\mathrm{mV})\end{array}$ & $\begin{array}{c}\text { Equivalent } \\
\text { Current (A) }\end{array}$ & $\begin{array}{c}\text { Can it be } \\
\text { calibrated? }\end{array}$ \\
\hline Step size & 0.305 & 0.061 & No \\
\hline Offset & 1.526 & 0.3052 & Yes \\
\hline Gain error @FS & 4.578 & 0.9156 & $\begin{array}{c}\text { Match } \\
\text { channels only }\end{array}$ \\
\hline Non-linearity & $\begin{array}{c}0.00915 \% \\
\text { FSR }\end{array}$ & 0.183 & No \\
\hline Total @FS & 7.019 & 1.4 & NA \\
\hline
\end{tabular}

Table 3.2: DAQ errors

input voltage limitation of $9 \mathrm{~V}$. This gave some buffer allowing for some fluctuation in the $\mathrm{AC}$ voltage due to circuitry. The ESC and motor being use are rated for up to $25 \mathrm{~V}$ and are recommended for $12 \mathrm{~V}$. In order to read this voltage in future tests, the voltage would have to be accurately reduced to within the operating limits of the DAQ. Simple resistor voltage dividers used in the original circuitry are not accurate enough to reduce the high common mode voltage across the current sense resistors. The small difference in their values combined with the high common mode can cause enough error to make it appear as if current is in the reverse direction of the actual current. More research for the solution still needs to be undertaken.

\subsection{SINGLE ENDED SIMULTANEOUS DAQ}

The last method not integrated in the final instrumentation that was attempted was using a single ended simultaneous DAQ, MC USB-1608FS-Plus, to measure the two wattmeter method. The single ended DAQ was three times cheaper than the simultaneous DAQ. At the time it was assumed that taking the difference of the signals is the same whether it is done in software or hardware. Mathematically this is true. However each reading whether single ended or differential has several errors described in Table 3.2.

The more measurements the more error. Each error is based on its reading range, full scale range (FSR). Offset, gain, and non-linearity all scale directly with range. Also, given 
the high common mode of the current sense voltage, the reading range for the single ended DAQ had to be high, increasing the error. The larger range also lead to digitization errors because the step size was too large. Figure 3.7 demonstrates the discrete steps caused by the step size. These errors lead to the use of a differential DAQ which was the system used to measure the presented data.

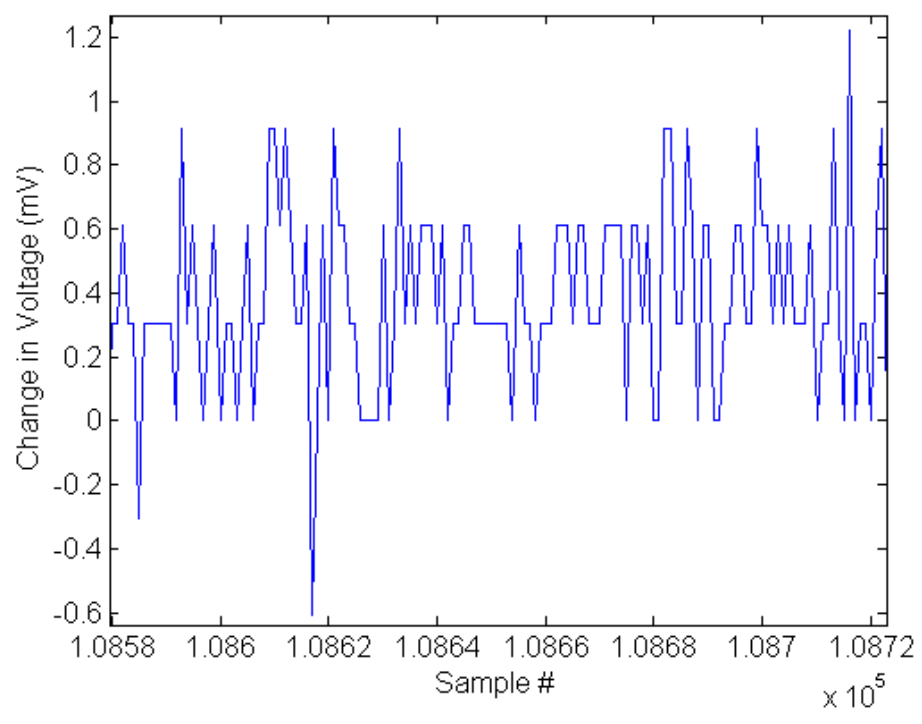

Figure 3.7: Discrete steps caused by digitization 


\section{FINAL INSTRUMENTATION}

A differential simultaneous DAQ, Measurement Computing 1608HS [27], was the final test setup used for this thesis. The elimination of the circuitry board greatly reduced the complexity of the setup. All required measurements were inputted directly into the DAQ without external circuitry. However this limited the input to $\pm 10 \mathrm{~V}$. The differential reading reduced noise and measurement range reducing errors. A conversion factor was applied to current in software and multiplied by the appropriate voltages. The measured powers were averaged as previously described and divided to get efficiency. Figure 4.1 is a picture of the simultaneous DAQ used.

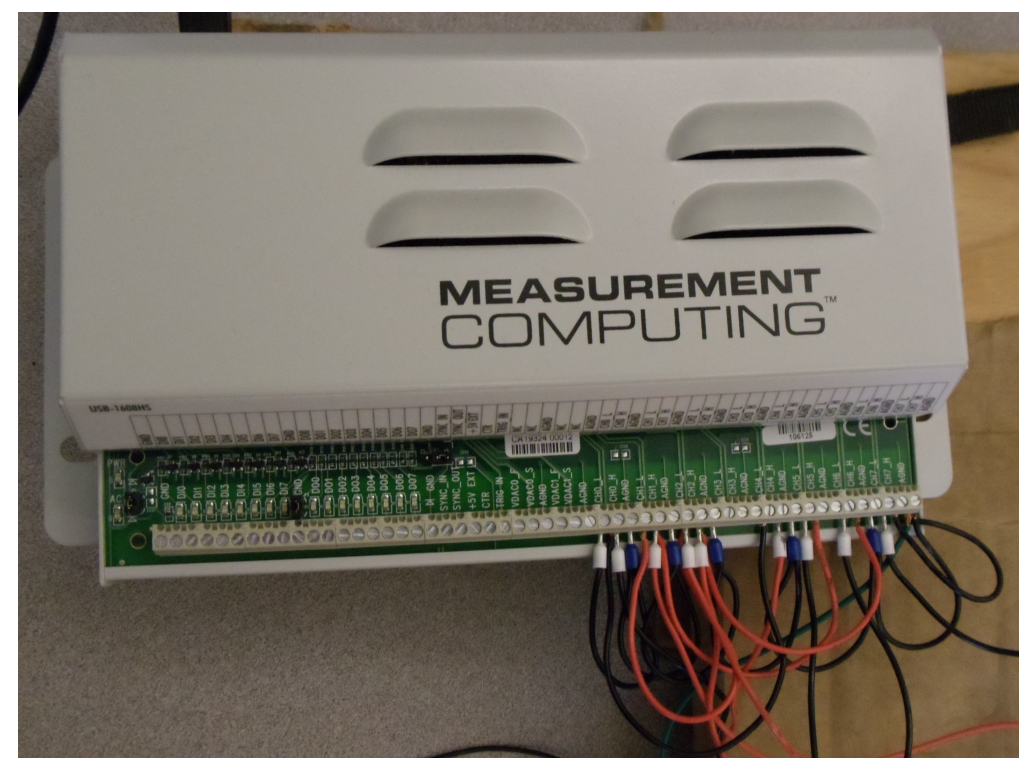

Figure 4.1: Simultaneous DAQ used

A power supply was used instead of batteries in order to increase repeatability. The power supply was a $1000 \mathrm{~W}$ HP 6012B DC power supply [28]. The ESC used for all of the test except the ESC Size and Brand test was a Hobbywing Platinum 50A [29]. The other ESCs used were Hobbywing Flyfun $30 \mathrm{~A}$ and $40 \mathrm{~A}$, and the Hitec $50 \mathrm{~A}[29,30]$. The motor was a E-Flite Power 46 [31]. Master Airscrew and APC propellers were used. 


\begin{tabular}{|l|c|}
\hline$R_{E S C}$ & NA \\
\hline$f_{s w}(k H z)$ & $8,16,24,32$ \\
\hline$V_{\text {in }}(V)$ & $5.2-25.2$ \\
\hline
\end{tabular}

(a) Hobbywing Platinum 50 A specifications

\begin{tabular}{|l|c|}
\hline$K_{v} \mathrm{rpm} / \mathrm{V}$ & 670 \\
\hline$R_{i}(\Omega)$ & 0.04 \\
\hline$I_{o}(A) @ 10 \mathrm{~V}$ & 3.88 \\
\hline \# of poles & 12 \\
\hline $\begin{array}{l}\text { Max continuous } \\
\text { current }(\mathrm{A})\end{array}$ & 40 \\
\hline Max power $(\mathrm{W})$ & 800 \\
\hline
\end{tabular}

(b) E-Flite Power 46 specifications

\section{Table 4.1: Test system specifications}

The current sense resistors used are $0.005 \Omega$ for low currents and $0.002 \Omega$ for high currents with a $0.25 \%$ accuracy. The DC side current sense resistor was placed on the high side to avoid extra wires entering the DAQ. For higher common mode current sensing, the resistor can be placed on the ground return line. However the AC resistors cannot avoid the higher common modes. Unless otherwise stated the Hobbywing Platinum 50 A ESC was used at $8 \mathrm{kHz}$ switching frequency at $9 \mathrm{~V}$.

Figure 4.2 was the final test setup used in this thesis. The cage was built around the propeller for safety. Ducting effects from the cage was considered unimportant because propeller efficiency was not measured. The propellers were only used as an easy applied load. Top left is the National Instruments sequential DAQ that was tested. This DAQ was still used as throttle control. Software changes to implement this throttle control on the Measurement Computing DAQ is possible but complicated; due to time constraints this was not implemented. Bottom left is the wired Measurement Computing DAQ used in the tests. In the center are the four current sense resistors. The third resistor was placed in-line to balance the load. The red and black line on the bottom right goes to the power supply. For safety, on high power tests, temperature of the ESC was measured using an Eagle Tree Data Logger.

As previously stated, the ESC was controlled by the DAQ in order to get repeatable measurements. In Labview the throttle was stepped by 0.001 divided by the number of steps requested. Each step has a three second delay before data collection. Then 10 sample 


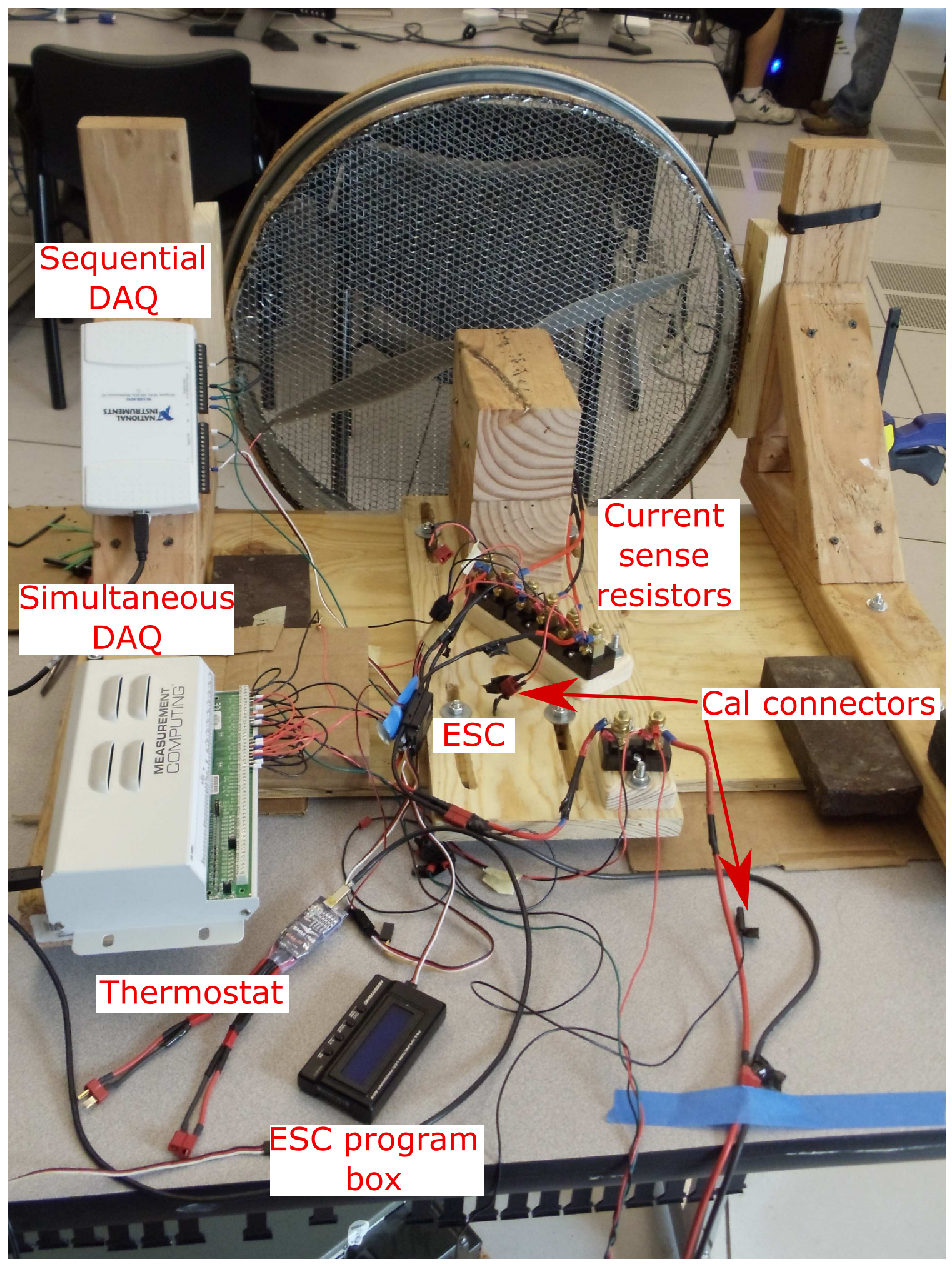

Figure 4.2: Final setup used

sets of 300 kilo-samples were taken at $250 \mathrm{kHz}$. Each set was processed as previously described and then averaged per division. $250 \mathrm{kHz}$ sampling rate and 300 kilo-samples sets 
were used in order to achieve maximum performance from the hardware. 10 sample sets were used to get a reasonably large sample size to average. The three second delay between throttle change was applied to avoid transient behavior. Figure 4.3 shows the Labview front panel with all of the controls previously described. 


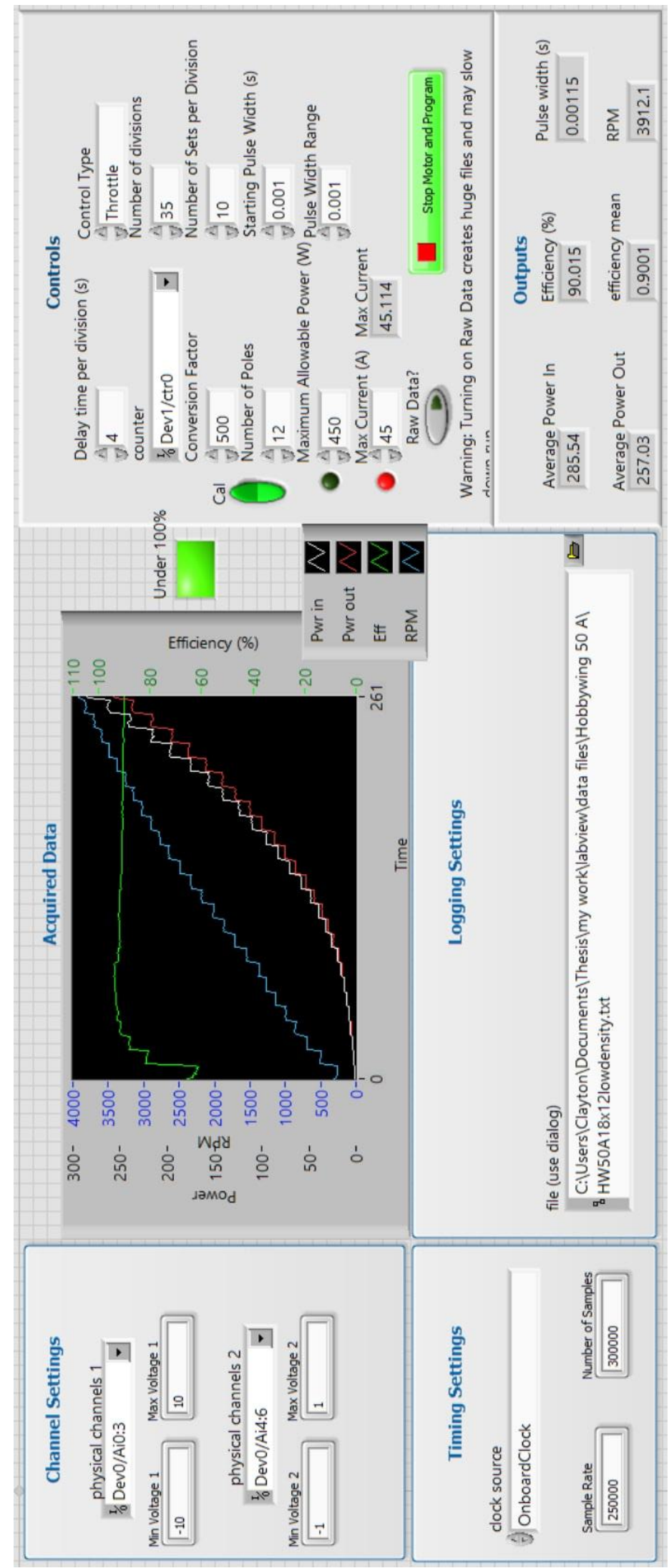

Figure 4.3: Labview control panel 


\section{UNCERTAINTIES AND SENSITIVITIES}

Uncertainties and sensitivities were used throughout this thesis to decide part tolerance and magnitudes. For example, through error propagation it was found that the largest contribution to error at the time was the current sense resistors because they imposed such a large gain. Higher precision resistors were then bought to reduce the error. Table 5.1 shows the changes they imposed on the uncertainties. The base test for the initial calculations was for a $12 \mathrm{~V}$ system drawing $8 \mathrm{~A}$. It also lead to the decision for resistor size, DAQ precision, and appropriate DAQ reading ranges using the same methodology. The rest of the uncertainties presented in this chapter are for the final system.

\begin{tabular}{|l|c|c|}
\hline & $\begin{array}{c}1 \% \text { Current } \\
\text { Sense } \\
\text { Resistors }\end{array}$ & $\begin{array}{c}0.25 \% \\
\text { Current Sense } \\
\text { Resistors }\end{array}$ \\
\hline$\varepsilon_{\text {power in }}(W)$ & \pm 2.51 & \pm 0.71 \\
\hline$\varepsilon_{\text {power out }}(W)$ & \pm 1.97 & \pm 0.70 \\
\hline$\varepsilon_{\text {efficiency }}(\%)$ & \pm 2.91 & \pm 1.04 \\
\hline
\end{tabular}

Table 5.1: Comparison of sense resistor accuracy error propagation for $96 \mathrm{~W}$

\subsection{UNCERTAINTIES}

Uncertainties or error propagation for the final system shows the bounds that a majority of the runs should fall within. Differences less than these bounds become uncertain whether it was caused by random error or the desired system change. This thesis used the standard Equation 5.1.

$$
\varepsilon q=\sqrt{\left(\frac{\partial q}{\partial a} \varepsilon_{a}\right)^{2}+\left(\frac{\partial q}{\partial b} \varepsilon_{b}\right)^{2}}
$$

Where "q" is the desired equation under consideration, and "a" and "b" are the independent variables in the function "q". " $\varepsilon$ " is the error associated with the subscript. Table 


\begin{tabular}{|l|c|c|c|}
\hline Error Source & $\begin{array}{c}\text { Magnitude } \\
(\mathrm{mV})\end{array}$ & $\begin{array}{c}\text { Equivalent } \\
\text { Current (A) }\end{array}$ & $\begin{array}{c}\text { Can it be } \\
\text { calibrated? }\end{array}$ \\
\hline Step size & 0.305 & 0.061 & No \\
\hline Offset & 1.526 & 0.3052 & Yes \\
\hline Gain error @FS & 4.578 & 0.9156 & $\begin{array}{c}\text { Match } \\
\text { channels only }\end{array}$ \\
\hline Non-linearity & $\begin{array}{c}0.00915 \% \\
\text { FSR }\end{array}$ & 0.183 & No \\
\hline Total @FS & 7.019 & 1.4 & NA \\
\hline
\end{tabular}

Table 5.2: DAQ errors from Chapter 3 Table 3.2

5.2 and the $0.25 \%$ accuracy of the current sense resistors are all of the hardware errors incorporated in the system.

The error analysis was performed for Equation 2.15 copied below and the DAQ readings.

$$
P_{\text {inst }}=\frac{\left(v_{H}-v_{L}\right)_{2}}{R_{\text {sense }}}\left(v_{2}-v_{1}\right)+\frac{\left(v_{H}-v_{L}\right)_{3}}{R_{\text {sense }}}\left(v_{3}-v_{1}\right)
$$

The partial derivatives in Equation 5.1 requires each variable's magnitudes. These magnitudes change as throttle is changed. A throttle sweep was run to get relative magnitudes of current and voltage expected at each throttle. This had to be run for the low current setup and the high current setup. Since the system only records powers, it was assumed that there was a constant input voltage of $9 \mathrm{~V}$ as set by the power supply. To estimate current, power in was divided $9 \mathrm{~V}$ as in Equation 5.2. To estimate output voltage, power out was divided by the current found in Equation 5.2 getting Equation 5.3. This is assuming a DC equivalent for the AC mearsurement. Figure 5.1 is the output current and voltage for low current, Figure 5.1a, and high current, Figure 5.1b. The current does not go all the way to $20 \mathrm{~A}$ because the maximum current safety stops the acquisition system due to spikes reaching 20 A . Likewise for the 50 A system. Note these values are only rough estimates to evaluate the errors, and were not used for calculations of the presented efficiencies.

$$
I_{\text {est }}=\frac{P_{\text {in }}}{9 V}
$$




$$
V_{\text {est }}=\frac{P_{\text {out }}}{I_{\text {est }}}
$$

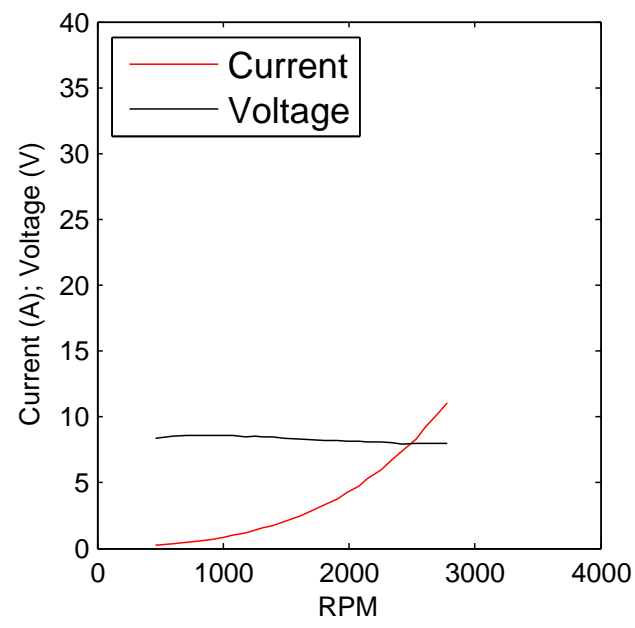

(a) For current less than $20 \mathrm{~A}$

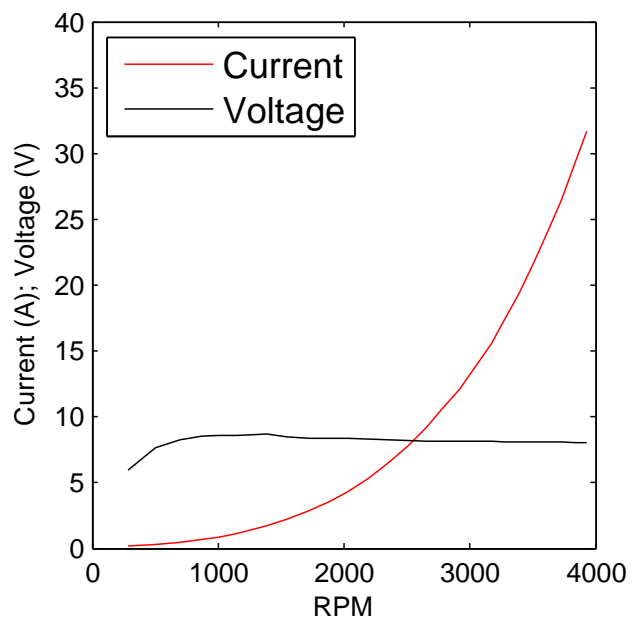

(b) For current greater than $20 \mathrm{~A}$

Figure 5.1: Estimated current and voltage out of the ESC

There are six steps in a motor rotation as described in Subsection 1.1.1. Three of them are reverse current pairs. Current at one of the steps will go through one of the following paths: $I_{1}$ and $I_{2}, I_{2}$ and $I_{3}$, or $I_{1}$ and $I_{3}$. For error analysis, opposite direction or whether it goes through $I_{2}$ or $I_{3}$ does not affect the results. That leaves two different scenarios for error calculations: $I_{1}$ and $I_{2}$ and $I_{2}$ and $I_{3}$. Figure 5.2 is the low and high current system error for the $I_{1}$ and the $I_{2}$ and $I_{2}$ and $I_{3}$ cases respectively, and Figure 5.3 is the low and high current system error for $I_{2}$ and $I_{3}$ respectively. All errors that can be calibrated per run are considered to have zero error. Refer to Subsection 5.1.1 for calibration. Percent error shown in Figure 5.2-5.4 is the percent error on the efficiency.

$I_{2}$ and $I_{3}$ always have higher errors because there is an additional reading that is nonzero. Figure 5.4 demonstrates the importance of using a larger resistor for lower currents. At low currents the error is almost five times higher for the high current resistor. However it quickly approaches the same accuracy above 2,500 rpm. 


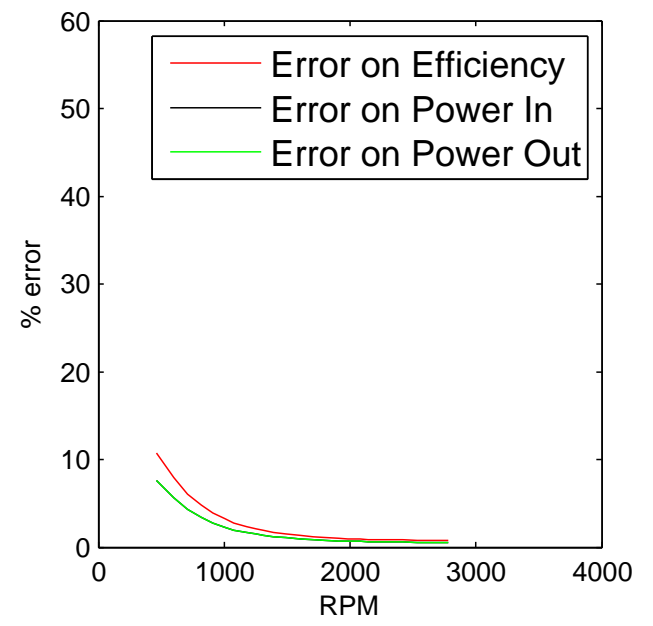

(a) For current less than $20 \mathrm{~A}$ through $I_{1}$ and $I_{2}$

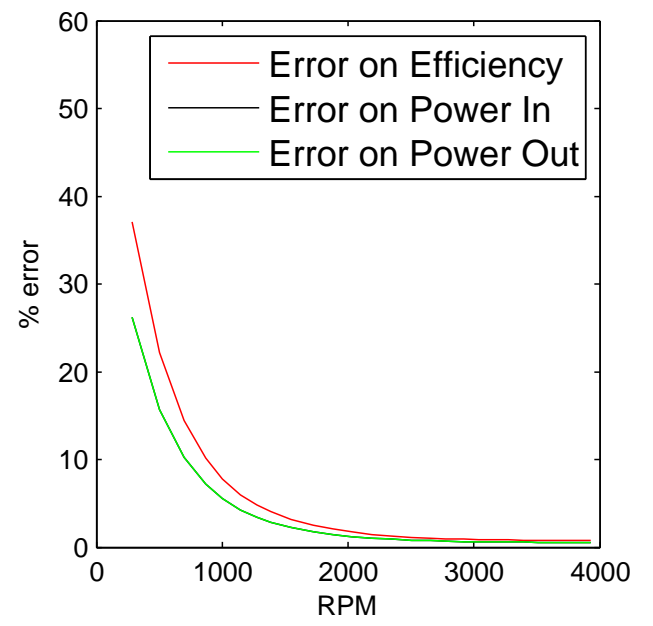

(b) For current greater than $20 \mathrm{~A}$ through $I_{1}$ and $I_{2}$

\section{Figure 5.2: Propagated error through $I_{1}$ and $I_{2}$}

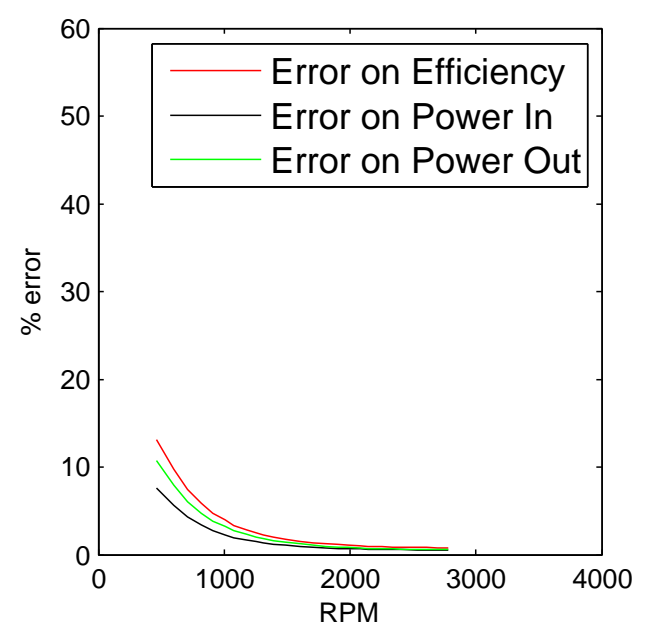

(a) For current less than $20 \mathrm{~A}$ through $I_{2}$ and $I_{3}$

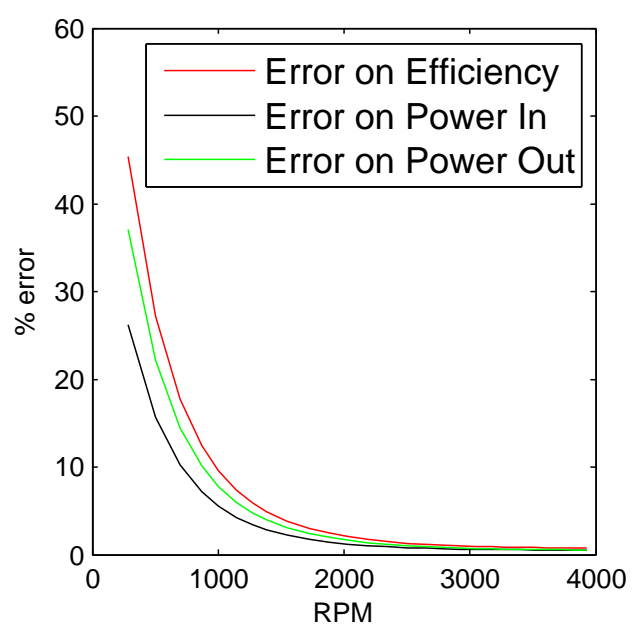

(b) For current greater than $20 \mathrm{~A}$ through $I_{2}$ and $I_{3}$

Figure 5.3: Propagated error through $I_{2}$ and $I_{3}$

\subsubsection{CALIBRATION}

Some errors of the systems can be calibrated to reduce the overall error. As shown in Table 5.2 offsets and gain errors can be calibrated. Differential offset errors can be simply calibrated by shorting the HIGH and LOW connections of each input to each other and ground. The results are the offsets that should be subtracted off of each input. This calibration is done at the start of each test. Before running a test, two calibration connectors are attached 


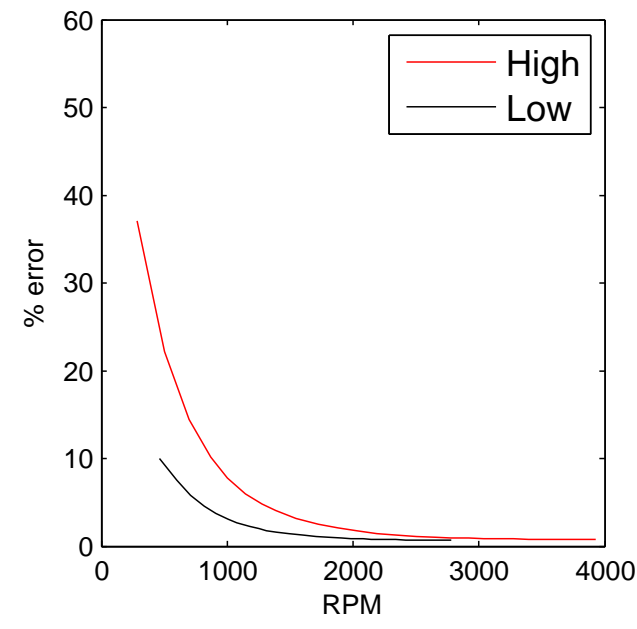

(a) Uncertainties through $I_{1}$ and $I_{2}$

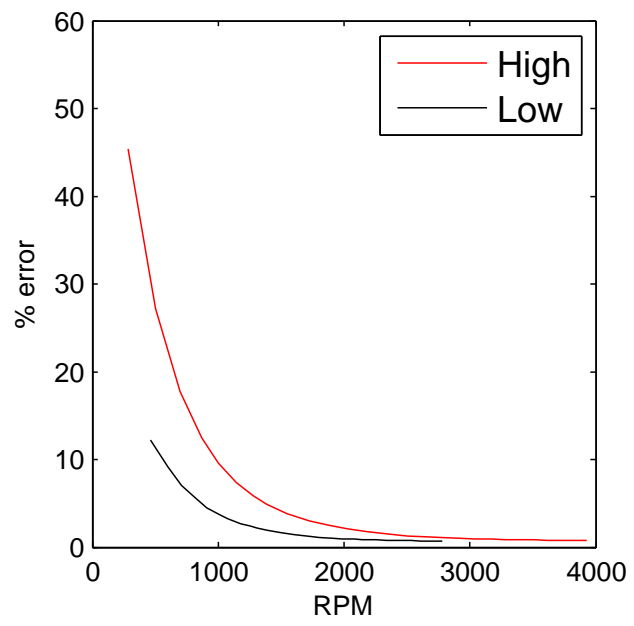

(b) Uncertainties through $I_{2}$ and $I_{3}$

Figure 5.4: Comparison of propagated error between the high and low current systems

shorting all of the inputs as instructed by the software without changing the DAQ inputs. As a safety, one of the calibration connectors disconnects the power supply. The software records these values and applies the offsets to inputs automatically. The connectors are removed and the test is run. For more details on the test procedure refer to Appendix 8.

Gain calibration takes a great deal more work. The ideal gain is one. The voltage into the DAQ equals measured voltage. However to calibrate gain error, an extremely accurate voltage supply is required. The error in the power supply used is greater than the gain error. Therefore the gain calibration can only make the gain the same for all of the inputs. This means that all of the inputs will read the same magnitude if given the same input. For this calibration all of the DAQ input HIGHs must be wired to the same voltage high of the power supply. Likewise the DAQ input LOWs must be wired to the same power supply ground. The gain error changes depending on the reading range, so two voltage ranges are tested. The first one is a stepped reading from 0 to $1 \mathrm{~V}$ for the current sense channels. For the voltage channels, the voltage is stepped from 0 to $10 \mathrm{~V}$. Using a linear approximation the slopes of each channel is found and compared to the first channel. The inverse of the slope is the correction applied to each input. This will force all channels to match the first 
channel. This method does not eliminate the error but reduces error caused by variations in input channels. Gain error was still included in the uncertainties calculation because it could not be eliminated.

The current sense resistors have a relatively constant resistance so their error seems possible to calibrate. However, no available ohmmeter could measure the extremely small resistance better than the factory spectates. Series and parallel tests were considered, but in order to calculate the resistance to higher accuracy, a voltage or current source with an even higher accuracy is required. The only possible information gained from such a test would be relative magnitudes compared to each other. However given the already high accuracy, these tests were not performed.

\subsection{SENSITIVITY}

Sensitivity analysis demonstrates which parameters in the system are sensitive to change. Sensitivity analysis was performed on the hardware characteristics and the software control inputs. Hardware sensitivities were calculated using a derivative. The derivative is the change in the error of the system given a change in the hardware characteristic, Equation 5.4. The larger the derivative, the more sensitive the system is to that error. However magnitude of variable can make this deceiving, therefore sensitivities were done for a percent change in hardware characteristic. This makes comparisons with each sensitivity possible.

$$
\chi_{\text {hardware }}=\frac{\Delta \varepsilon_{\text {efficiency of the system }}}{\% \Delta \varepsilon_{\text {hardware }}}
$$

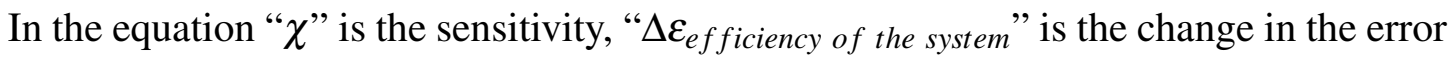
of the percent efficiency of the system, and "\% $\% \varepsilon_{\text {hardware" }}$ is the change in the error of the hardware specification. Also, software control inputs had additional tests run to demonstrate the variances caused by the control parameter. This section will explain why the controls inputs and hardware were selected. 


\subsubsection{HARDWARE SENSITIVITIES}

Offset error, gain error, non-linearity error, resolution and resistor accuracy are the five uncertainties in the system. Also the sensitivity caused by the current sense resistor magnitude must be considered. Offset error was calibrated before each test. Therefore offset error was considered zero and was not included in the sensitivities. The voltage readings used an input range of $\pm 10 \mathrm{~V}$, and the current sense readings used an input range of \pm 1 V. Most of the DAQ errors scale with the range. Gain error scales with range. However if a DAQ with a smaller input voltage range was used, the error for just the current sense readings would be changed. Figure 5.5a shows the effect of changing the overall gain error, and Figure 5.5b demonstrates the effect of changing the current sense gain error only.

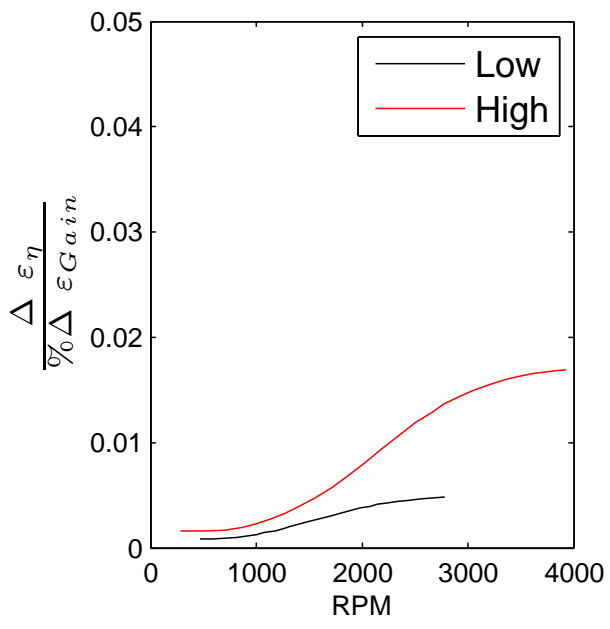

(a) Sensitivity of overall gain error

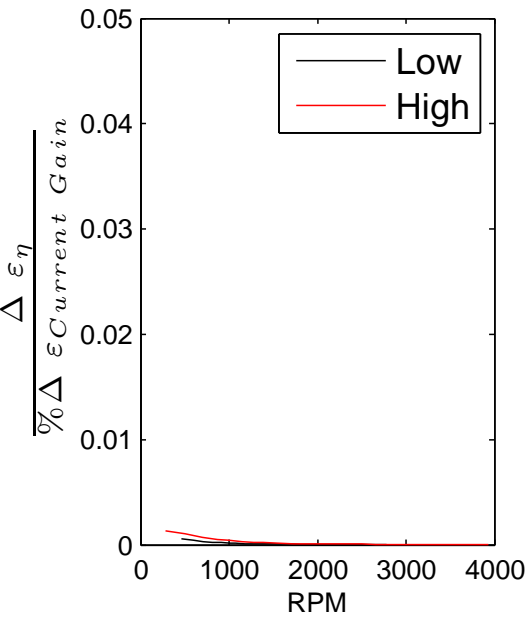

(b) Sensitivity of current sense gain error

\section{Figure 5.5: Gain error sensitivities of the DAQ}

There was little sensitivity at low speed for the overall gain error which increased with speed. Gain error increases as read input voltage increased matching the trend in Figure 5.5a. Changing the current sense gain error has the opposite affect, yet its influence is minimal. Non-linearity error has a greater affect on the small change in voltage from the current sense resistors. This results in greater sensitivity at low speeds as shown in Figure 


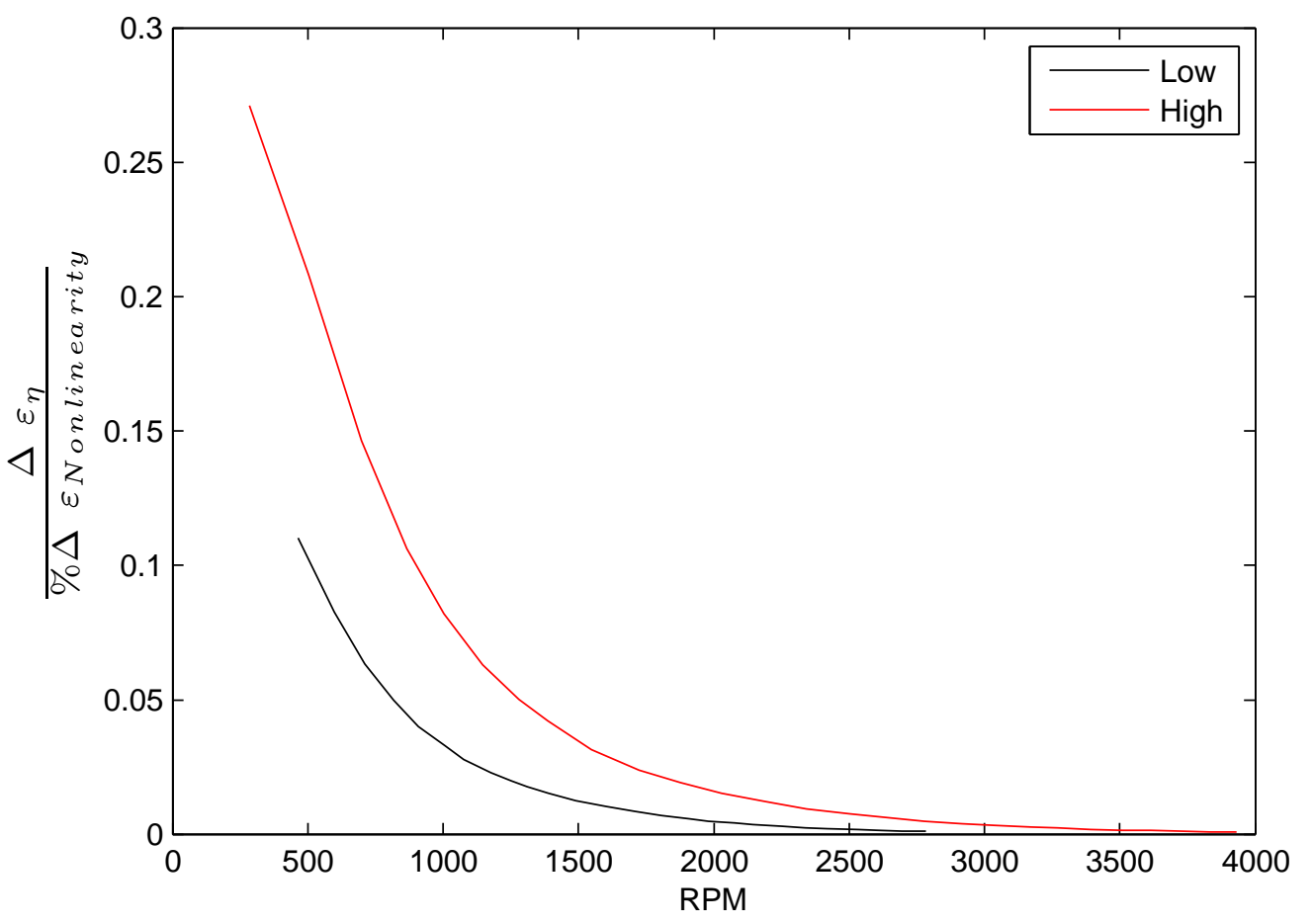

Figure 5.6: Sensitivity of non-linearity error of the DAQ

5.6. Note the change in $y$-axis scale required in order to demonstrate its magnitude. Nonlinearity error, although seemly small, has the largest influence on accuracy of the system.

The DAQ used in this thesis employed an AD converter with a resolution of 16 bits. The current sense voltage at the $1 \mathrm{~V}$ range was small enough that resolution started to become a problem. There are two ways to increase resolution: buy a DAQ with a higher resolution $\mathrm{AD}$ or with a smaller input voltage range. This is because resolution is the full scale range divided by the total number of bits. Figure 5.7 illustrates the sensitivity of resolution.

Lastly the current sense resistor greatly affects the behavior of the system. The resistor can change size and accuracy. Changing the size of the resistor increases the change in voltage across it giving a larger reading, but as it increases resistance it starts drawing too much power out of the system under test. The error analysis does not capture the behavioral changes of the system caused by load of the resistors. The resistors were kept well under the resistance of the motor in order to prevent loading on the system. Regardless, Figure 5.8a 


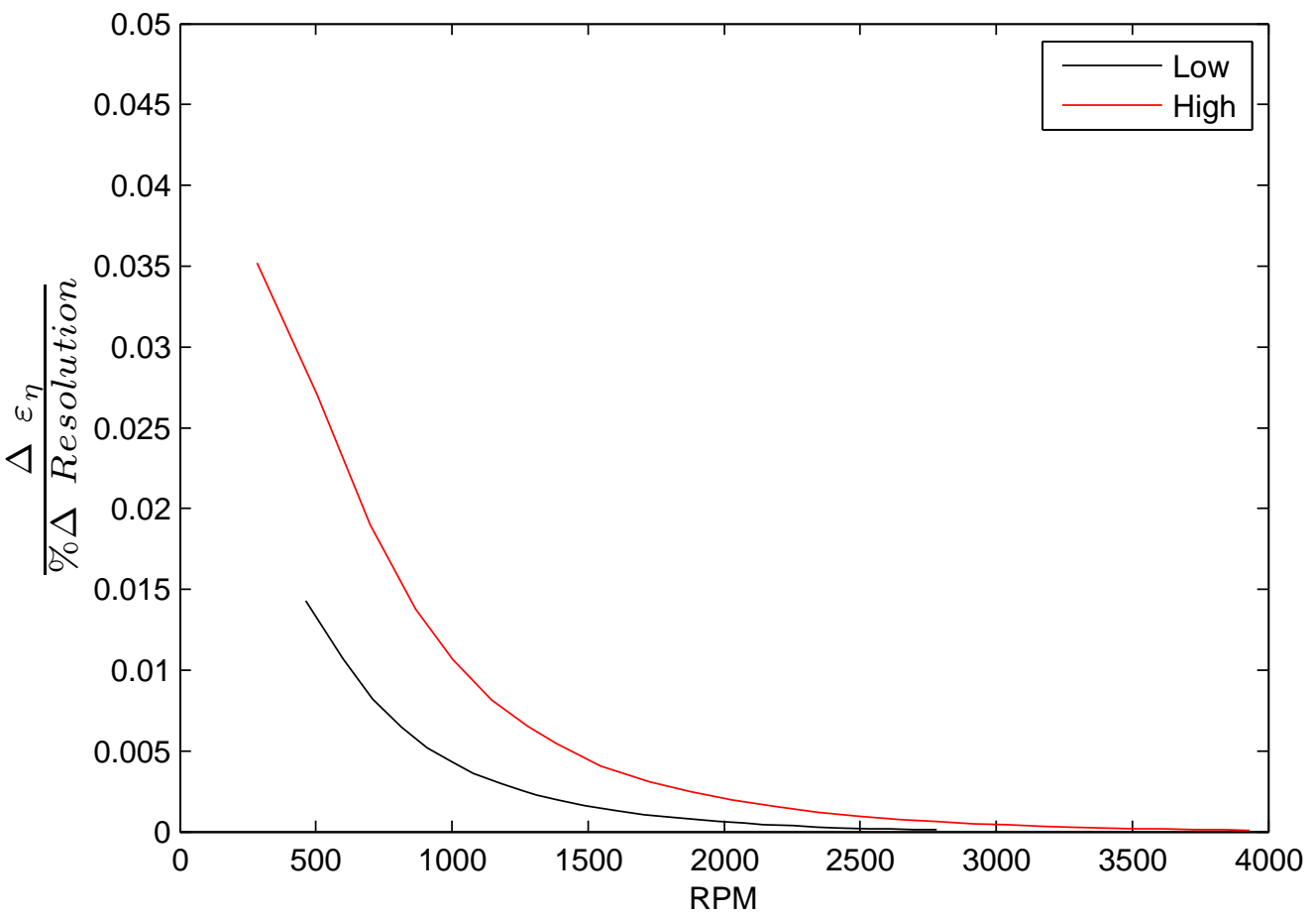

Figure 5.7: Sensitivity of the resolution in the DAQ

is the sensitivity for the size of the current sense resistor and Figure 5.8b is the sensitivity for the error of the current sense resistor. Figure 5.8a has a negative derivative because an increase in resistance decreases overall error. Also note the change in y-axis scale is four times larger than the other sensitivities. The resistor error only has little affect on the overall error because the existing resistors already have an extremely small tolerance of $0.25 \%$.

\subsubsection{CONTROL INPUT SENSITIVITIES}

The error propagation calculations did not account for control inputs. Control inputs are inputs that change acquisition behavior. Hardware specification inputs are not control inputs. The test conductor can change seven control inputs: sample rate, number of samples per set, delay time per division, number of divisions, number of sample sets per division, starting pulse width, and ending pulse width. Starting pulse width and ending pulse width 


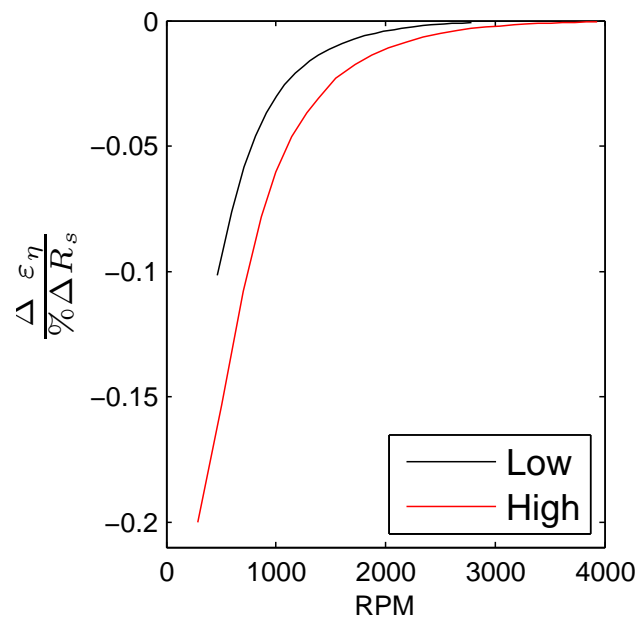

(a) Sensitivity of current sense resistor size

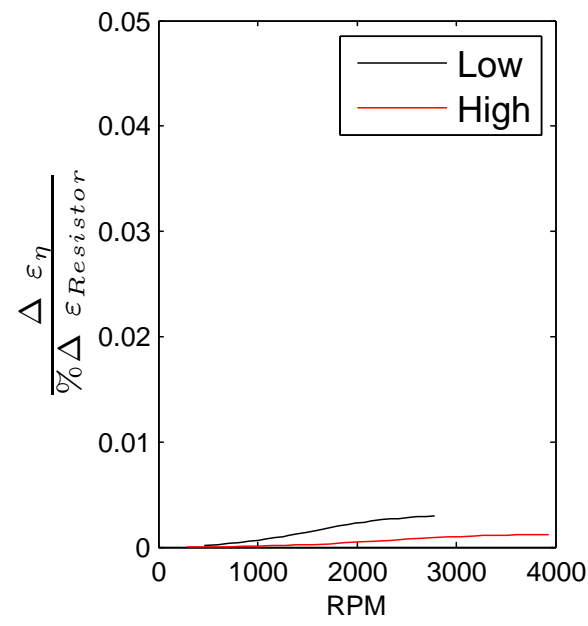

(b) Sensitivity of current sense resistor's error

Figure 5.8: Current sense resistor sensitivities

changed the speed control range and does not affect uncertainties. Number of divisions was the number of equally spaced speed steps that was taken. Number of samples per set is the demanded size of the data packets sent from the DAQ. Number of sets per division is how many times it is requested per division. Delay time per division is the delay between each throttle change to avoid transients. All control input test were done on the high current system with the $18 \times 12$ propeller.

The current system takes power readings at a sampling rate that is not in sync with any frequency or harmonic that the ESC or motor produce. After a great number of samples it averages the powers to get average power into and out of the ESC. Since it averages the power readings, it should be unaffected by sampling rate. Figure 5.9 shows throttle sweeps for different sampling rates.

All of the sampling rates read almost the same efficiency. The variance is well within the uncertainties given in Section 5.1. This thesis used a sampling rate of $250 \mathrm{kHz}$ because it had little affect on testing time with the comfort of knowing it accurately captured the signal.

Number of samples per set and number of sets per division have the same effect on the results. Number of samples per set is limited by the DAQ hardware. Their product is the 


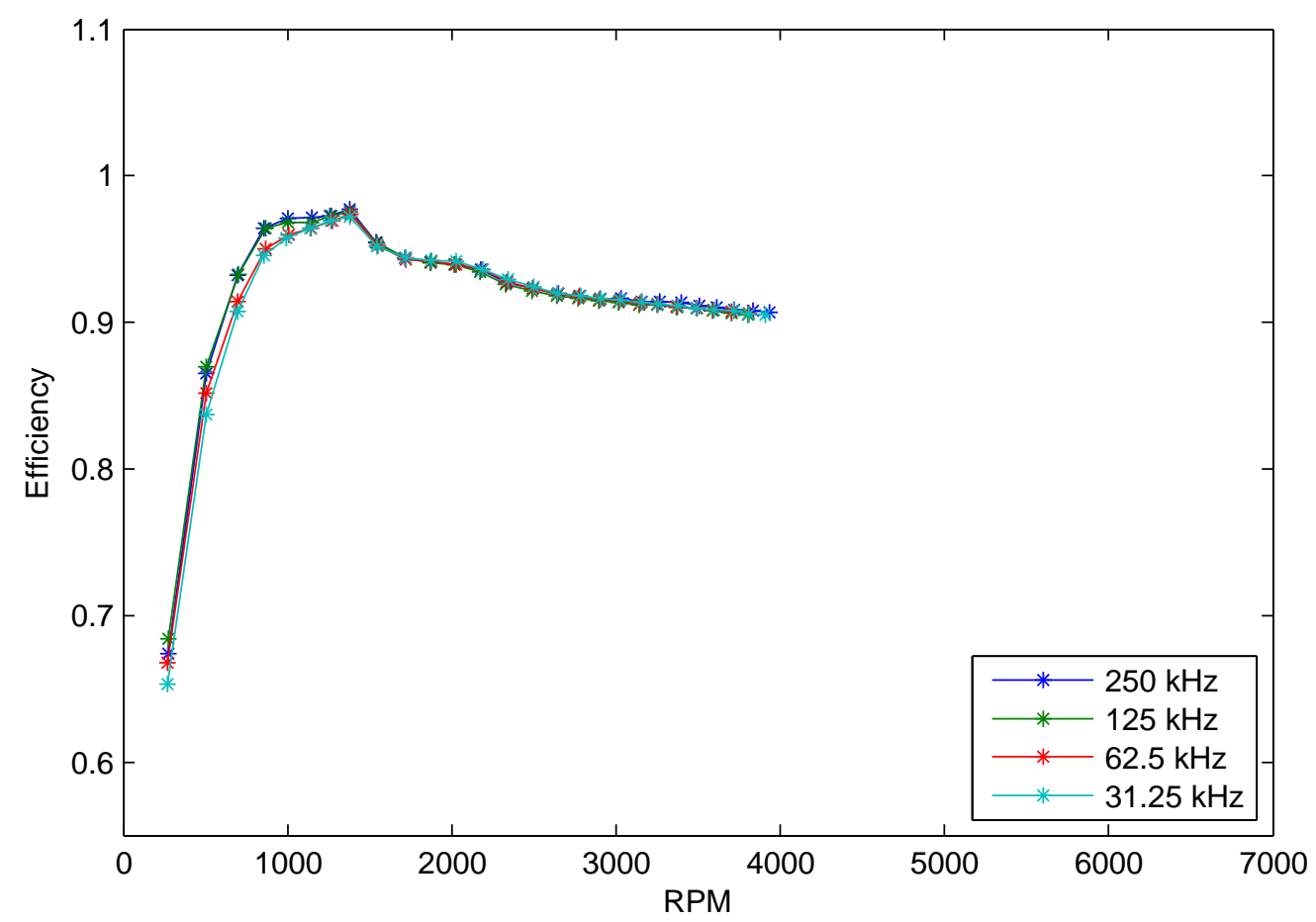

Figure 5.9: Variance of data recorded while DAQ sampling rate is varied holding the total number of samples constant. 


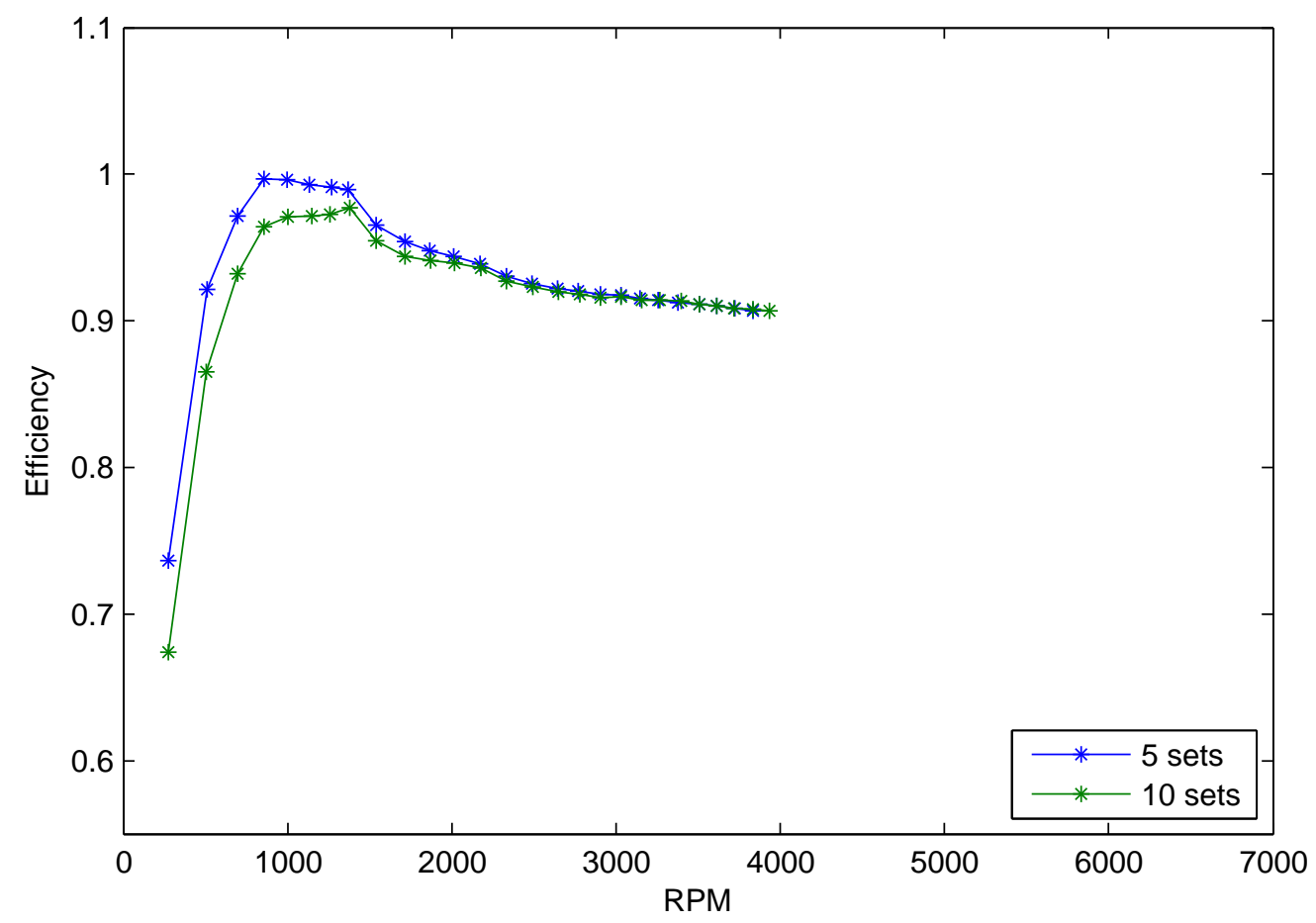

Figure 5.10: Variance of data recorded while varying number of sets per division

number of samples averaged per speed division. Figure 5.10 shows a test with ten and a test with five sets per division. There is little difference between the tests. Ten sets per division was chosen to have a large data set for averaging, and it also does not drastically affect testing time.

An adequate number of divisions is important to catch variations and discontinuities in the behavior of the system. Figure 5.11 shows a test of 35 divisions and a test of 100 divisions. The behavior of both tests was the same. The 100 division test did not reveal any discontinuities or behaviors that the 35 division test did not capture. The difference between the two is within the given errors. In order to save time testing, 35 divisions was selected for all other tests.

To avoid transients a delay time per division was implemented. Figure 5.12 shows a data set taken without a delay. Each division is $1.2 \mathrm{~s}$ of data. A $3 \mathrm{~s}$ delay was chosen to 


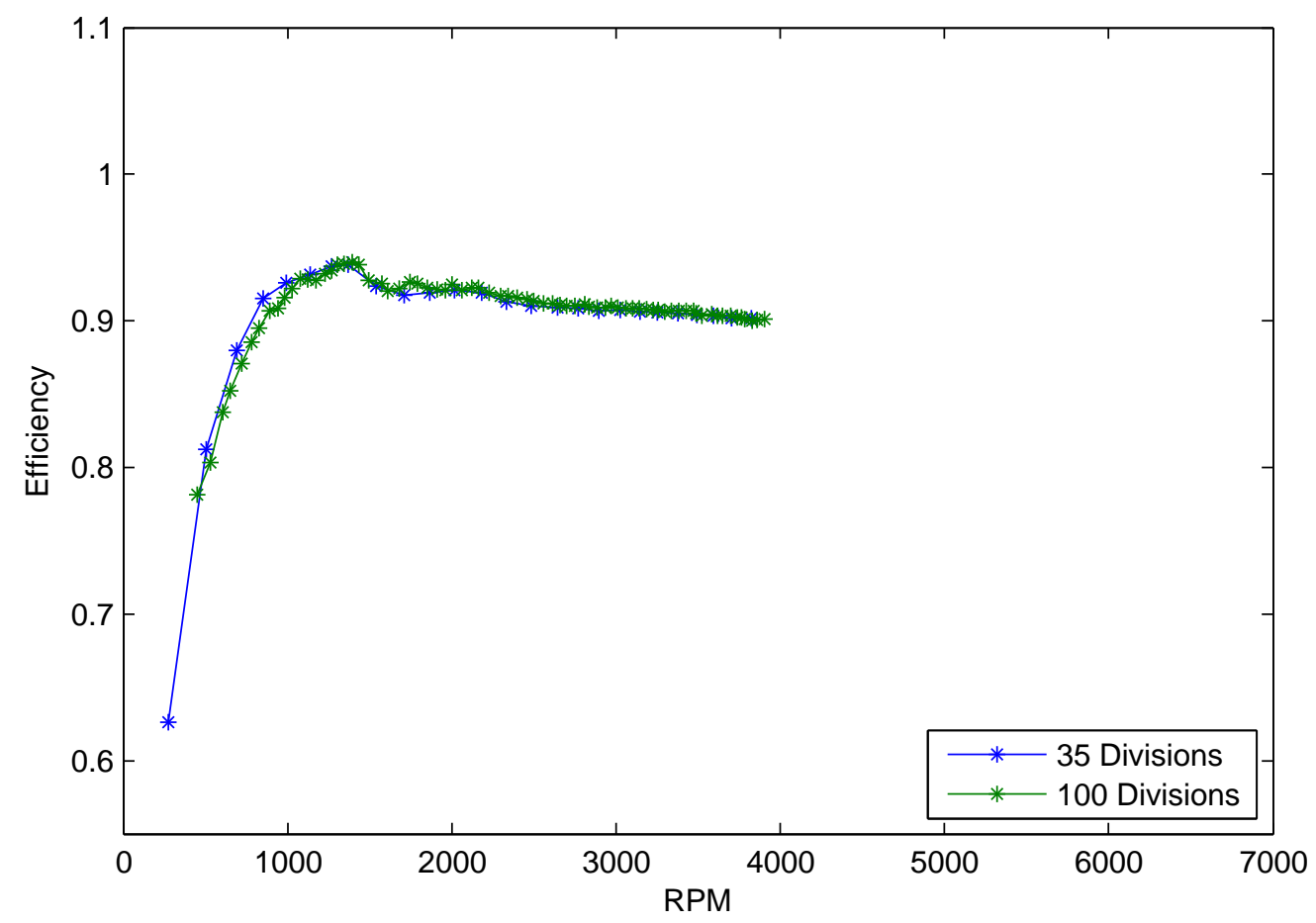

Figure 5.11: Variance of data recorded while varying number of divisions

avoid the shown transients. The data highlighted by the green bar is after a three second delay.

\subsubsection{REPEATABILITY}

Several tests were run to investigate the repeatability of the test system. The setup for all of the tests was the high current system with an 18x12 propeller, and nothing was changed in between tests. The first test was a standard throttle sweep from minimum to maximum throttle. The next test was an exact repeat of the test a day later. The third and fourth test are a throttle sweep from minimum to maximum and back to minimum throttle. The third and fourth tests were run back-to-back with enough time in between to allow for the ESC to return back to $78^{\circ}$. All four tests are shown in Figure 5.13.

The magenta shaded area is the error bounds for the min to max July 14th run. It does not capture all runs, but if the other runs had similar error bounds they would all overlap. 


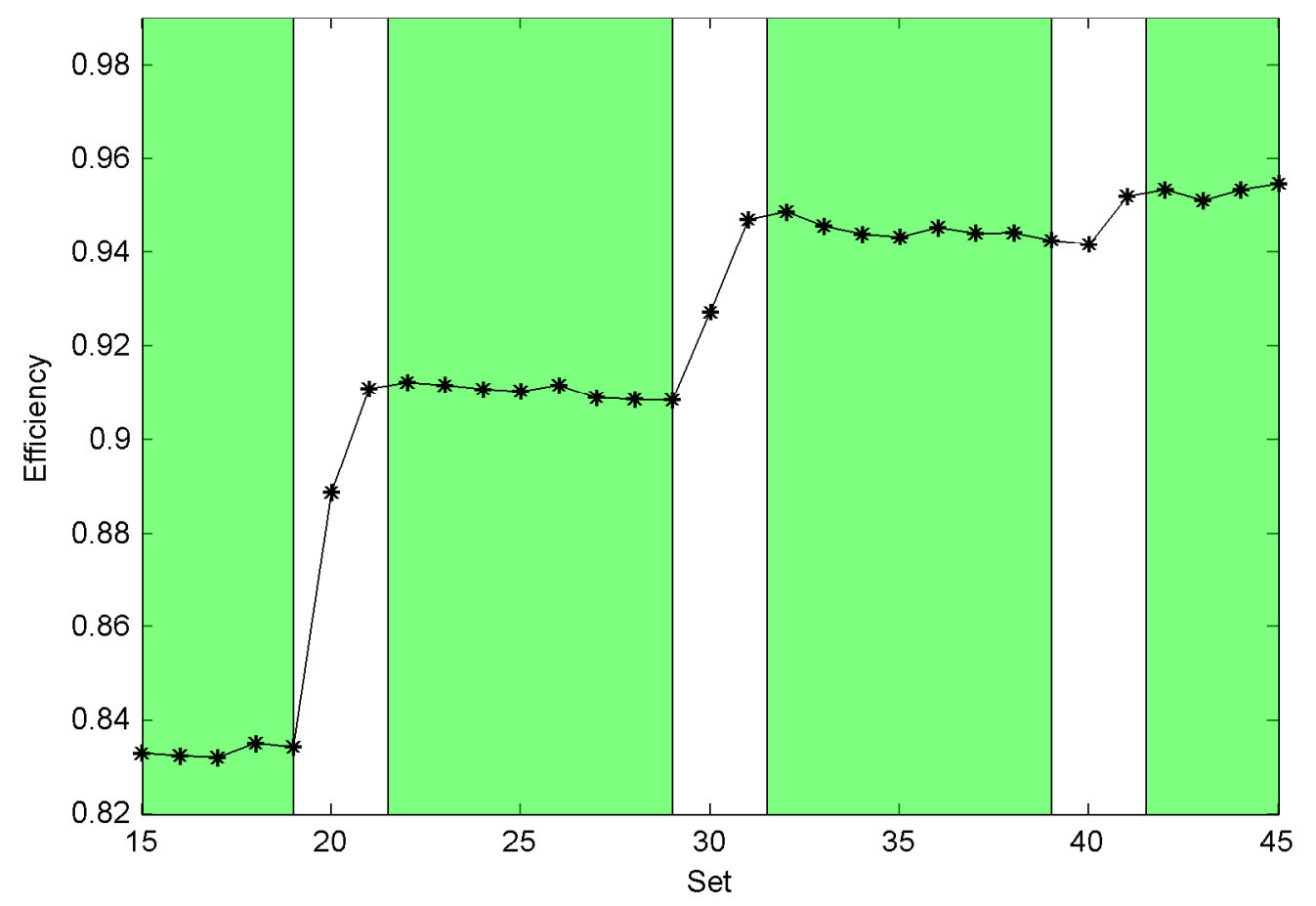

Figure 5.12: A test with no delay per division showing transients. Green is data taken after $3 \mathrm{~s}$. 


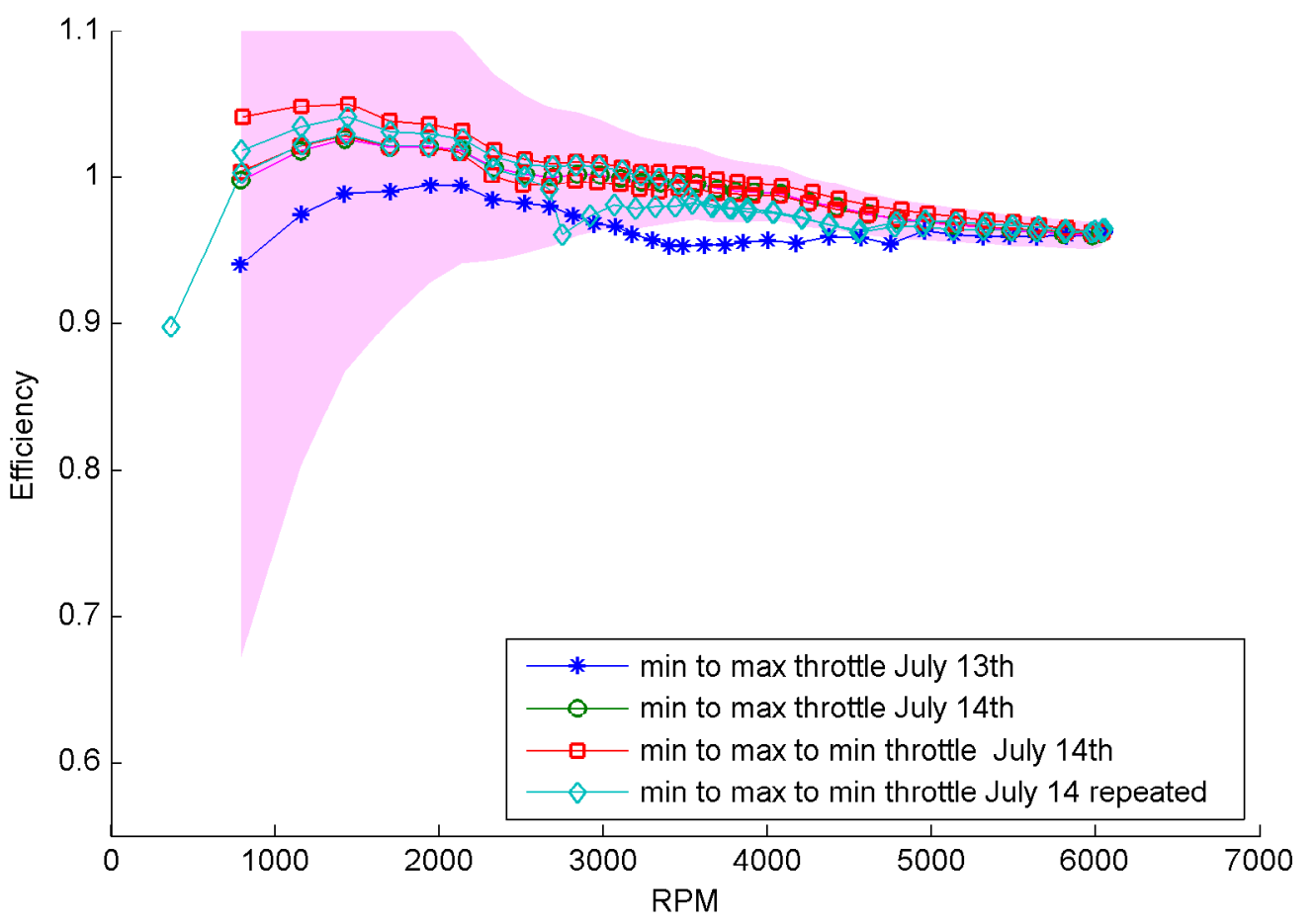

Figure 5.13: Variance of data recorded for repeated efficiency tests. Magenta shaded area is the error bounds for the min to max July 14th run 
Tests done on the same day tended to display reduced spread all within the uncertainties given in Section 5.1. Day to day differences are also within the estimated uncertainties, but the differences are larger. A majority of the tests being compared to were run on the same day. The low current tests were run one day and the high current tests were run on the next day. However it is important to note the range of differences in order to compare the results. 


\section{RESULTS}

All variables of the models presented in Section 1.2 are tested and presented in this chapter. This includes throttle, bus voltage, switching frequency, internal resistance, and quiescent power. Internal resistance can be varied by changing ESC. However the resistance of each ESC cannot be measured with the described equipment. All tests unless otherwise stated are using the Hobbywing Platinum $50 \mathrm{~A}$ ESC at $8 \mathrm{kHz}$ switching frequency at $9 \mathrm{~V}$ with the $18 \times 12$ propeller. "Low" stated in the legend stands for the low current measurement system, and "High" stands for the high current measurement system. Some tests in this thesis gave measurements of efficiency over 100\%. This is arises from the large amount of error at low throttle as discussed in chapter 5. However it is believed that relative behavior is still accurately represented.

\subsection{LOAD MAP}

Propellers were used to simulate loads similar to those seen on a small UAV. Different propellers were used to gather unique load lines. These load lines can be see on Figure 6.1a with their corresponding efficiencies in Figure 6.1b. All of the load lines were gathered together to create a load map that covers most of the operational range of this ESC seen in Figure 6.1c. The low current system was used for all load tests to give more accurate comparisons.

The load lines follow an $n^{3}$ relationship with power matching the theoretical Equation 2.20. Measured values for efficiency sometime exceed $100 \%$ due to the uncertainties. Efficiency has a negative relationship with applied load. No load is the highest efficiency because it has the lowest current draw for the given speed. As seen in Figure 6.1c efficiency is more adversely affected by torque than speed. Torque is proportional to current 
as described in Section 1.1. This leads to the conclusion that a majority of power loss out of the ESC is from conduction loss.

\subsection{BUS VOLTAGE}

Bus voltage is a system characteristic often overlooked due to its seemingly constant nature. Battery voltage, however, is almost never constant but instead decreases as it loses charge. Also batteries can be rearranged to get different voltages and capacities. Figure 6.2 displays the ESC's performance at different voltages. Lower voltages require higher currents, and, as seen by the load map in Section 6.1, a majority of the ESC's losses are contributed by conduction losses. This relationship is the inverse of the total efficiency data presented by the Army Research Laboratory. Therefore the increase in overall efficiency must come from huge gains in efficiency from the motor.

\subsection{SWITCHING FREQUENCY}

Switching frequency is a controllable parameter on a lot of high end ESC. Nonetheless most manufacturers give almost no guidance as to what is recommended and why. The Hobbywing Platinum 50 A ESC has four options for switching frequency: 8, 16, 24, and $32 \mathrm{kHz}$. These four switching frequencies were tested for the $18 \times 12$ as well as $13 \times 6.5$ propeller to see if the optimum switching frequency was load dependent. Figure 6.3a and $6.3 \mathrm{~b}$ are the results for the $18 \times 12$ and the $13 \times 6.5$ propeller respectively.

The optimum switching frequency varies with the load. For the $18 \times 12$ the optimum frequency was $8 \mathrm{kHz}$, but higher frequencies were optimum for the $13 \times 6.5$. These switching frequencies are only optimum for ESC efficiencies. It is likely to be different for the overall efficiency. Some people claim higher switching frequency is supposed to reduce the torque rippling seen at low throttle. This improvement would only be seen in the overall efficiency. 


\subsection{ESC SIZE AND BRAND}

Four different ESCs were tested on the $18 \times 12$ and $13 \times 6.5$ propellers. The goal of testing different current limited ESCs was to see if there was a benefit of buying the more expensive high current ESC for low current applications and to see the effect of internal resistance on efficiency. The $13 \times 6.5$ propeller was included to see the Hobbywing $30 \mathrm{~A}$ as it could not turn the $18 \times 12$ propeller. Unfortunately it is not possible to identify the MOSFETs or the configuration of the MOSFETs without destroying the ESC. Therefore there is no way to tell if the current limit is increased due to better MOSFETs or more MOSFETs in parallel. Also without the identification of the MOSFETs or a manufacturer's specification, it is not possible to measure the resistance. The Hobbywing 30 A and 40 A were of the same family called FLYFUN. Figure 6.4a and 6.4b illustrates the performance of the four ESCs. The Hobbywing ESCs have relatively similar efficiencies. The Hitec in both cases had the lowest efficiencies. The Hobbywing $40 \mathrm{~A}$ at lower speeds had higher efficiencies than the $30 \mathrm{~A}$ of the same family. This might be due to a lower resistance of the 40 A ESC but their resistances are unknown. The Hobbywing 50 A ESC might have had different family and configuration of MOSFETs than the FLYFUN family resulting no identifiable pattern with the other two Hobbywing ESCs.

\subsection{QUIESCENT POWER}

Quiescent power was a simple test of measuring the on-state power into the ESC without delivering power to the motor. It was run for 10 sample sets and than averaged like all other tests. The extremely low current of the on-state quiescent power causes a great deal of uncertainty. Regardless, the system measured a quiescent power loss of $0.584 \pm 0.165$ W. 


\subsection{COMPARISONS}

Section 1.2 and 1.3 presented several models and data sets that are available. The models and data sets were not completely recreated, but the captured data for Hobbywing $50 \mathrm{~A}$ ESC using the $18 \times 12$ propeller was reshaped to be able to compare trends. A lot of models try simulating power loss of the system rather than efficiency. This is because power loss can be easily defined into components. Figure 6.5 demonstrates the power loss over speed for Hobbywing 50 A ESC using the $18 \times 12$ propeller. These comparisons are only using the Hobbywing 50 A ESC using the $18 \times 12$ propeller. Further comparison with a variety of loads would be required before making final conclusions. Also the error caused by the acquisition system make comparison and conclusions difficult.

The Texas Instruments, Infineon, and International Rectifier did not supply switching schedule so a comparison graph was unable to be recreated. Also the characteristics required by those models was not able to be extracted from the ESCs. The Tritium model supplied a set of constants representing their system. Their model was reconstructed and compared with the experimental results. The comparison is shown in Figure 6.6.

The experimental power loss was almost linear to DC current unlike the very curved power loss predicted by Tritium. The linear switching component of the Tritium model would have to be twenty times larger and resistance would have to be half as much in order to match the experimental data. This model would suggest that the majority of the losses for Hobbywing Platinum 50 A ESC come from switching losses. This would concur with the switching frequency tests in Section 6.3 that resulted in the lowest switching frequency having the highest efficiency.

Section 1.3 presented VFD efficiency which are for induction motors. Figure 6.7 illustrates the differences between VFDs and ESCs. ESCs achieve greater efficiency at part power and drop slightly as power increases. VFD asymptotically approach their maxi- 
mum efficiency at $100 \%$ power. Therefore VFD models might not be applicable to ESC performance modeling.

The Army Research Laboratory presented the most reliable data for ESCs. Figure 6.8 is their data compared to the Hobbywing Platinum 50 A ESC. Their data was for small motors about a third the torque of the motor used in this thesis. This could be the cause for their significantly lower efficiencies. Regardless, they also experience the negatively sloped linear behavior seen in the Hobbywing ESC, but they do not capture any rise or fall in efficiency at very low part torque. 


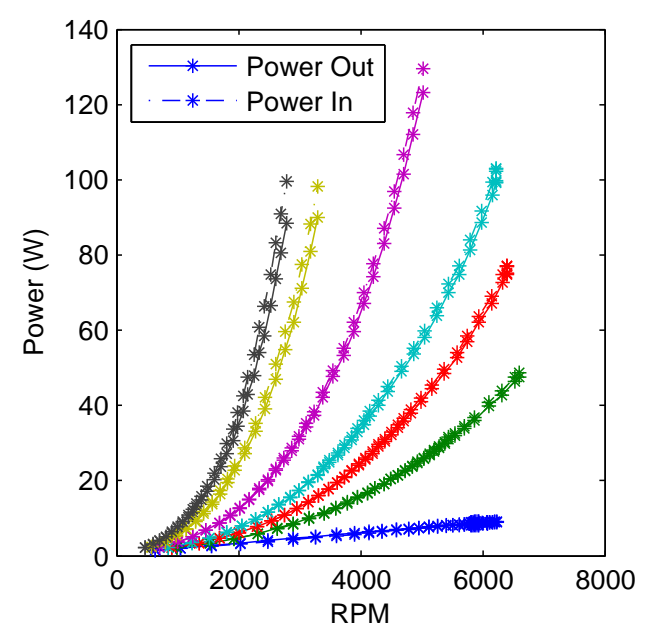

(a) Load lines for the Hobbywing Platinum $50 \mathrm{~A}$

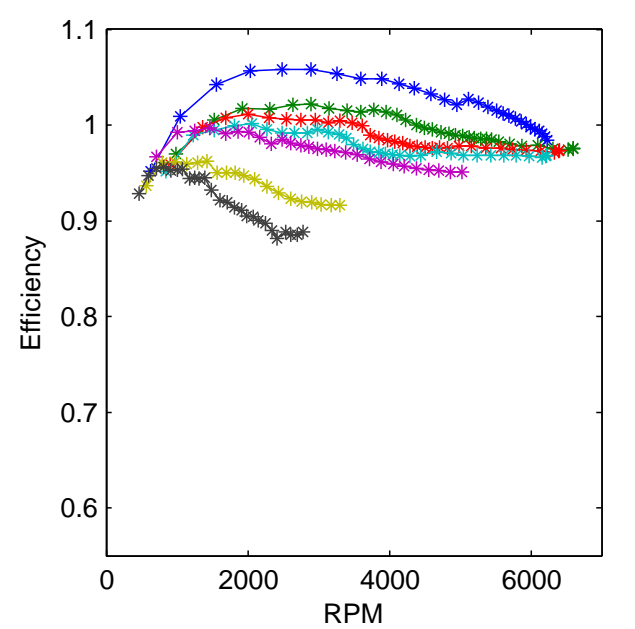

(b) Efficiency for the Hobbywing Platinum $50 \mathrm{~A}$
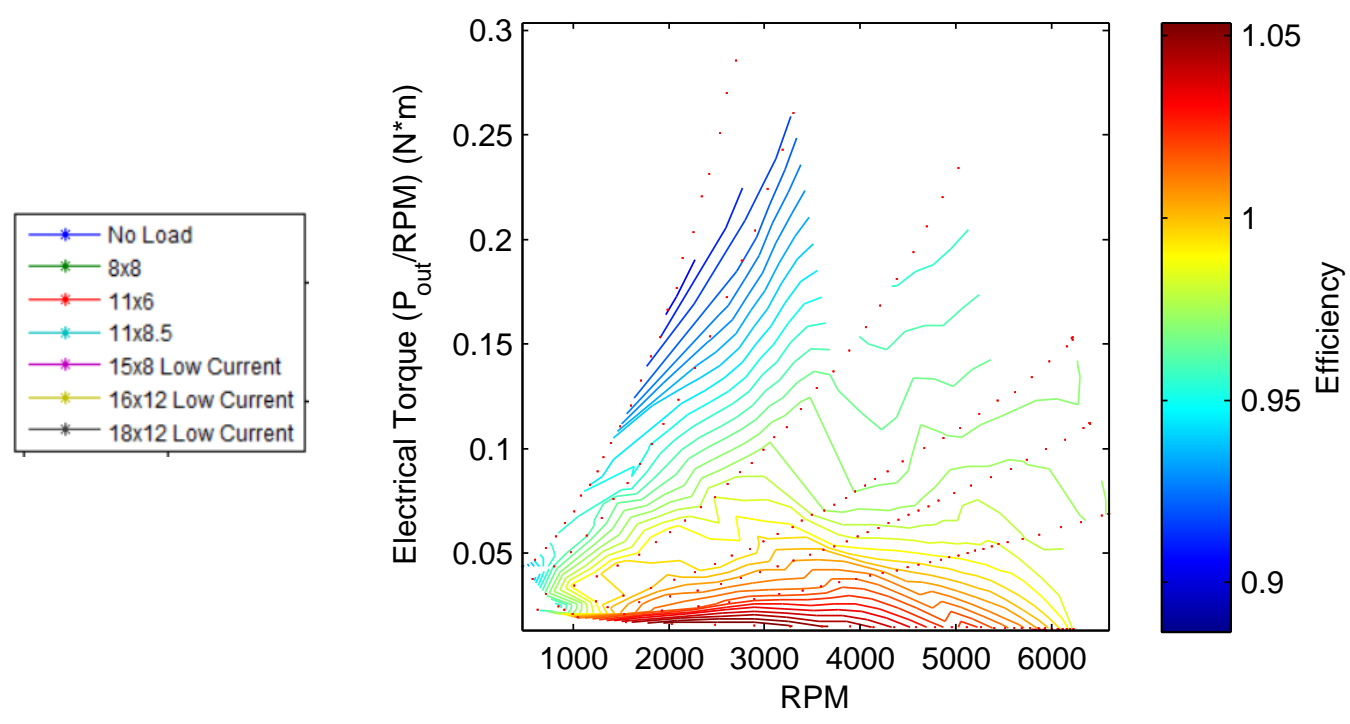

(c) Load map for the Hobbywing Platinum $50 \mathrm{~A}$

Figure 6.1: Efficiency load map and load lines for the Hobbywing Platinum 50 A 


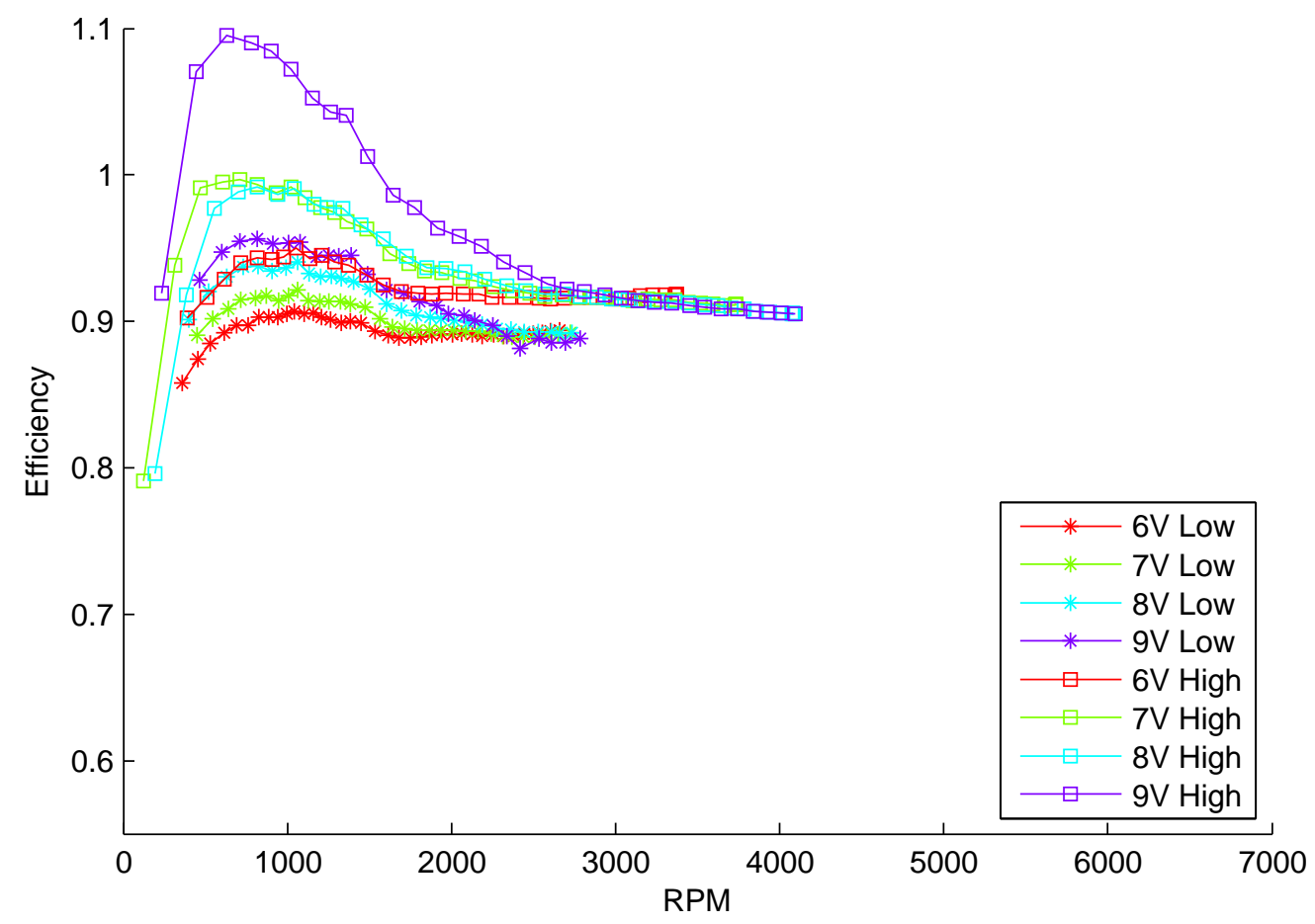

Figure 6.2: The effects on the ESC performance from changing bus voltage

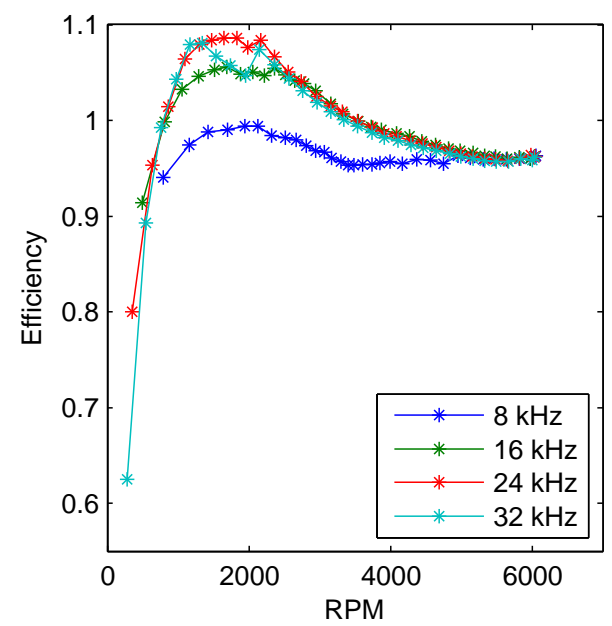

(a) Switching frequencies for the $13 \times 6.5$ propeller

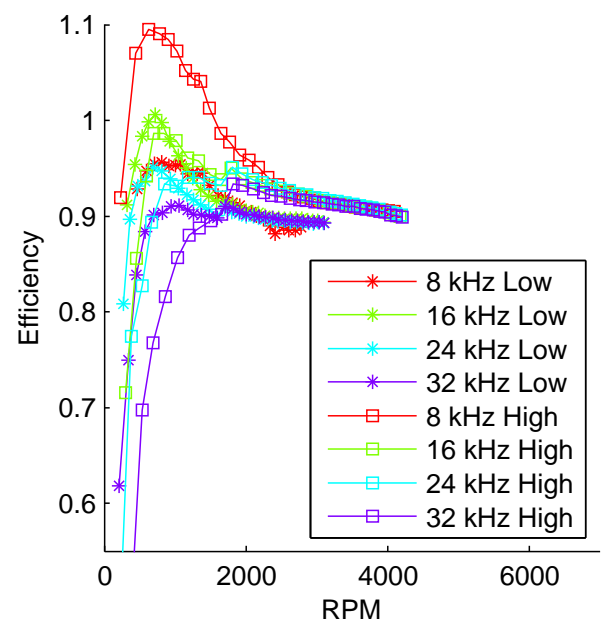

(b) Switching frequencies for the $18 \times 12$ propeller

Figure 6.3: Comparison of the effects on the ESC performance from changing switching frequency for the $13 \times 6.5$ and the $18 \times 12$ propellers 


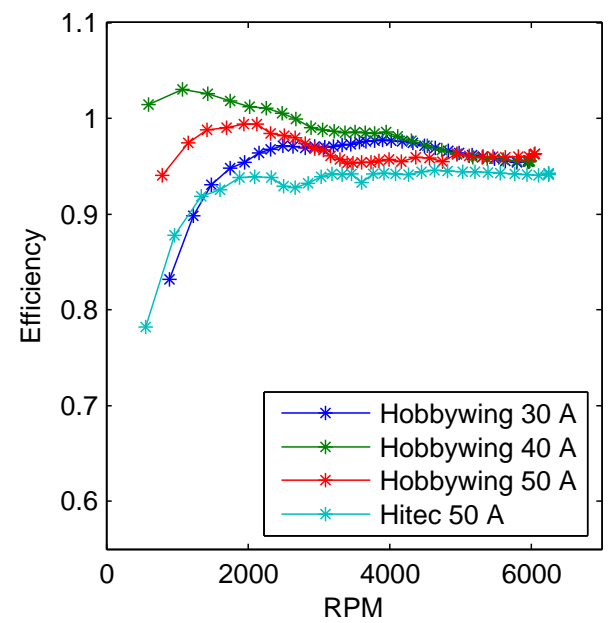

(a) Different ESCs for the $13 \times 6.5$ propeller

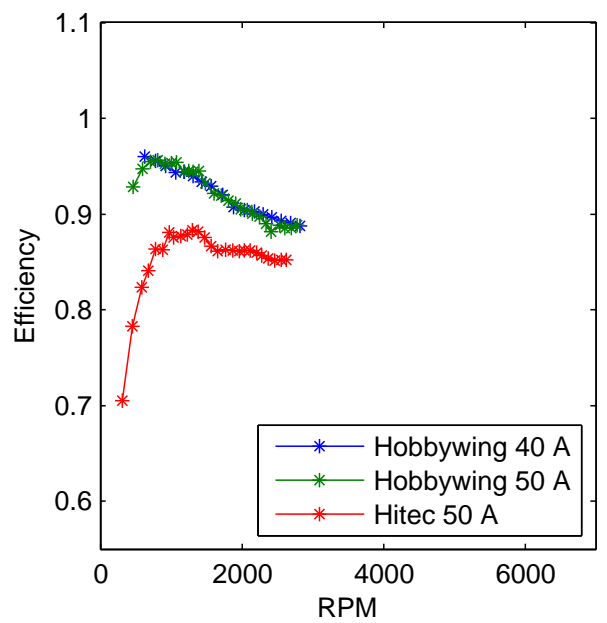

(b) Different ESCs for the $18 \times 12$ propeller

Figure 6.4: Comparison of different ESCs for the 13x6.5 and the 18x12 propellers

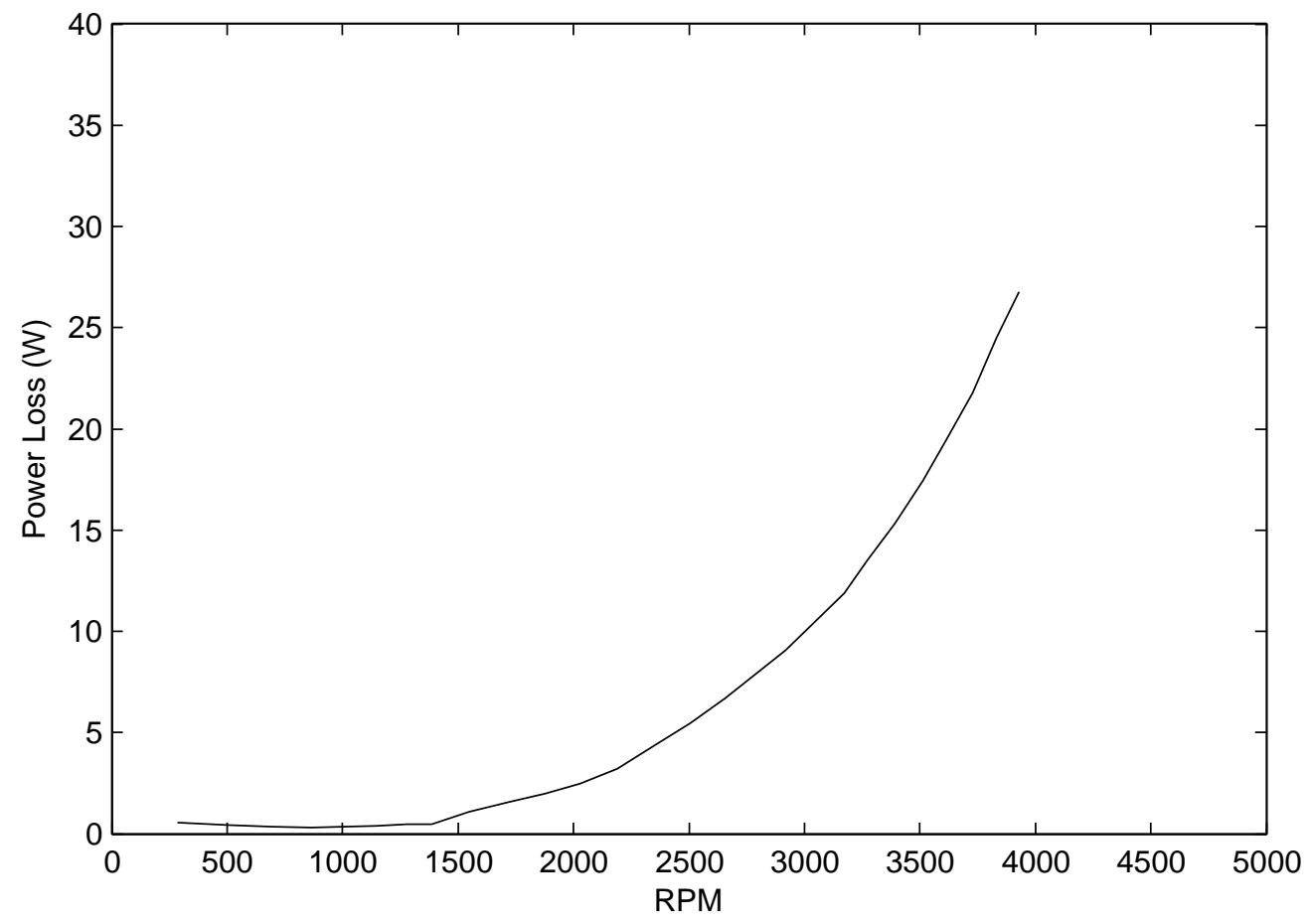

Figure 6.5: Power loss of the ESC versus speed for Hobbywing 50 A ESC using the $18 \times 12$ propeller 


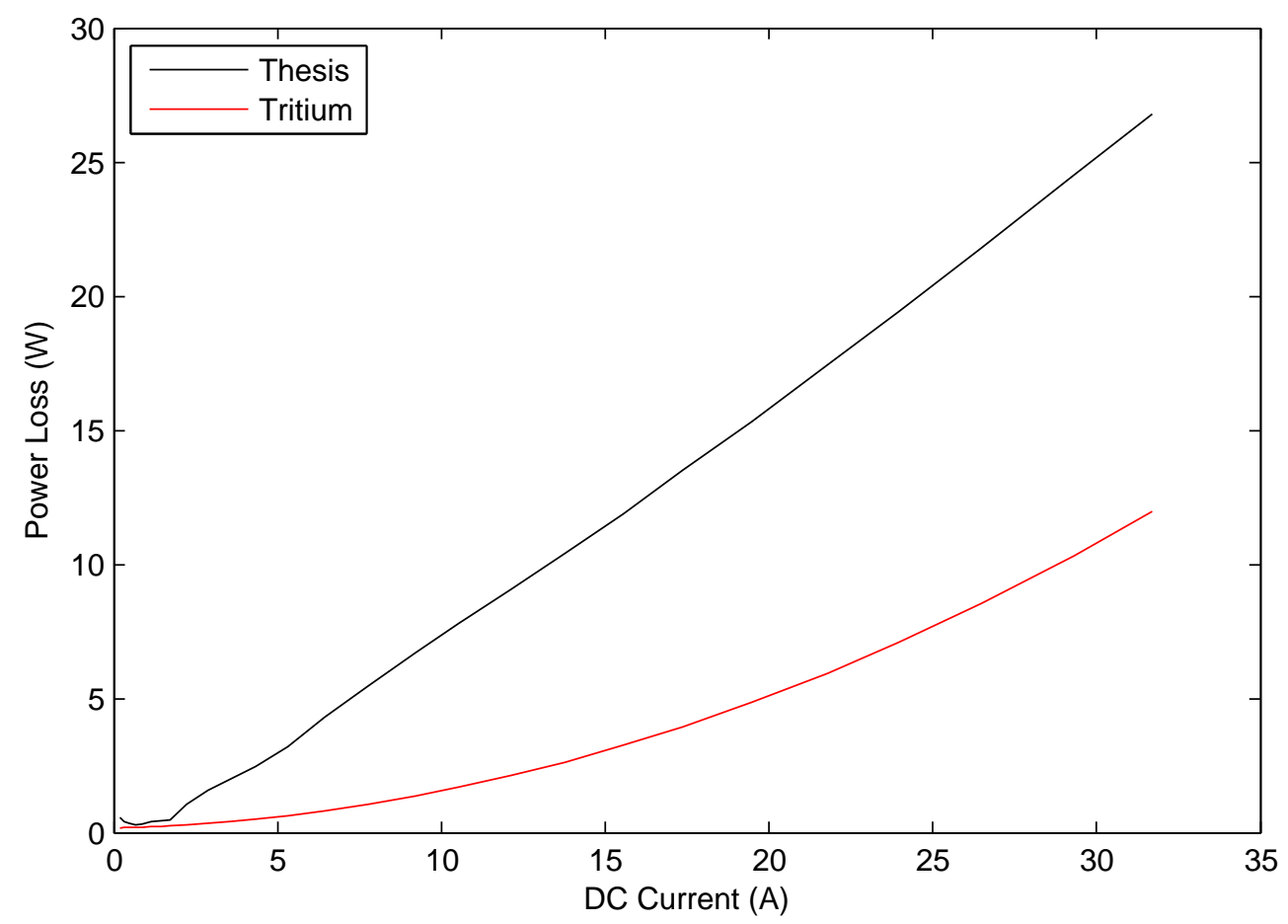

Figure 6.6: Comparison of the experimental ESC performance data of the Hobbywing 50 A ESC using the 18x12 propeller with the Tritium model 


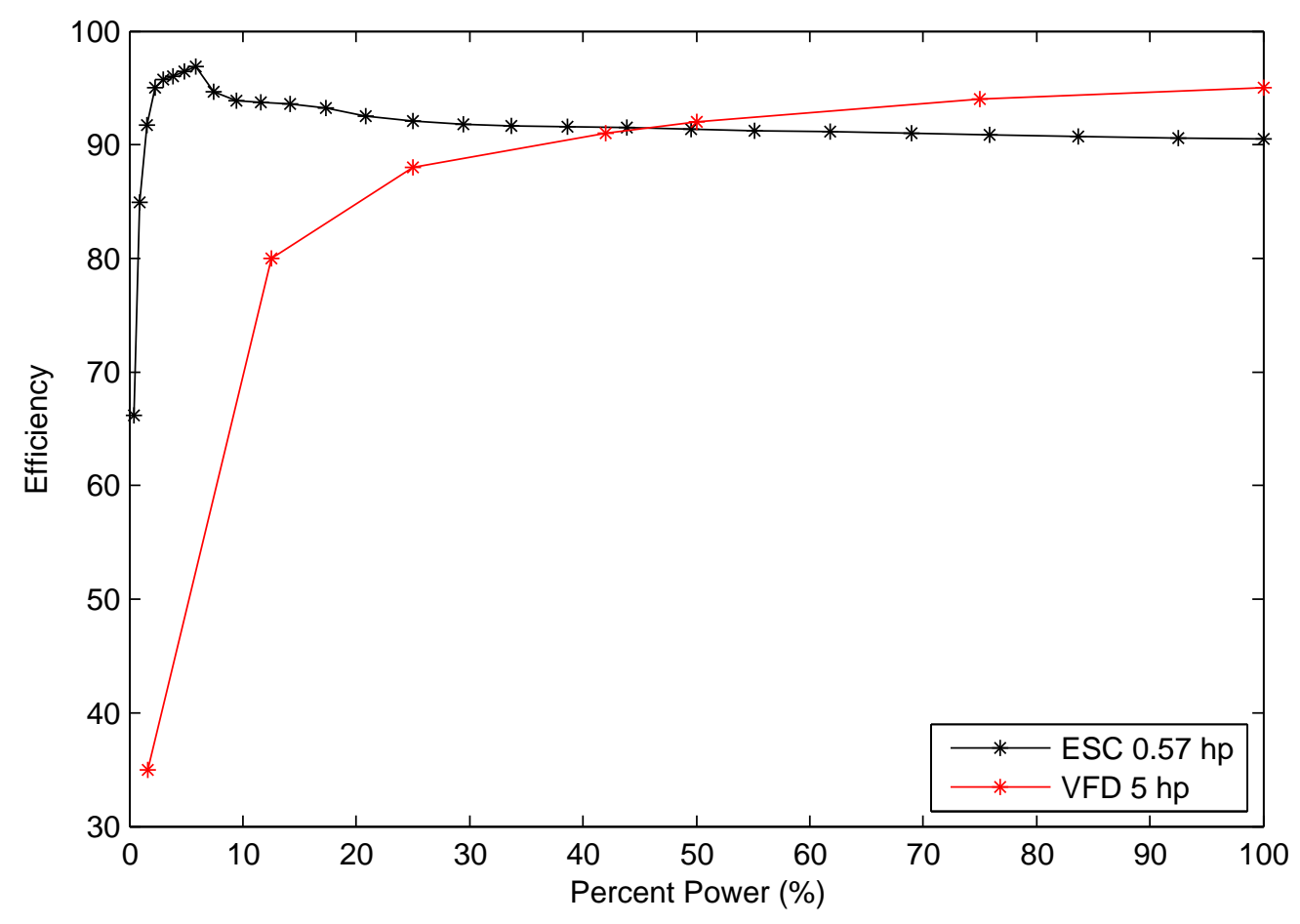

Figure 6.7: Comparison of ESC performance with the VFD data

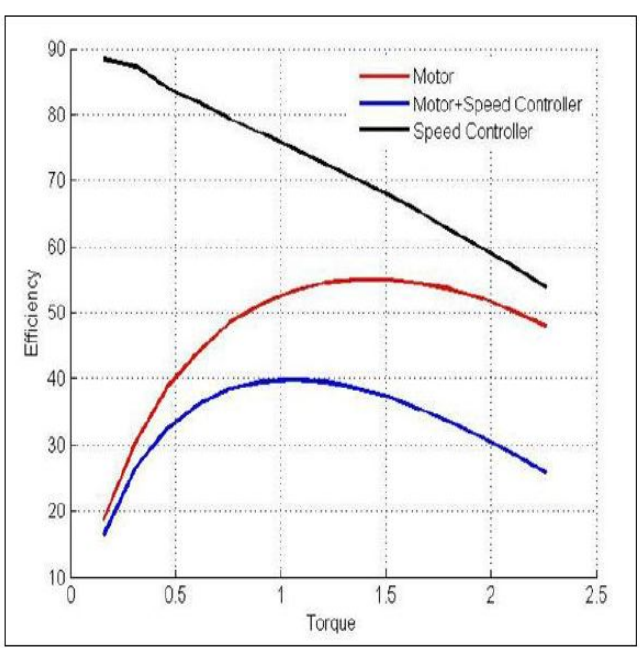

(a) Copy of Figure 1.6 of the Army Research Laboratory data

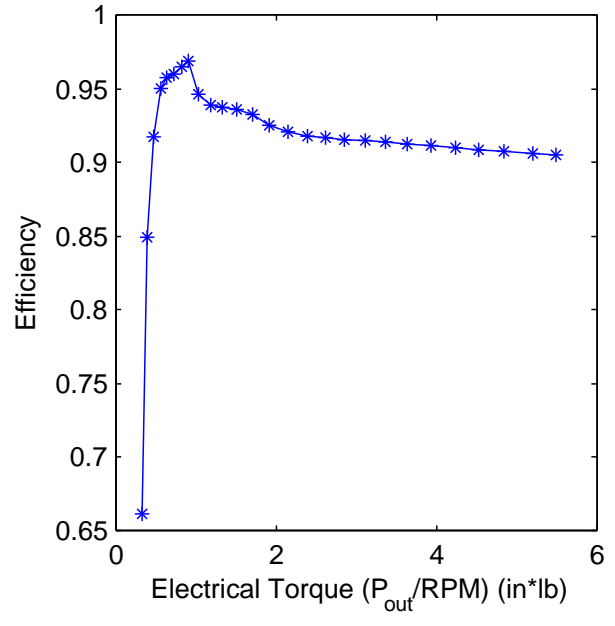

(b) Hobbywing performance for the $18 \times 12$ propeller

Figure 6.8: Comparison of ESC performance with the Army Research Laboratory 


\section{TEST SYSTEM IMPROVEMENTS}

Chapter 3 demonstrated the difficulties involved with building an accurate three phase wattmeter, and Section 5.1 described the uncertainties in the final system. This chapter will explain the ways to further improve the accuracy and range of the final system.

There are five errors that can be improved: step size, offset error, gain error, nonlinearity error, and resistor accuracy. The first four are all DAQ error. Offset error can be calibrated as explained in Subsection 5.1.1. Gain error and nonlinearity error could be calibrated if there was a highly calibrated voltage source. Of course all four DAQ errors could be reduced by buying a more accurate DAQ. Also there are some DAQs on the market that have smaller input ranges which would reduce the step size error on the current sense readings. The current sense resistors are the most accurate available for their size. Higher resistance current sense resistors would reduce measurement errors, but they would start dissipating too much power through conduction affecting the system behavior. The resistors used were already $0.005 \Omega$ compared to the motor's resistance of $0.04 \Omega$. Therefore the main way to improve the accuracy of the test system would be to buy a more accurate DAQ.

The final system was limited to $10 \mathrm{~V}$. Most of the systems tested have a recommended input voltage of $12 \mathrm{~V}$. There are three ways to increase the range of the system to any range desired. The easiest solution would be to buy a DAQ that can handle the higher input voltage without changing the existing DAQ accuracies. The second method would be to highly calibrate the voltage divider resistors used in the PCB board. The resistors without calibration add too much error for the current sense voltage. However the voltage divider resistors are in the kilo-ohm range which is easier to measure to a great deal higher accuracy than the manufacturer's specification. This would mean that each input would 
have a separate voltage divider factor. Two sets of highly equivalent resistance would have to be used for every channel due to the fact that differential readings are read together. This could require a great number of resistor to mix and match or higher accuracy resistors in order to find matching voltage dividers. The last option would be to use IC differential like the analog PCB. All of the same problems would apply but the multipliers and the voltage dividers could be skipped. This would greatly reduce the errors incorporated. However just like in the PCB really fast differential are required, and it is unsure of whether their accuracy and overshoot will affect the system too much.

One of the problems experienced on the existing system was unsteady speed control. This was hypothesized to be changing relative ground of the control DAQ compared to the ESC. This unsteady control only happened when the system was under high load. The ground wire connect to the control DAQ was removed as a temporary solution. After the removal the speed stabilized. Presently the speed is controlled by the sequential DAQ while the measurements are taken with the simultaneous DAQ. This does not affect the data, but it would reduce the complexity of the system if control and acquisition could be done with the same DAQ. The sequential DAQ is a National Instruments DAQ with a counter. It is easy to create a PWM control signal with this DAQ. The simultaneous DAQ is a Measurement Computing DAQ with only digital outputs with no counters. It is still possible to make a control signal but conversion takes a great deal more work.

There is still the possibility that there are other better options available. For example, the Yokogawa WT-3000 precision three-phase power analyzer might be able to accurately measure the system. However as previous described in Section 1.3, it will require further research and correspondence with the manufacturer. There is also the possibility that power loss can be derived by measuring the heat generated by the ESC. This comes with several problems though. Heat is unevenly dissipated on the ESC, and the ESC must be in the air flow in order to prevent overheating. Any enclosure used for a heat dissipation calculation 
could cause the ESC to overheat. Therefore the test system would have to measure heat dissipation using convection. 


\section{CONCLUSION}

A test bed able to record efficiency of an ESC was constructed with limitations. Data was taken to observe the effects of torque, speed, voltage, switching frequency, and ESC size. It was deduced that the greatest efficiencies are gained for low torque, low speed loads and efficiency reduces significantly with torque. It was seen that higher voltages have higher ESC efficiency at all throttles. It was also noted that optimal switching frequency changes with the applied load. However all of these tests were of only ESC efficiency at below recommended voltage. The system needs to be enhanced to allow for higher bus voltage.

ESC efficiency is only one part of the electric power system. Small changes in the ESC efficiency can be outweighed by greater changes in performance by the other three components: battery, motor, and propeller. Bus voltage is a excellent example of this. The Army Research Laboratory found that they could increase the combined efficiency of the motor and speed controller by decreasing the bus voltage at part power. However as could be seen in Section 6.2, ESC efficiency decreases as bus voltage is decreased. Therefore the increase in efficiency seen by the Army Research Laboratory must have been from great increases in the efficiency of the motor. A test bed needs to be developed that records motor and ESC efficiencies. Their interactions and their nontraditional control inputs such as bus voltage are the last parts of the system not yet heavily researched. The same test done in this thesis might show benefits in the overall efficiency.

The author researched what is available in order to build such a test bed. A Texas Instruments (TI) F28069M LaunchPad, two BOOSTXL-DRV8301 REVB booster boards, and a two motor dynamometer kit 2MTR-DYNO was acquired in order to build the system. The TI kit allowed one motor to be the motor under test controlling speed while the other motor acted as the load controlling torque. The TI was able to measure speed and torque 
as well as power into the test motor and out of the load motor. The speed controller's code could be edited, built, and uploaded to the ESC. This allowed for all of the control inputs including wave type to be controlled. However this also made an extremely steep learning curve for use. This system in combination with the three phase wattmeter presented in this thesis could measure ESC, motor, and combined efficiency. Due to the complexity of this system in combination with the three phase wattmeter, it was considered too much for this thesis.

Now that there is experimental data on speed controller efficiency, a parametric model using manufacturer's given data can be constructed. The MOSFET manufacturers' recommended model might be able to accurately model the ESC efficiency, but, in order for it to work, the MOSFETs data sheet must be acquired. Also the average number of switches per cycle at each throttle is needed requiring a deep understanding of MOSFET switching schedule. This data would not be easy to acquire for each electric power system. Assumptions might be able to be made in order to simplify this model into the supplied data of switching frequency, overall ESC internal resistance, bus voltage, motor characteristics, and applied load. Instead a system level approach might be more appropriate for a design performance model. For a given bus voltage, power loss appears to be closely proportional to input power. This can be better seen when looking at Figure 6.6 which compares power loss to DC current. Except for very low currents, power loss increases linearly with DC current. This seems to indicate that the power loss is not a dominated by conduction loss which would have quadratic gain with current as $I^{2} R$. Research on the reasons and validation of this near linear power loss are needed in order to build a system level model.

The data presented in this thesis will help build ESC performance models and understanding of the causes of system level changes. The rapid growth of the small UAV industry will create a demand for deeper understandings of the performance and behavior of the electric power system than what is available today. 


\section{BIBLIOGRAPHY}

[1] T. G. Wilson and P. H. Trickey. "D-C machine with solid-state commutation". In: IEEE 81.11 (1962), pp. 879-884.

[2] Clayton Green and Thomas Mackin. Advanced Lithium-Ion Batteries. Department of Energy report. San Luis Obispo, 2011.

[3] M. Ehsani A. Emadi and J. Miller. Vehicular Electric Power Systems: Land, Sea, Air, and Space Vehicles. CRC Press, 2003.

[4] Bernie Wolfard. Letter to Castle Creations. 6-3-2014.

[5] Ohad Gur and Aviv Rosen. “Optimizing Electric Propulsion Systems for Unmanned Aerial Vehicles". In: Journal of aircraft (2009). URL: http: / / www . gordon-se . technion.ac.il/files/2012/05/421072-11.pdf.

[6] John Carri. A four-constant model for electric motors (Draft No. 2). Tech. rep. Internet draft.[Online]. Available: http://flbeagle. rchomepage. com/research/4 consts paper ver 02. pdf, 2007.

[7] United Aircraft Corporation. Hamilton Standard Propeller Division. Hamilton standard controllable and constant speed propellers ...: Operation and maintenance instructions. Service manual; no.110-C. East Hartford, Conn., 1937, p. 79.

[8] Tritium. WaveSculptor 22 Motor Drive User's Manual. Australia Brisbane, 2010.

[9] Peter Millett. SLVA504_Calculating Motor Driver Power Dissipation. 2012. URL: http://www.ti.com/lit/an/slva504/slva504.pdf.

[10] A. Guerra N. Keskar M. Battello and A. Gorgerino. Application note AN-1048. El Segundo, CA. 
[11] Dušan Graovac and Marco Pürschel. MOSFET Power Losses Calculation Using the Data- Sheet Parameters. 2006.

[12] Dale A Lawrence and Kamran Mohseni. "Efficiency Analysis for Long-Duration Electric MAVs”. In: Aerospace Engineering Sciences. AIAA 2005-7090. 2005, pp. 113.

[13] K Amadori D Lundström and P Krus. "Validation of Small Scale Electric Propulsion System Models". In: Aerospace Sciences. AIAA 2010-483. 2010, pp. 1-16.

[14] Department of Energy. Motor Tip Sheet \#11: Adjustable Speed Drive Part-Load Efficiency. 2005.

[15] T. G. Wilson and P. H. Trickey. "Energy Efficiency of Variable Speed Drive Systems”. In: IEEE Transactions on Industry Applications (2003), pp. 763-768.

[16] Franklin Gaudi Bryan Busch Charles M. Burt Xianshu Piao and N. F. N. Taufik. “Electric Motor Efficiency under Variable Frequencies and Loads". In: Journal of Irrigation and Drainage Engineering 134.2 (2008), pp. 129-136.

[17] Aaron M Harrington and Christopher Kroninger. Characterization of Small DC Brushed and Brushless Motors. 2013.

[18] Kilowatt Classroom. "VFD Fundamentals". In: Kilowatt Classroom, LLC. (2003), p. 5.

[19] Barnes Warnock McCormick, Barnes Warnock McCormick, and Barnes Warnock McCormick. Aerodynamics, aeronautics, and flight mechanics. Vol. 2. Wiley New York, 1995.

[20] John Brandt. "Small-Scale Propeller Performance at Low Speeds". MA thesis. Illinois: Department of Aerospace Engineering, University of Illinois at Urbana-Champaign, 2005.

[21] Rochester, New York, United States. 
[22] Linear Technology Corporation. "LT6100 Precision, Gain Selectable High Side Current Sense Amplifier”. In: ().

[23] Analog Devices. "High Common-Mode Voltage, Programmable Gain Difference Amplifier AD628”. In: ().

[24] Texas Instruments. "INA 827 Wide Supply Range, Rail-to-Rail Output Instrumentation Amplifier with a Minimum Gain of 5". In: ().

[25] Linear Technology Corporation. "LT1995 32MHz, 100V/ $\mu$ s Gain Selectable Amplifier". In: ().

[26] Robert B Kelman. "Applications of Discrete and Continuous Fourier Analysis (H. Joseph Weaver)”. In: SIAM Review 28.1 (1986), pp. 109-109.

[27] MEASUREMENT COMPUTING. USB-1608HS. URL: http: / / www. mccdaq. com/ usb-data-acquisition/USB-1608HS.aspx (visited on 05/19/2015).

[28] Hewlett-Packard. 6012B 1200W DC System Power Supply, No Interface, Single Output [Obsolete] - Keysight (Agilent). URL: http : / /www . keysight. com/en/pd867546 - pn - 6012B / 1200w - dc - system-power - supply - no - interface single-output?cc=US $\backslash \& l \mathrm{c}=\mathrm{eng}$.

[29] HOBBYWING TECHNOLOGY CO.; LTD. Platinum-50A-V3. URL: http: //www . hobbywing.com/product \_show.asp?id=307 (visited on 05/19/2015).

[30] Hitec RCD USA, Inc. Energy Sport 50 amp Electronic Speed Controller. URL: http: / / hitecrcd.com/products / electronic-speed-controls / energysport-50-amp-electronic-speed-controller/product (visited on 05/19/2015).

[31] E-Flite. Power 46 Brushless Outrunner Motor, 670Kv. URL: http : / / www . efliterc.com/Products/Default.aspx?ProdID=EFLM4 046 A (visited on 01/01/2015). 


\section{APPENDICES}

\section{A PROCEDURES}

The Labview program built within this thesis automates most of the steps required in order to perform a run of the system. This section will describe the necessary setup and procedures not covered in this program. All setup will be to match default inputs of the Labview program.

\section{A.1 TEST BED SETUP}

This subsection will explain the wiring diagram and setup required for the tests.

1. Clamp down the cage mount to the table.

2. Screw motor onto motor rise as in Figure A.1

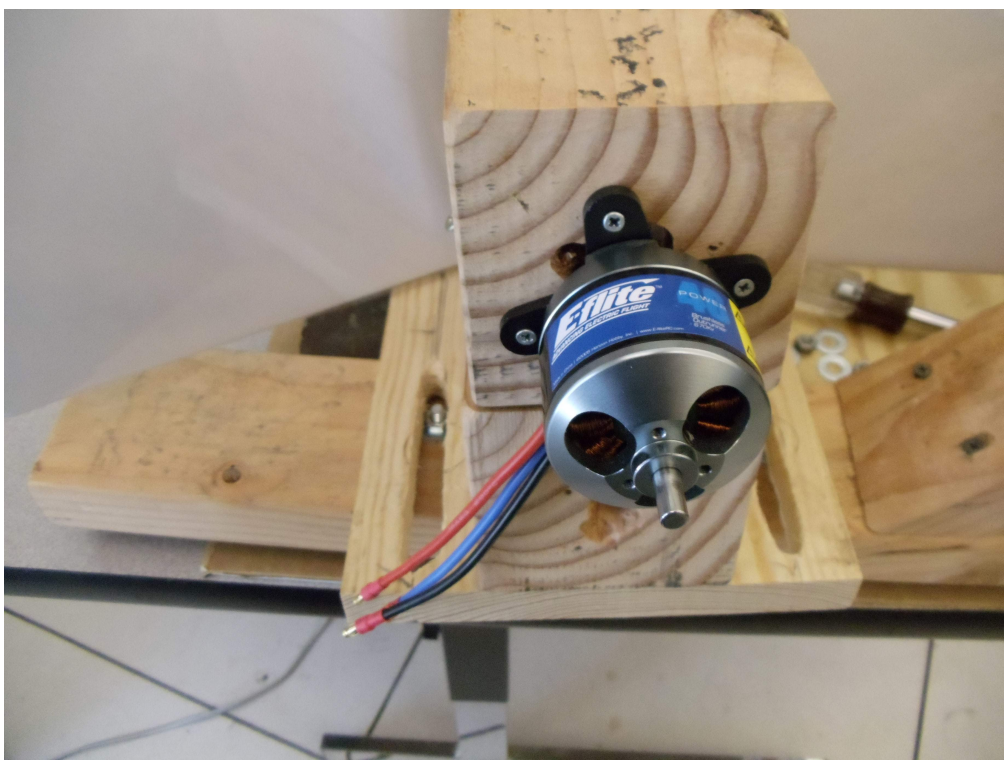

Figure A.1: Mounting of the motor 
3. Attach propeller to motor inside the cage and tighten holding the propeller.

4. Align the propeller in the center of the cage by sliding the whole mount as shown in Figure A.2. Spin the propeller around to verify it has proper clearance from the sides.

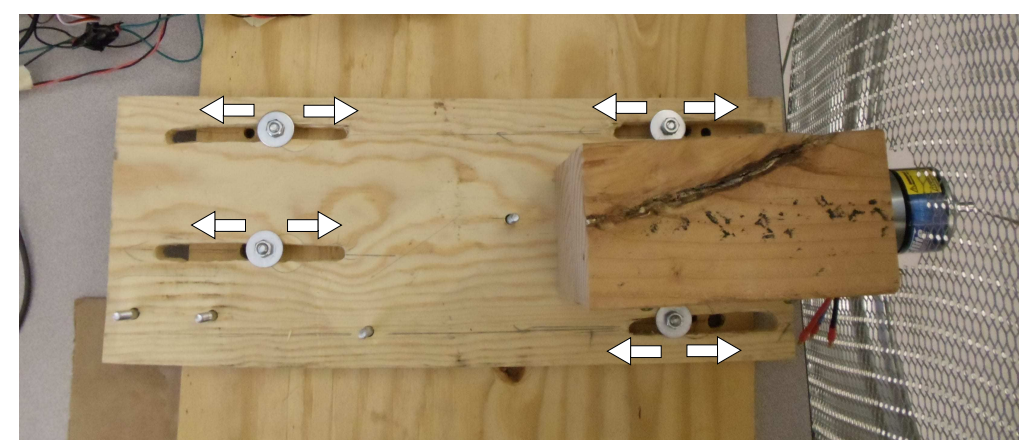

Figure A.2: Alignment of the propeller within the cage

5. Screw tight the mount and push on the cage cover.

6. Screw on the appropriate current sense resistor blocks.

7. Connect wires as shown in the wiring diagram in Figure A.3. Figure A.3a is the electric power system, Figure A.3b is the simultaneous DAQ connections, and Figure A.3c is the in the control DAQ wiring. Note that the control DAQ uses system ground not control ground.

8. Connect the DAQs to the computer.

9. Confirm that the DAQ has its separate power connected.

10. Plug in the power supply and its grounding plug.

Optionally, a thermostats can be connected to the ESC to monitor temperature.

\section{A.2 TEST RUN PROCEDURES}

The test bed was built to be mostly automated. However calibration and control inputs still required user interface. This subsection will describe the necessary procedures. These 


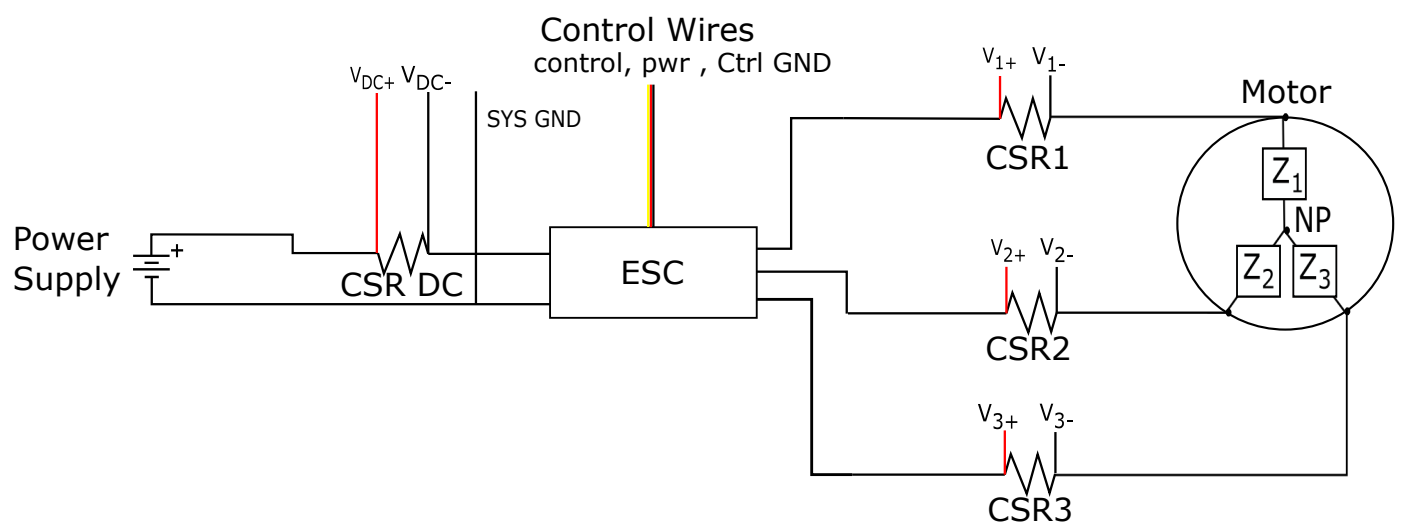

(a) Wiring diagram for the electric power system

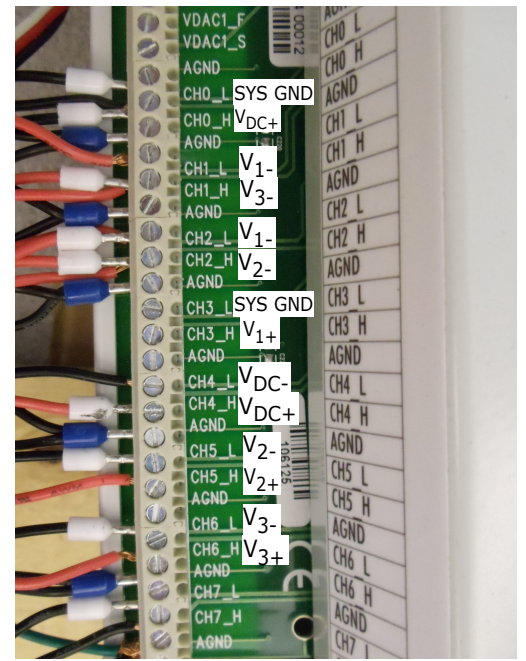

(b) Wiring diagram for the simultaneous DAQ

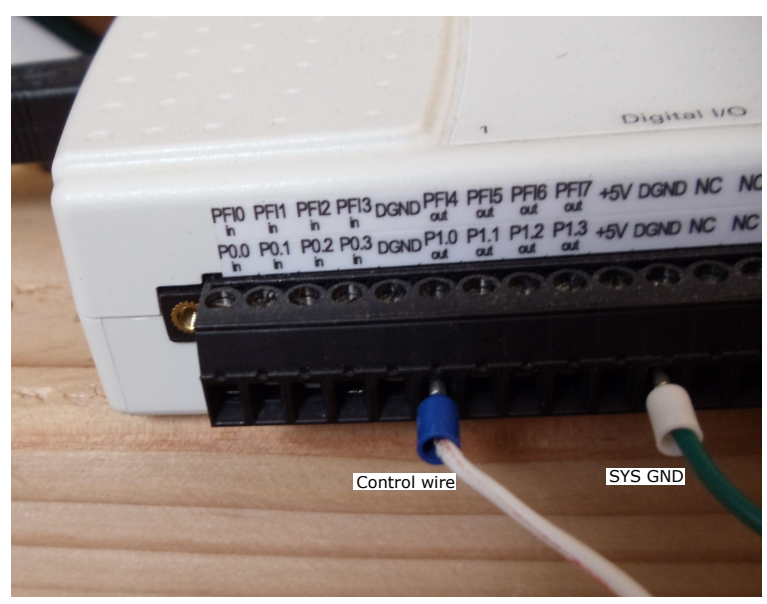

(c) Wiring diagram for the control DAQ

Figure A.3: Wiring diagram of the test bed

are the steps for running a test. It does not include steps for changing the propeller or changing an ESC parameter such as switching frequency. For changing a propeller or an ESC parameter refer to manufacturer.

1. Reaffirm default inputs on physical channels, min and max voltage range, sample rate, and number of samples under Channel Settings and Timing Settings are correct and match hardware setup shown in Figure A.4.

2. Select the save file under Logging Settings.

3. Select a control type: Always Off, Always Full Throttle, or Throttle under Controls. 


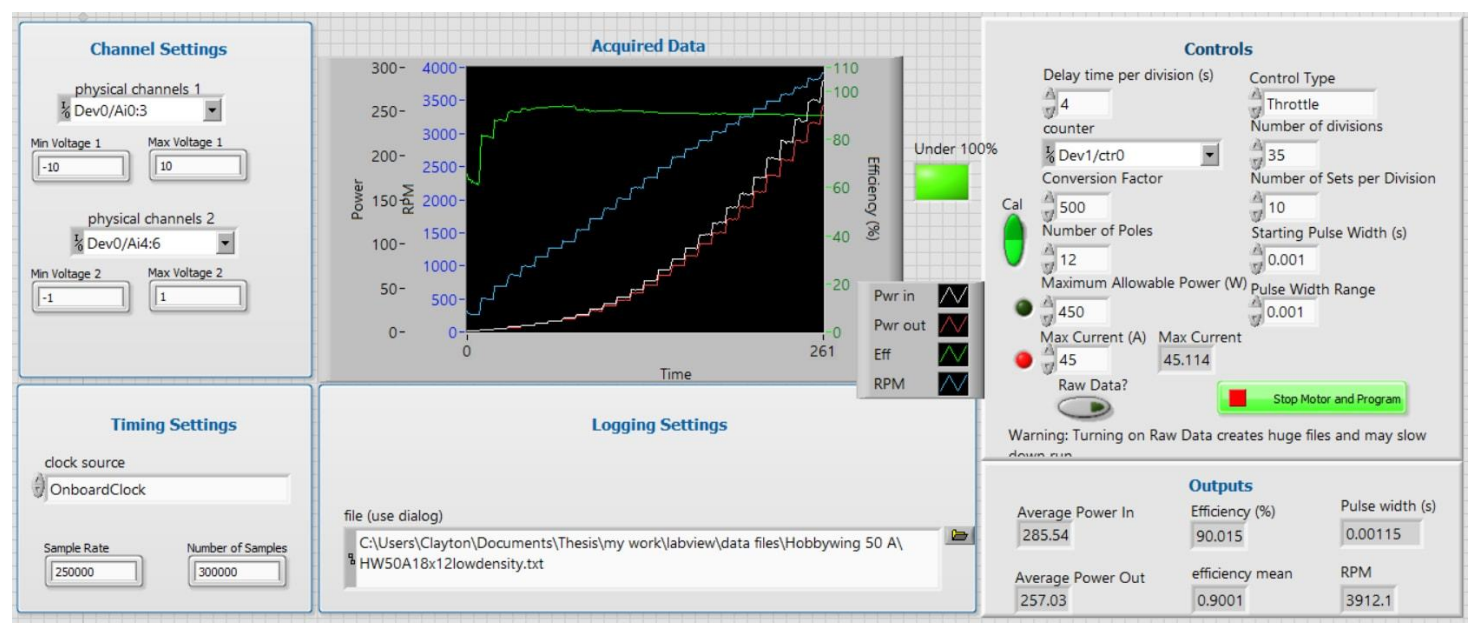

Figure A.4: Copy of Figure 4.3 of the Labview front panel

(a) "Always Off" records a number of samples equivalent to the product of Number of Divisions, Number of Sets per Division, and Number of Samples with the throttle control set to zero.

(b) "Always Full Throttle" records the same number of samples but at full throttle.

(c) "Throttle" steps from Starting Pulse Width to Starting Pulse Width plus Pulse Width Range. The step size is the quotient of Pulse Width Range and Number of Divisions.

4. Enter the appropriate Delay time per Division, Number of Divisions, Number of Sets per Division, Conversion Factor, Number of Poles, Starting Pulse Width, and Pulse Width Range under Controls shown in Figure A.4.

5. Enter the Max Allowable Power and Max Current under Controls considering ALL parts of the system shown in Figure A.4.

6. Select Cal to perform offset calibration at the start of the test.

7. Select "Raw Data?" if raw data is desired.

However turning on raw data creates huge files and may slow down the run. Long runs will cause the program to crash. If raw data is required, take data in short burst on separate files. 
8. Inspect the connection on the hardware. Verify they match Subsection A.1.

9. Run Labview program. It should return a dialog like Figure A.5.

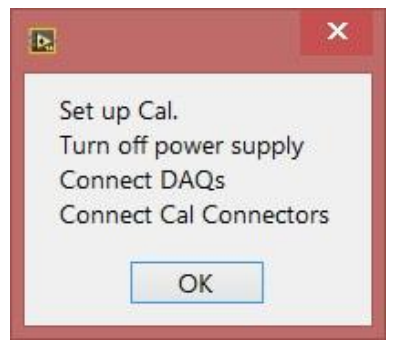

Figure A.5: First Labview command dialog to operator

10. Verify the power supply is off. Connect Cal connectors as seen in Figure A.6.

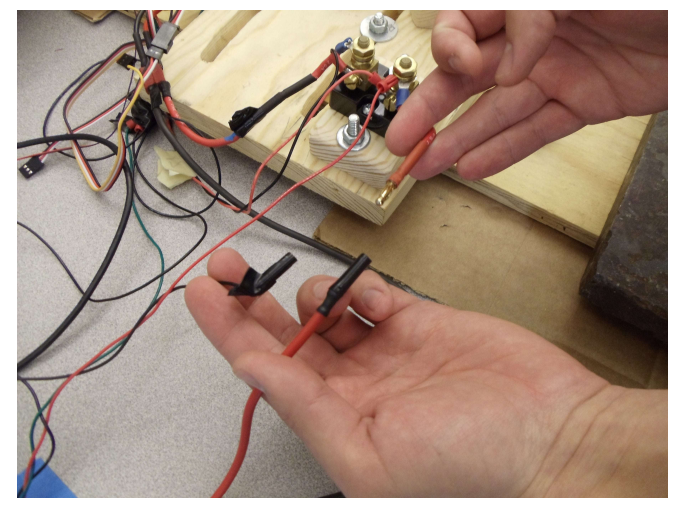

(a) DC calibration connectors. Bottom left wire is the calibration wire and bottom right is the power wire.

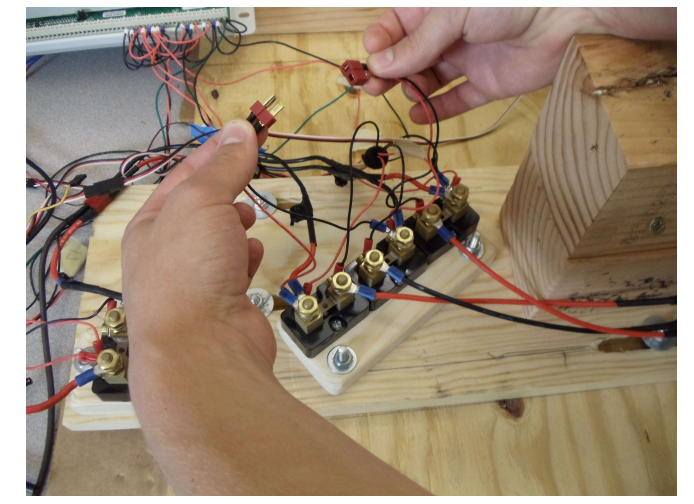

(b) AC calibration connectors

Figure A.6: DC offset calibration connectors

The DC Cal connector requires the test conductor to disconnect power as a safety. Therefore connect the DC Cal connector first and disconnect it last.

11. Hit "ok" on dialog box. Another dialog box should appear like Figure A.7.

12. Disconnect Cal connectors and reconnect power.

13. Verify AC Cal connector is disconnected before turning on power.

14. Turn on power. 


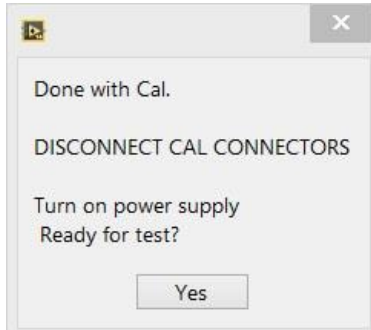

Figure A.7: Second Labview command dialog to operator

15. Hit "Yes" on dialog box.

Test should run through the entire throttle sweep, be always off, or always on depending on the throttle control chosen. Results can be seen live in the Acquired Data plot. Values are given live for the performance qualities in the Outputs section. Test will stop automatically for three reasons: Max Allowable Power has been exceeded, Max Current has been exceeded, or all data has been taken. In all cases throttle will return to zero and data will be logged to file.

16. Turn off power supply

NOTE: If for some reason the test conductor would like to stop the program immediately but would like to keep the data, hit "Stop Motor and Program." It will set the throttle to zero, log the data, and stop the program.

NOTE: Max Current will stop the program if any DC pulses exceed this maximum. Therefore the average may not have reached this maximum yet. 


\section{B PCB BOARD DESIGNS}

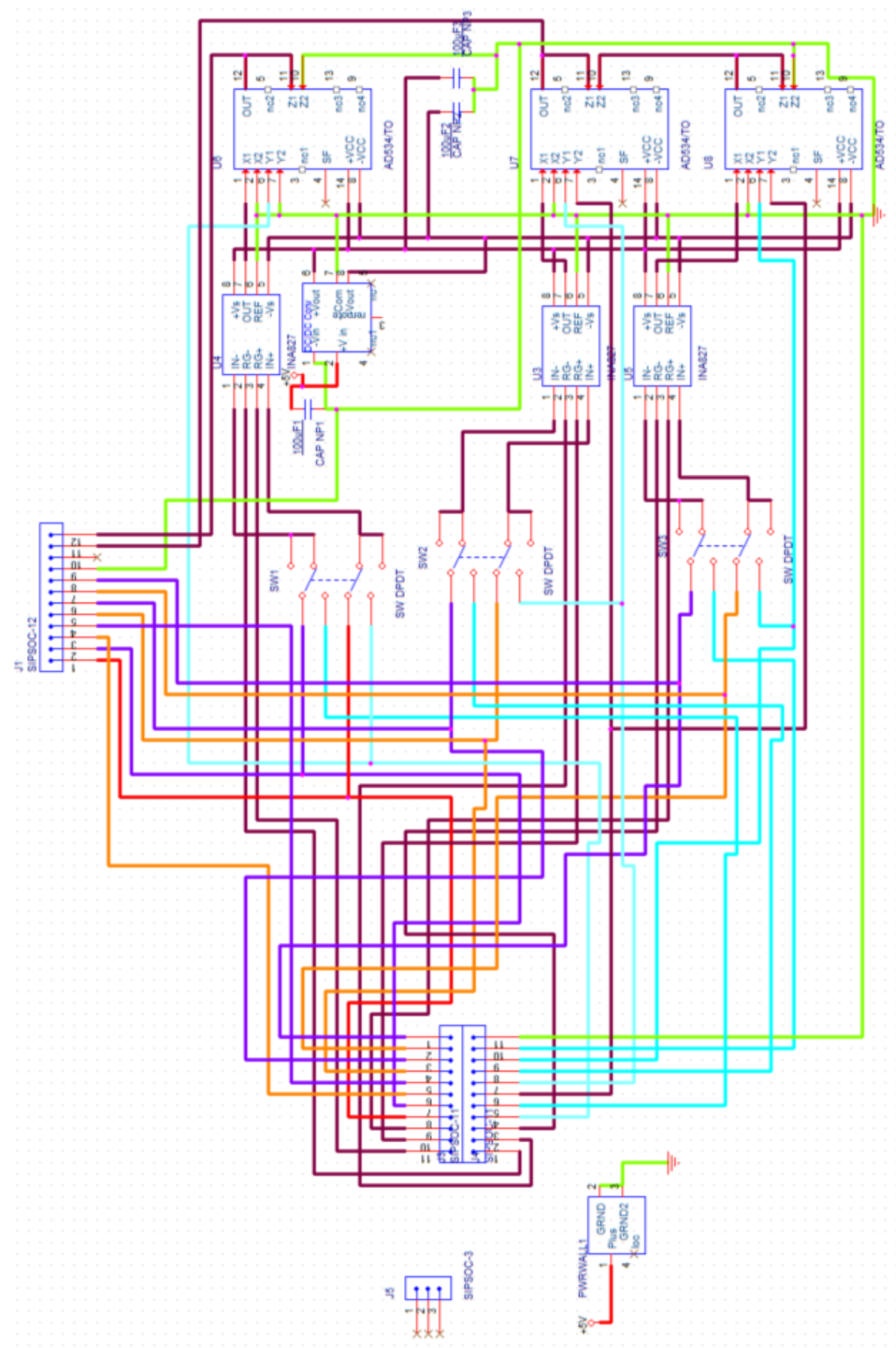

Figure B.1: OrCAD wiring design of the main PCB 


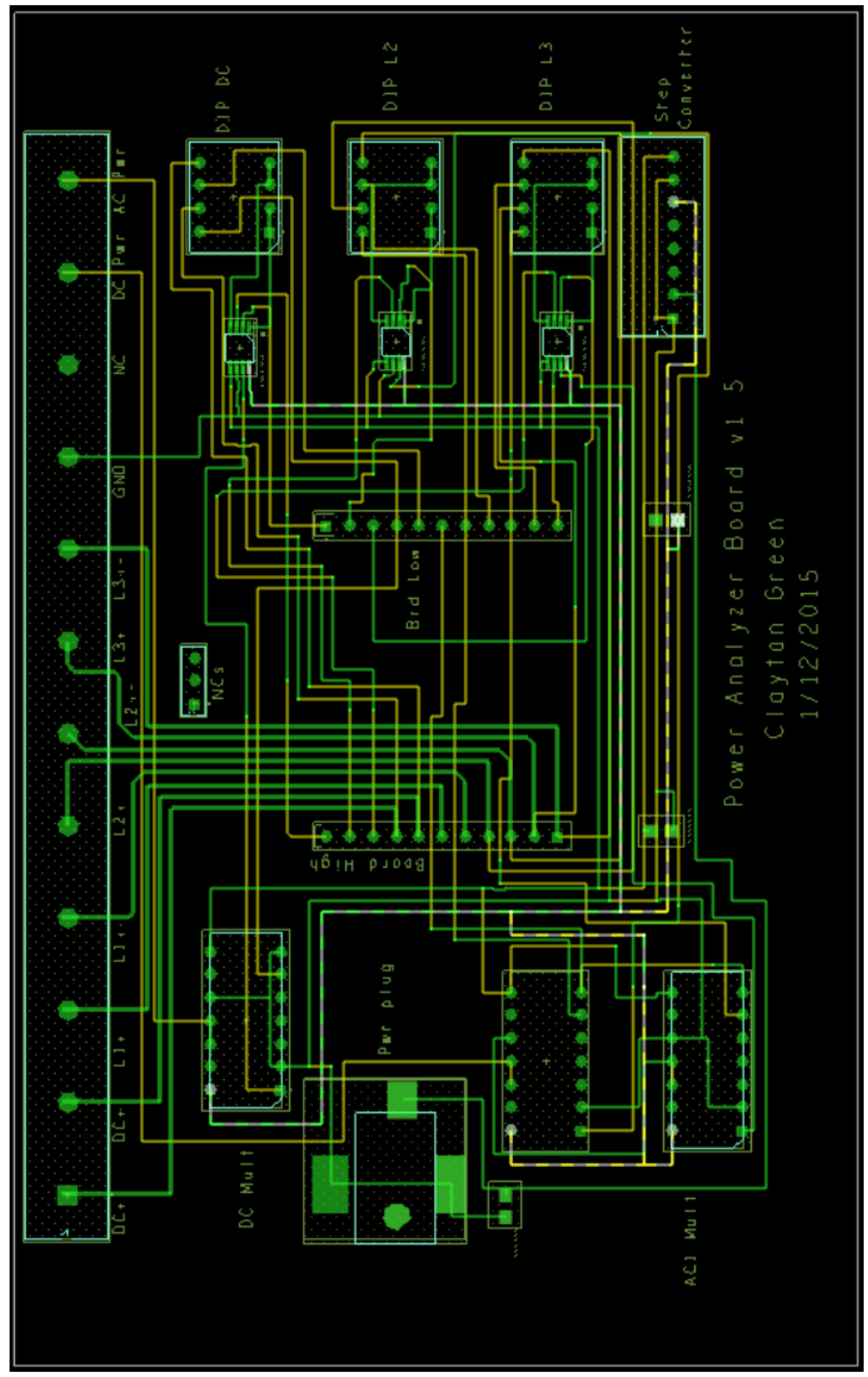

Figure B.2: Manufacturing design of the main PCB 


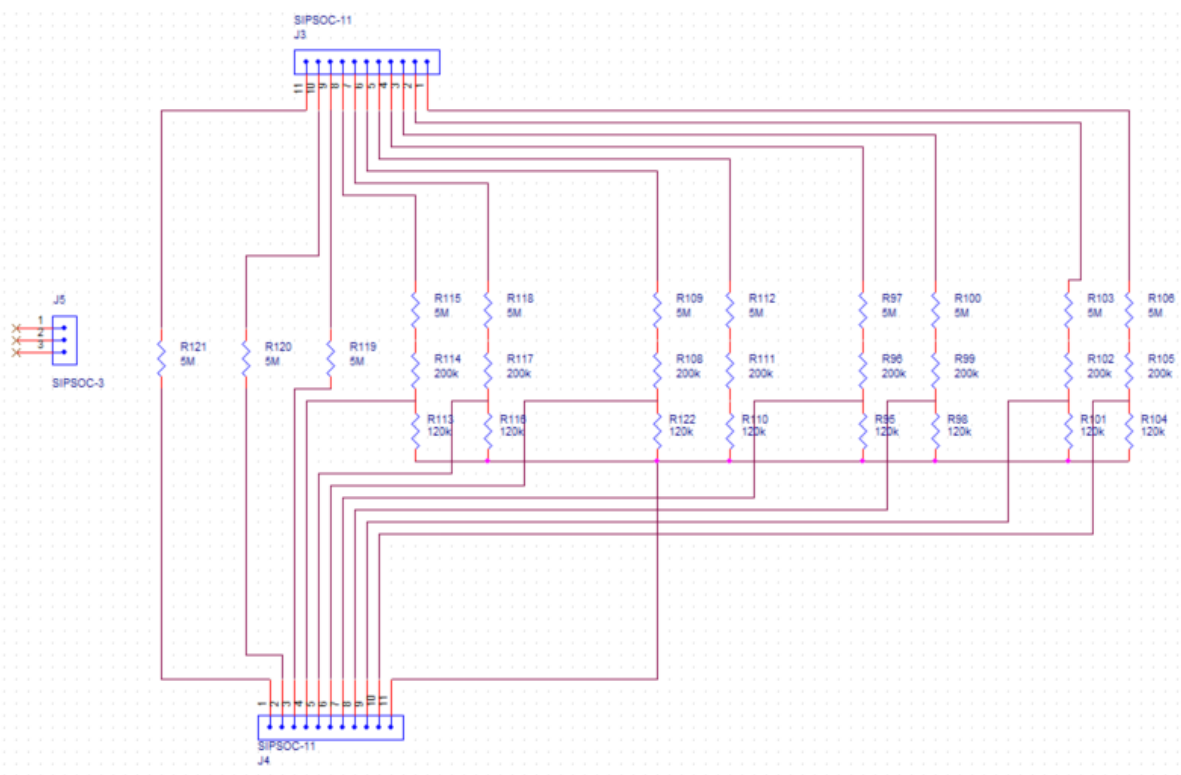

Figure B.3: OrCAD wiring design of the gain and voltage divider resistor PCB

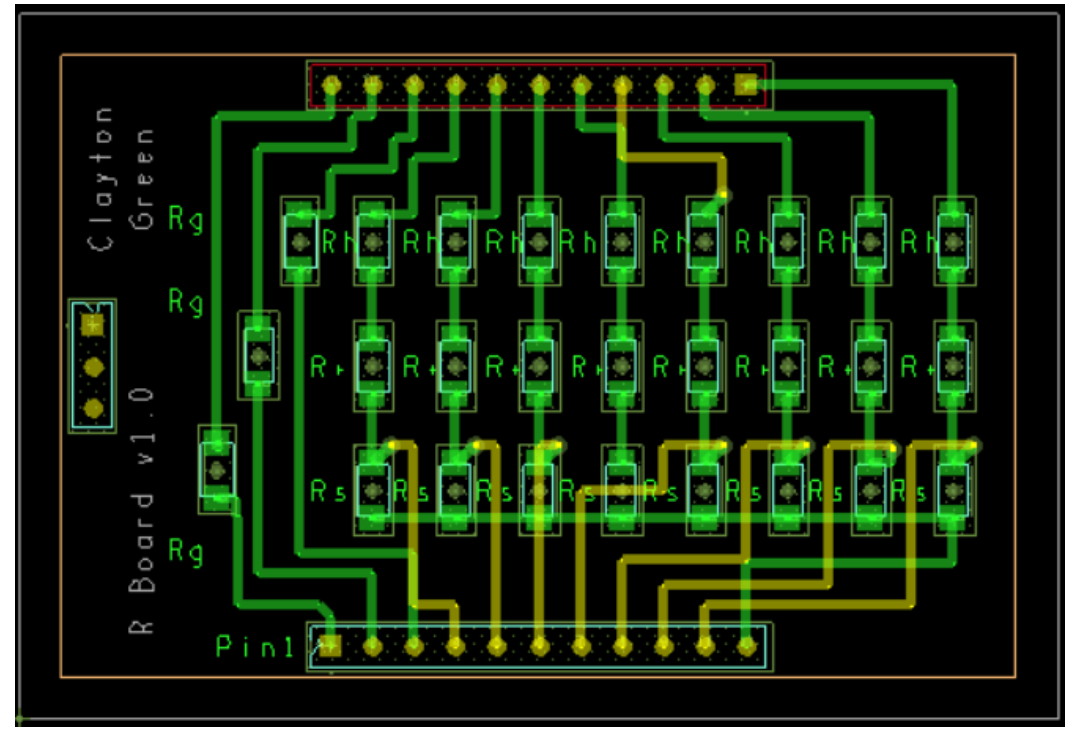

Figure B.4: Manufacturing design of the gain and voltage divider resistor PCB 